\title{
The economics and psychology of personality traits
}

Citation for published version (APA):

Borghans, L., Duckworth, A. L., Heckman, J., \& ter Weel, B. J. (2008). The economics and psychology of personality traits. Researchcentrum voor Onderwijs en Arbeidsmarkt, Faculteit der Economische

Wetenschappen. ROA Research Memoranda No. 001 https://doi.org/10.26481/umaror.2008001

Document status and date:

Published: 01/01/2008

DOI:

10.26481/umaror.2008001

Document Version:

Publisher's PDF, also known as Version of record

\section{Please check the document version of this publication:}

- A submitted manuscript is the version of the article upon submission and before peer-review. There can be important differences between the submitted version and the official published version of record.

People interested in the research are advised to contact the author for the final version of the publication, or visit the DOI to the publisher's website.

- The final author version and the galley proof are versions of the publication after peer review.

- The final published version features the final layout of the paper including the volume, issue and page numbers.

Link to publication

\footnotetext{
General rights rights.

- You may freely distribute the URL identifying the publication in the public portal. please follow below link for the End User Agreement:

www.umlib.nl/taverne-license

Take down policy

If you believe that this document breaches copyright please contact us at:

repository@maastrichtuniversity.nl

providing details and we will investigate your claim.
}

Copyright and moral rights for the publications made accessible in the public portal are retained by the authors and/or other copyright owners and it is a condition of accessing publications that users recognise and abide by the legal requirements associated with these

- Users may download and print one copy of any publication from the public portal for the purpose of private study or research.

- You may not further distribute the material or use it for any profit-making activity or commercial gain

If the publication is distributed under the terms of Article $25 \mathrm{fa}$ of the Dutch Copyright Act, indicated by the "Taverne" license above, 


\section{The Economics and Psychology of Personality Traits}

Lex Borghans

Angela Lee Duckworth

James J. Heckman

Bas ter Weel

ROA-RM-2008/1

February 08

\section{Research Centre for Education} and the Labour Market

P.O. Box 616

6200 MD Maastricht

The Netherlands

E-mail:

secretary@roa.unimaas.nl

Internet:

www.roa.unimaas.nl

Maastricht University

Faculty of Economics and Business Administration 
The ROA Research Memorandum Series was created in order to make research results available for discussion, before those results are submitted for publication in journals.

Sec08.017.pdf 
ROA-RM-2008/1 » http://www.roa.unimaas.nl/resmem.htm

\section{Abstract}

\section{The Economics and Psychology of Personality Traits}

This paper explores the interface between personality psychology and economics. We examine the predictive power of personality and the stability of personality traits over the life cycle. We develop simple analytical frameworks for interpreting the evidence in personality psychology and suggest promising avenues for future research.

Lex Borghans

Dept. of Economics and ROA

P.O. Box 616

6200 MD Maastricht

The Netherlands

lex.borghans@algec.unimaas.nl

James J. Heckman

Dept. Of Economics

University of Chicago

1126 East 59th Street

Chicago, Illinois 60637

USA

jjh@uchicago.edu
Angela Lee Duckworth

University of Pennsylvania

3701 Market St. Suite 209

Philadelphia, PA 19104

USA

duckworth@psych.upenn.edu

Bas ter Weel

CPB and UNU-MERIT, Maastricht

University

P.O. Box 80510

2508 GM Den Haag

The Netherlands

b.terweel@merit.unimaas.nl 


\section{Acknowledgements}

Chris Hsee gave us very useful advice at an early stage. We are grateful to Arianne Zanolini for helpful comments and research assistance. We have received very helpful comments on various versions of this draft from Gary Becker, Dan Benjamin, Dan Black, Ken Bollen, Sam Bowles, Frances Campbell, Flavio Cunha, John Dagsvik, Michael Daly, Kevin Denny, Liam Delany, Thomas Dohmen, Greg Duncan, Armin Falk, James Flynn, Linda Gottfredson, Lars Hansen, Joop Hartog, Moshe Hoffman, Bob Hogan, Nathan Kuncel, John List, Lena Malofeeva, Kenneth McKenzie, Kevin Murphy, Frank Norman, David Olds, Friedhelm Pfeiffer, Bernard Van Praag, Elizabeth Pungello, Howard Rachlin, C. Cybele Raver, Bill Revelle, Brent Roberts, Carol Ryff, Larry Schweinhart, Jesse Shapiro, Rebecca Shiner, Burt Singer, Richard Suzman, Harald Uhlig, Sergio Urzua, Gert Wagner, Herb Walberg, and participants in workshops at the University of Chicago (Applications Workshop), Iowa State University, Brown University, University College Dublin, and Washington State University. The views expressed in this paper are those of the authors and not necessarily of the funders or commenters listed here. A website, http://jenni.uchicago.edu/econ-psych-traits/, presents supplemental tables. The data used in this article can be obtained beginning [six months after publication] through [three years hence] from Lex Borghans, Department of Economics and ROA, Maastricht University. 


\section{Introduction}

There is ample evidence from economics and psychology that cognitive ability is a powerful predictor of economic and social outcomes. ${ }^{1}$ It is intuitively obvious that cognition is essential in processing information, learning, and in decision making. ${ }^{2}$ It is also intuitively obvious that other traits besides raw problem-solving ability matter for success in life. The effects of personality traits, motivation, health, strength, and beauty on socioeconomic outcomes have recently been studied by economists. ${ }^{3}$

The power of traits other than cognitive ability for success in life is vividly demonstrated by the Perry Preschool study. This experimental intervention enriched the early family environments of disadvantaged children with subnormal intelligence quotients (IQs). Both treatments and controls were followed into their 40s. As demonstrated in Figure 1, by age ten, treatment group mean IQs were the same as control group mean IQs. Yet on a variety of measures of socioeconomic achievement, over their life cycles, the treatment group was far more successful than the control group. ${ }^{4}$ Something besides IQ was changed by the intervention. Heckman et al. (2007) show that it is the personality and motivation of the participants. This paper examines the relevance of personality to economics and the relevance of economics to personality psychology.

Both economists and psychologists estimate preference parameters such as time preference, risk aversion, altruism, and, more recently, social preferences, to explain the behaviors of individuals. The predictive power of these preference parameters, their origins and the stability of these parameters over the lifecycle, are less well understood and are actively being studied. 
Economists are now beginning to use the personality inventories developed by psychologists. This paper examines these measurement systems and their relationship with the preference parameters of economists. There is danger in economists taking the labels assigned to psychologists' personality scores literally and misinterpreting what they actually measure. We examine the concepts captured by the psychological measurements and the stability of the measurements across situations in which they are measured.

We eschew the term "noncognitive" to describe personality traits even though many recent papers in economics use this term in this way. In popular usage, and in our own prior work, "noncognitive" is often juxtaposed with "cognitive". This contrast has intuitive appeal because of contrast between cognitive ability and traits other than cognitive ability. However, a contrast between "cognitive" and "noncognitive" traits creates the potential for much confusion because few aspects of human behavior are devoid of cognition. Many aspects of personality are influenced by cognitive processes. We show that measurements of cognitive ability are affected by personality factors.

We focus our analysis on personality traits, defined as patterns of thought, feelings, and behavior. We do not discuss in depth motivation, values, interests, and attitudes which give rise to personality traits. Thus, we focus our discussion on individual differences in how people actually think, feel, and act, not on how people want to think, feel, and act. This omission bounds the scope of our work and focuses attention on traits that have been measured. We refer the interested reader to McAdams (2006), Roberts et al. (2006), and McAdams and Pals (2007) for an overview of the literature in psychology on aspects of personality that we neglect. ${ }^{5,6}$

Our focus is pragmatic. Personality psychologists have developed measurement systems for personality traits which economists have begun to use. Most prominent is the "Big Five" 
personality inventory. There is value in understanding this system and related systems before tackling the deeper question of the origins of the traits that are measured by them.

The lack of familiarity of economists with these personality measures is one reason for their omission from most economic studies. Another reason is that many economists have yet to be convinced of their predictive validity, stability or their causal status, believing instead that behavior is entirely situationally determined. Most data on personality are observational and not experimental. Personality traits may, therefore, reflect, rather than cause, the outcomes that they are alleged to predict. Large-scale studies are necessarily limited in the array of personality measures that they include. Without evidence that there is value in knowing which personality traits are most important in predicting outcomes, there is little incentive to include sufficiently broad and nuanced personality measures in empirical studies.

Most economists are unaware of the evidence that certain personality traits are more malleable than cognitive ability over the life cycle and are more sensitive to investment by parents and to other sources of environmental influences at later ages than are cognitive traits. Social policy designed to remediate deficits in achievement can be effective by operating outside of purely cognitive channels.

This paper shows that it is possible to conceptualize and measure personality traits and that both cognitive ability and personality traits predict a variety of social and economic outcomes. We study the degree to which traits are stable over situations and over the life cycle. We examine the claim that behavior is purely situation-specific and show evidence against it. Specifically, in this paper we address the following questions.

\section{Is It Conceptually Possible to Separate Cognitive Ability from Personality Traits?}


Many aspects of personality are a consequence of cognition, and cognition depends on personality. Nonetheless, one can separate those two aspects of human differences.

\section{Is It Possible to Empirically Distinguish Cognitive from Personality Traits?}

Measures of economic preferences are influenced by numeracy and intelligence. IQ test scores are determined not only by intelligence, but also by factors such as motivation and anxiety. Moreover, over the life cycle, the development of cognitive ability is influenced by personality traits such as curiosity, ambition, and perseverance.

\section{What Are the Main Measurement Systems in Psychology for Intelligence and Personality, and How Are They Validated?}

Most personality psychologists rely on paper-and-pencil self report questionnaires. Other psychologists and many economists measure conventional economic preference parameters, such as time preference and risk aversion. We summarize both types of studies. There is a gap in the literature in psychology: it does not systematically relate the two types of measurement systems.

Psychologists seeking to create valid personality questionnaires balance multiple concerns. One objective is to create questionnaires with construct-related validity defined as constructs with an internal factor structure that is consistent across time, gender, ethnicity, and culture. A distinct concern is creation of survey instruments with predictive validity. With notable exceptions, contemporary personality psychologists seeking direct measures of personality traits privilege construct validity over predictive validity in their choice of measures.

\section{What is the Evidence on the Predictive Power of Cognitive and Personality Traits?}

We summarize evidence that both cognitive ability and personality traits predict important outcomes, including schooling, wages, crime, teenage pregnancy, and longevity. For many outcomes, certain personality traits (that is, traits associated with Big Five 
Conscientiousness and Emotional Stability) are more predictive than others (that is, traits associated with Agreeableness, Openness to Experience, and Extraversion). Tasks in social and economic life vary in terms of the weight placed on the cognitive and personality traits required to predict outcomes. The relative importance of a trait varies by the task studied. Cognitive traits are predictive of performance in a greater variety of tasks. Personality traits are important in explaining performance in specific tasks, although different personality traits are predictive in different tasks. The classical model of factor analysis, joined with the principle of comparative advantage, helps to organize the evidence in economics and psychology.

\section{How Stable Are Personality Traits Across Situations and Across The Life Cycle? Are They More Sensitive than Cognitive Traits to Investment and Intervention? ${ }^{7}$}

We present evidence that both cognitive and personality traits evolve over the lifecyclebut to different degrees and at different stages of the life cycle. Cognitive processing speed, for example, tends to rise sharply during childhood, peak in late adolescence, and then slowly decline. In contrast, some personality traits, such as conscientiousness, increase monotonically from childhood to late adulthood. Rank-order stability for many personality measures peaks between the ages of 50 to 70 , whereas IQ reaches these same levels of stability by middle childhood. We also examine the recent evidence on the situational specificity of personality traits. Traits are sufficiently stable across situations to support the claim that traits exist, although their manifestation depends on context and the traits themselves evolve over the life cycle. Recent models of parental and environmental investment in children explain the evolution of these traits. We develop models in which traits are allocated differentially across tasks and activities. Persons may manifest different levels of traits in different tasks and activities. 


\section{Do the Findings from Psychology Suggest That Conventional Economic Theory Should}

Be Enriched? Can Conventional Models of Preferences in Economics Explain the Body of Evidence from Personality Psychology? Does Personality Psychology Merely Recast WellKnown Preference Parameters into Psychological Jargon, or is There Something New for Economists to Learn?

Conventional economic theory is sufficiently elastic to accommodate many findings of psychology. However, our analysis suggests that certain traditional concepts used in economics should be modified and certain emphases redirected. Some findings from psychology cannot be rationalized by standard economic models and could fruitfully be incorporated into economic analysis. Much work remains to be done in synthesizing a body of empirical knowledge in personality psychology into economics.

The evidence from personality psychology suggests a more radical reformulation of classical choice theory than is currently envisioned in behavioral economics which tinkers with conventional specifications of preferences. Cognitive ability and personality traits impose constraints on agent choice behavior. More fundamentally, conventional economic preference parameters can be interpreted as consequences of these constraints. For example, high rates of measured time preference may be produced by the inability of agents to delay gratification, interpreted as a constraint, or by the inability of agents to imagine the future. We develop a framework that introduces psychological variables as constraints into conventional economic choice models.

The paper proceeds in the following way. Section II defines cognitive ability and personality traits and describes how these concepts are measured. Section III considers methodological issues that arise in interpreting the measurements. Section IV presents evidence 
by psychologists and economists on basic economic parameters. Section V examines the predictive power of the traits studied by personality psychologists who, in general, are a distinct body of scholars from the psychologists measuring economics preference parameters. Section VI examines the evidence on the evolution of preference parameters and personality traits over the life cycle. We summarize recent work in psychology that demonstrates stability in preference parameters across diverse settings. Section VII presents a framework for interpreting personality and economic parameters. Recent work in behavioral economics and psychology that seeks to integrate economics and psychology focuses almost exclusively on preference parameters. In contrast, we present a broader framework that includes constraints, skill acquisition, learning as well as conventional preference parameters. Section VIII concludes by summarizing the paper and suggesting an agenda for future research.

\section{Definitions And A Basic Framework Of Measurement And Interpretation}

We distinguish between cognitive ability on the one hand and personality traits on the other. We do not mean to imply that personality traits are devoid of any elements of cognitive processing, or vice versa. Schulkin (2007) reviews evidence that cortical structures associated with cognition and higher level functions play an active role in regulating motivation, a function previously thought to be the exclusive domain of sub-cortical structures ${ }^{8}$. Conversely, Phelps (2006) shows that emotions associated with personality traits are involved in learning, attention, and other aspects of cognition. A distinction between cognitive ability and personality traits begs for a specific definition of cognitive ability. Before defining these concepts, we first review the rudiments of factor analysis, which is the conceptual framework that underlies much of the literature in psychology, and is a basis for unifying economics with that field. We use the factor 
model as an organizing device throughout this paper, even in our definitions of cognitive and personality traits.

\section{A. Factor Analysis}

Central to psychology and recent empirical work at the intersection of economics and psychology is the concept of factors. Let $T_{i, j}$ denote performance on task $j$ for person $i$. There are $J$ tasks. The task could be a test, or the production of tangible outputs (for example, assembling a rifle or managing a store). Individuals perform many tasks. Output on tasks is generated in part by latent "traits" or factors. Factors or psychological traits for individual $i$ are represented in a vector $f_{i}, i=1, \ldots, I$, where $I$ is the number of individuals. The vector has $L$ components so $f_{i}=\left(f_{i, 1}, \ldots, f_{i, L}\right)$. The traits may include cognitive and personality components.

Let $U_{i, j}$ be other determinants of productivity in task $j$ for person $i$. We discuss these determinants in this paper.

The task performance function for person $i$ on $\operatorname{task} j$ can be expressed as

$$
T_{i, j}=h_{j}\left(f_{i}, U_{i, j}\right), i=1, \ldots, I, j=1, \ldots, J .
$$

Different factors are more or less important in different tasks. For example, a purely cognitive task would place no weight on the personality components in vector $f_{i}$ in generating task output. ${ }^{9}$

Linear factor models are widely used in psychology. These models write

$$
T_{i, j}=\mu_{j}+\lambda_{j} f_{i}+U_{i, j}, i=1, \ldots, I, j=1, \ldots, J,
$$

where $\mu_{j}$ is the mean of the $j^{\text {th }}$ task and $\lambda_{j}$ is a vector of factor loadings. The number of components in $f_{i}, L$, has to be small relative to $J(L<<J)$ if the factor model is to have empirical content. A purely cognitive task would be associated with zero values of the components of vector $\lambda_{j}$ on elements of $f_{i}$ that are associated with personality traits. Factor models (1) and (2) capture the notion that: (a) latent traits $f_{i}$ generate a variety of outcomes, (b) task outputs are 
imperfect measures of the traits $\left(f_{i}\right)$, and (c) that tasks other than tests may also proxy the underlying traits. Latent traits generate both test scores and behaviors. Notice that tasks may depend on vector $f_{i}$ and outcomes across tasks may be correlated even if the components of $f_{i}$ are not. A correlation can arise because tasks depend on the same vector of traits. ${ }^{10}$

\section{B. Cognitive Ability}

Intelligence (or cognitive ability) has been defined by an official taskforce of the American Psychological Association as the "ability to understand complex ideas, to adapt effectively to the environment, to learn from experience, to engage in various forms of reasoning, to overcome obstacles by taking thought" (Neisser et al. 1996, p. 77). The term "IQ" is often used synonymously with intelligence but in fact refers specifically to scores on intelligence tests. ${ }^{11}$ In this paper, we present evidence on how measurements of cognitive ability are affected by the environment, including incentives and parental investment.

Scores on different tests of cognitive ability tend to be highly intercorrelated, often with half or more of the variance of diverse tests accounted for by a single general factor labeled " $g$ " and more specific mental abilities loading on other factors (Jensen 1998; Lubinski 2004; Spearman 1904, 1927). Both IQ and achievement tests proxy latent factors $f_{i}$, but to varying degrees and with different mediating variables.

Most psychologists agree that cognitive abilities are organized hierarchically with " $g$ " as the highest-order factor (Spearman 1904). In this context, the order of a factor indicates its generality in explaining a variety of tests of cognitive ability with different emphases (for example, verbal ability, numeracy, coding speed, and other tasks). A first-order factor is predictive in all tasks, $j=1, \ldots, J$ in equation (1). A lower order factor is predictive in only some tasks. There is less agreement about the number and identity of lower-order factors. ${ }^{12}$ Cattell 
$(1971 ; 1987)$ contrasts two second-order factors: fluid intelligence (the ability to solve novel problems) and crystallized intelligence (knowledge and developed skills). ${ }^{13}$ The relative weighting of fluid versus crystallized intelligence varies among tests according to the degree to which prior experience is crucial to performance. These factors operate in addition to the firstorder factor, $g$. Achievement tests, like the Armed Forces Qualifying Test used by economists and psychologists alike, are heavily weighted towards crystallized intelligence, whereas tests like the Raven Progressive Matrices (1962) are heavily weighted towards fluid intelligence. ${ }^{14}$ Carroll (1993) and Horn and McArdle (2007) summarize the large body of evidence against the claim that a single factor " $g$ " is sufficient to explain the correlation structure of achievement and intelligence tests. ${ }^{15}$

\section{Personality Traits}

A distinction between personality and cognition is not easy to make. Consider, for example, so-called “quasi-cognitive" traits (Kyllonen, Walters, and Kaufman 2005). These include creativity (Csikszentmihalyi 1996), emotional intelligence (Mayer and Salovey 1997), cognitive style (Stanovich 1999; Perkins and Tishman 2001), typical intellectual engagement (Ackerman and Heggestad 1997), and practical intelligence (Sternberg 2000).

The problem of conceptually distinguishing cognitive traits from personality traits is demonstrated in an analysis of executive function which is variously described as a cognitive

function or a function regulating emotions and decision, depending on the scholar. ${ }^{16}$ Executive function is not a trait but, rather, a collection of behaviors thought to be mediated by the prefrontal cortex. Components of executive function include behavioral inhibition, working memory, attention, and other so-called "top-down" mental processes whose function is to 
orchestrate lower-level processes. These components are so distinct that it is odd that psychologists have bundled them into one category.

Ardila, Pineda, and Rosselli (2000), Welsh, Pennington, and Grossier (1991), and Schuck and Crinella (2005) find that many measures of executive function do not correlate reliably with IQ. Supporting this claim are case studies of lesion patients who suffer marked deficits in executive function, especially self-regulation, the ability to socialize and plan, but who retain the ability to reason (Damasio 1994). However, measures of one aspect of execution functionworking memory capacity in particular - correlate very highly with measures of fluid intelligence (Heitz, Unsworth, and Engle 2005). In fact, the 2007 APA Dictionary defines executive function as "higher level cognitive processes that organize and order behavior, including logic and reasoning, abstract thinking, problem solving, planning and carrying out and terminating goal-directed behavior." Currently there is a lively debate among psychologists as to the precise relationship among working memory, other aspects of executive function, and intelligence (see Blair 2006, and ensuing commentary).

This paper focuses on personality traits that are more easily distinguished from cognitive ability. They are distinguished from intelligence, defined as the ability to solve abstract problems. Most measures of personality are only weakly correlated with IQ (Webb 1915; McCrae and Costa 1994; Stankov 2005; Ackerman and Heggestad 1997). There are, however, a small number of exceptions. Most notably, IQ is moderately associated with the Big Five factor called openness to experience, with the trait of sensation seeking, and with measures of time preference. The reported correlations are of the order $r=.3$ or lower. We note in Section III that performance on IQ tests is affected by personality variables. Even if there is such a thing as pure 
cognition or pure personality, measurements are affected by a variety of factors besides purely cognitive ones.

\section{Operationalizing the Concepts}

Intelligence tests are routinely used in a variety of settings including business, education, civil service, and the military. ${ }^{17}$ Testers attempt to use a test score (one of the $T_{i, j}$ in equation (1) interpreting test scores as tasks) to measure a factor (a component of $f_{i}$ ). The working hypothesis in the intelligence testing business is that specific tests measure only a single component of $f_{i}$, and that tests with different "content domains" measure different components. We first discuss the origins of the measurement systems for intelligence and we then discuss their validity. ${ }^{18}$

\section{IQ Tests}

Modern intelligence tests have been used for just over a century, beginning with the decision of a Parisian minister of public instruction to identify retarded pupils in need of specialized education programs. Alfred Binet created the first IQ test. ${ }^{19}$ Other pioneers in intelligence testing include James McKeen Cattell (1890) and Francis Galton (1883), both of whom developed tests of basic cognitive functions (for example, discriminating between objects of different weights). These early tests were eventually rejected in favor of tests that attempt to tap higher mental processes. Terman (1916) adapted Binet's IQ test for use with American populations. Known as the Stanford-Binet IQ test, Terman's adaptation was, like the original French test, used primarily to predict academic performance. Stanford-Binet test scores were presented as ratios of mental age to chronological age multiplied by 100 to eliminate decimal points. IQ scores centered at 100 as the average are now conventional for most intelligence tests. Wechsler (1939) noted two major limitations of the Stanford-Binet test: (1) it was overly reliant on verbal skills and, therefore, dependent upon formal education, and (2) the ratio of 
mental to chronological age was inappropriate for adults (Boake 2002). Wechsler created a new intelligence test battery divided into verbal (similarities, for example) and performance subtests (block design, matrix reasoning, for example). He also replaced the ratio IQ score with deviation scores that had the same normal distribution at each age. This test, the Wechsler Adult Intelligence Scale (WAIS) - and, later, the Wechsler Intelligence Scale for Children (WISC) produces two different IQ subscores, verbal IQ and performance IQ, which sum to a full-scale IQ score. The WAIS and the WISC have for the past several decades been by far the most commonly used IQ tests.

Similar to Wechsler's Matrix Reasoning subtest, the Raven Progressive Matrices test is a so-called "culture-free" IQ test because it does not depend heavily on verbal skills or other knowledge explicitly taught during formal education. Each matrix test item presents a pattern of abstract figures. ${ }^{20}$ The test taker must choose the missing part. ${ }^{21}$ If subjects have not had exposure to such visual puzzles, the Raven test is an almost pure measure of fluid intelligence. However, the assumption that subjects are unfamiliar with such puzzles is not typically tested. It is likely that children from more educated families or from more developed countries have more exposure to such abstract puzzles (Blair 2006). To varying degrees, IQ tests reflect fluid intelligence, crystallized intelligence, and motivation. We summarize the evidence on this point in section III.

\section{E. Personality Tests}

There is a parallel tradition in psychology of measuring personality using a variety of tests and self-reports of observers about traits. It has different origins. Personality tests were initially designed to describe individual differences. IQ tests were designed to predict performance on specific tasks. As the field of personality psychology evolved, some personality 
psychologists began to focus on prediction although description remains the main point of interest.

Dominant theories of personality assume a hierarchical structure analogous to that found for intelligence. However, despite early efforts to identify a $g$ for personality (for example, Webb 1915), even the most parsimonious personality models incorporate more than one factor. The most widely accepted taxonomy of personality traits is the Big Five or five-factor model. ${ }^{22}$ The factors are obtained from conventional factor analysis using a version of (2) where the "tasks" are measures of different domains of personality based on observer reports or self reports.

This model originated in Allport and Odbert's (1936) lexical hypothesis, which posits that the most important individual differences are encoded in language. Allport and Odbert combed English dictionaries and found 17,953 personality-describing words, which were later reduced to 4,504 personality-describing adjectives. Subsequently, several different psychologists working independently and on different samples concluded that personality traits can be organized into five superordinate dimensions. These five factors have been known as the Big Five since Goldberg (1971).

The Big Five factors are Openness to Experience (also called Intellect or Culture), Conscientiousness, Extraversion, Agreeableness, and Neuroticism (also called Emotional Stability). A convenient acronym for these factors is "OCEAN". These factors represent personality at the broadest level of abstraction. Each factor summarizes a large number of distinct, more specific, personality characteristics. John (1990) and Costa and McCrae (1992a) present evidence that most of the variables used to assess personality in academic research in the field of personality psychology can be mapped into one or more of the dimensions of the Big 
Five. They argue that the Big Five may be thought of as the longitude and latitude of personality, by which all more narrowly defined traits (often called "facets") may be categorized (Costa and McCrae, 1992a). Table 1 presents these factors and summarizes the 30 lower-level facets (six facets for each of five factors) identified in the Revised NEO Personality Inventory (NEO-PI-R, Costa and McCrae, 1992b), shorthand for Neuroticism, Extroversion, Openness to experiencePersonality Inventory—Revised. It is the most widely-used Big Five questionnaire. Since 1996, free public-domain measures of Big Five factors and facets derived from the International Personality Item Pool have been made available. ${ }^{23}$

The Big Five model is not without its critics. For example, Eysenck (1991) offers a model with just three factors (that is, Neuroticism, Extraversion, and Psychoticism). Cloninger (1987) and Tellegen (1985) offer different three-factor models. Figure 2 shows the commonalities across competing taxonomies and also areas of divergence. Despite solid evidence that five factors can be extracted from most if not all personality inventories in English and other languages, there is nothing sacred about the five-factor representation. For example, Mershon and Gorsuch (1988) show that solutions with more factors substantially increase the prediction of such outcomes as job performance, income, and change in psychiatric status. More parsimonious models in which the five factors are reduced further to two "metatraits" have also been suggested (Digman 1997).

The most stinging criticism of the five-factor model is that it is atheoretical. The finding that descriptions of behavior as measured by tests, self-reports, and reports of observers cluster reliably into five groups has not so far been explained by a basic theory. Research is underway on determining the neural substrates of the Big Five (see Canli 2006). The Big Five model is derived from a factor analysis among test scores and is not derived from predictive criteria in 
performance on real-world tasks. Block (1995) questions not only the five-factor model itself but, more generally, the utility of factor analysis as a tool for understanding the true structure of personality. Anyone familiar with factor analysis knows that determining a particular factor representation often entails some amount of subjective judgment. However, the very same complaints apply to the atheoretical, factor-analytic basis for the extraction of " $g$ " and lower order factors from tests of cognition (see Cudek and McCallum, 2007). We discuss this issue further in Section III.

The five-factor model is largely silent on an important class of individual differences that do not receive much attention in the recent psychology literature: motivation. The omission of motivation (that is, what people value or desire) from measures of Big Five traits is not complete, however. The NEO-PI-R, for example, includes as a facet "achievement striving". Individual differences in motivation are more prominent in older (now rarely used) measures of personality. The starting point for Jackson's Personality Research Form (PRF; Jackson 1974), for example, was Murray's (1938) theory of basic human drives. Included in the PRF are scales for (need for) play, order, autonomy, achievement, affiliation, social recognition, and safety. The Schwartz Values Survey (Schwartz, 1992) is another self-report measure of motivation and yields scores on ten different motivations including power, achievement, benevolence, and conformity. Some motivation theorists believe that one's deepest desires are unconscious and, therefore, may dispute the practice of measuring motivation using self-report questionnaires (see McClelland et al, 1989). For a brief review of this debate and an overview of how motivation and personality trait measures differ, see Roberts et al. (2006).

A practical problem facing the analyst who wishes to measure personality is the multiplicity of personality questionnaires. The proliferation of personality measures reflects, in 
part, the more heterogeneous nature of personality in comparison to cognitive ability, although, as we have seen, various types of cognitive ability have been established in the literature. ${ }^{24}$ The panoply of measures and constructs also points to the relatively recent and incomplete convergence of personality psychologists on the Big Five model, as well as the lack of consensus among researchers about identifying and organizing lower-order facets of the Big Five factors (see DeYoung 2007 and Hofstee, de Raad, and Goldberg 1992). For example, some theorists argue that impulsivity is a facet of Neuroticism (Costa and McCrae, 1992b), others claim that it is a facet of Conscientiousness (Roberts et al. 2005a), and still others suggest that it is a blend of Conscientiousness, Extraversion, and perhaps Neuroticism (Revelle 1997). Figure 2 shows in italics facets whose classification is in debate. Another reason for the proliferation of measures is the methodology of verifying tests - a point we develop in Section III.

\section{F. Measures of Temperament}

The question of how to measure personality in adults leads naturally to a consideration of personality traits in childhood. Temperament is the term used by developmental psychologists to describe the behavioral tendencies of infants and children. ${ }^{25}$ Because individual differences in temperament emerge so early in life, these traits have traditionally been assumed to be biological (as opposed to environmental) in origin. ${ }^{26}$ However, findings in behavioral genetics suggest that, like adult personality, temperament is only partly heritable, and as discussed in Section VI, both adult and child measured traits are affected by the environment.

Temperament is studied primarily by child and developmental psychologists, while personality is studied by adult personality psychologists. The past decade has seen some convergence of these two research traditions, however, and there is evidence that temperamental differences observed during the preschool years to a limited extent anticipate adult personality 
and interpersonal functioning decades later (for example, Caspi 2000; Newman et al. 1997; Shiner and Caspi 2003).

Historically, many temperament researchers examined specific lower-order traits rather than broader, higher-level factors that characterize studies of adult intelligence and personality. ${ }^{27}$ Shiner (1998) suggests that "there is therefore a great need to bring order to this vast array of studies of single lower level traits." Recently, taxonomies of temperament have been proposed that group lower-order traits into higher-order dimensions; several of these taxonomies resemble the Big Five (for example, John et al., 1994; Putnam, Ellis, and Rothbart 2001; Rothbart, Ahadi, and Evans 2000; Shiner and Caspi 2003). However, compared to adults, there seem to be fewer ways that young children can differ from one another. Child psychologists often refer to the "elaboration" or "differentiation" of childhood temperament into the full flower of complex, adult personality. The lack of direct correspondence between measures of temperament and measures of adult personality presents a challenge to researchers interested in documenting changes in personality over the full life cycle. Developing the required measures is an active area of research.

\section{Measurement And Methodological Issues}

In studies gauging the importance of cognitive and personality traits on outcomes, economists are beginning to use measures developed by psychologists. ${ }^{28}$ We have discussed these measures in general terms in the preceding section and will discuss specific measurements in Sections IV and V. Before discussing the details of specific measurement schemes, it is useful to understand limitations of currently used measurement systems at an abstract level.

There are two general types of measurement schemes: (a) those that seek to measure or elicit conventional economic preference parameters, and (b) those that measure personality with 
self-reports or observer reports. Personality psychologists focus primarily on the latter.

Economists and the psychologists working at the interface of economics and psychology use the former. Given our focus in this paper on personality psychology, in this section we devote the lion's share of attention to the second approach, which is the source of most of the findings in personality psychology. However, many points we make apply to both approaches.

Personality psychologists marshal three types of evidence to establish the validity of their tests: content-related, construct-related, and criterion-related evidence (AERA, APA, 1999). Content-related evidence demonstrates that a given measure adequately represents the construct being measured. Qualitative judgments about content-related validity are made by experts in the subject. In recent years, psychologists have devoted more energy to establishing quantitative construct-related evidence for a measure. Test items for a construct that are highly correlated form a cluster. If items are highly correlated within a cluster but weakly correlated with items across other clusters, the set of tests are said to have both "convergent and discriminant validity," with the "convergent" referring to the intercorrelations within a cluster and the "discriminant" referring to lack of correlation across clusters. This method relies on factor analysis. ${ }^{29}$ A third approach is based on criterion-related evidence. As the term is used by psychologists, "predictive validity" is a type of criterion validity - a measure of association between tests or self-reports and future outcomes. Evidence for predictive validity is inherently more attractive to economists than construct validity but has its own problems. Neither approach assesses the causal validity of the underlying factors. Because of problems with measurement error in tests, an approach based on predictive validity almost certainly leads to a proliferation of measures that are proxies for a lower-dimensional set of latent variables, "constructs" or factors in the psychology literature. 


\section{A. The Factor Model for Test Scores}

To understand the approaches to the validation of intelligence and personality measures in psychology and their recent applications and extensions in economics, it is helpful to build on the simple factor model presented in Section II. There we defined a set of $J$ tasks which depend on a vector $f_{i}$ of unspecified dimension. These latent factors generate performance on a variety of tasks.

A task can be a test or performance on a real world task. We stress that measurements on either type of task are generated by the $f_{i}$. Some components of $f_{i}$ may be of no value in some tasks, so the derivatives of (1) with respect to those components for those task functions are identically zero.

Personality psychologists largely focus on observer and self reports. The measurements are designed to capture a particular latent factor. The concept of "discriminant validity" of a battery of tests captures the notion that the particular battery measures a component of $f_{i}$, for example, $f_{i, l}$, and not other components. Many measurements may be taken on $f_{i, l}$. We introduce a notation to distinguish the subset of tasks composed of tests and observer reports from other tasks. While the measurements are really just a type of task, it is fruitful to separate them out in order to survey the literature in psychology which assigns a special status to tests, self-reports, and observer reports of latent traits.

Let $M_{i, l}^{n}$ be the $n^{\text {th }}$ measurement (by test or observer report) on trait $l$ for person $i$. Using a linear factor representation, the $n$th measurement of factor $l$ for person $I$ is assumed to be representable as

$$
\begin{aligned}
& M_{i, l}^{n}=\mu_{l}^{n}+\lambda_{l}^{n} f_{i, l}+\varepsilon_{i, l}^{n}, \\
& n=1, \ldots, N_{l}, \quad i=1, \ldots, I, \quad l=1, \ldots, L .
\end{aligned}
$$


The factor $f_{i, l}$ is assumed to be statistically independent of the measurement errors, $\varepsilon_{i, l}^{n}, n=1, \ldots, N_{l}$. Different factors are assumed to be independent $\left(f_{l}\right.$ independent of $f_{l^{\prime}}$ for $\left.l \neq l^{\prime}\right)$. The measurement errors (or "uniquenesses") are assumed to be mutually independent within and across constructs.

In fact, measurement $M_{l, i}^{n}$ may depend on other components of $f_{i}$, so that the measurement captures a composite of latent traits. Thus in general we may have

$$
M_{i, l}^{n}=\mu_{l}^{n}+\lambda^{n} f_{i}+\varepsilon_{i, l}^{n}, n=1, \ldots, N_{l},
$$

where $\lambda^{n}$ is a vector with possibly as many as $L$ nonzero components. The $\varepsilon_{i, l}^{n}$ are assumed to be independent of $f_{i}$ and mutually independent within and across constructs ( $l$ and $l^{\prime}$ are two constructs). The test has discriminant validity if $\lambda_{l}^{n}$ is the only nonzero component of $f_{i}$. The $\mu_{l}^{n}$ and $\lambda_{l}^{n}$ can depend on measured characteristics of the agent, $Q_{i}{ }^{30}$

\section{B. The Psychometric Approach and Its Limits}

The standard approach to defining constructs in personality psychology is based on factor analysis. It takes a set of measurements (including observer and self reports) that are designed to capture a construct arrived at through intuitive considerations and conventions, and measures within-cluster and across-cluster correlations of the measurements to isolate latent factors $f_{l, i}, l=1, \ldots, L$ or their distributions. The measurements and clusters of tests are selected on intuitive grounds or a priori grounds, and not on the basis of any predictive validity in terms of real world outcomes (for example, success in college, performance on the job, earnings). This process gave rise to the taxonomy of traits that became the Big Five. Because of the arbitrary basis of these taxonomies, there is some controversy in psychology about competing construct systems. In practice, as we document below, the requirement of independence of the latent 
factors across constructs (lack of correlation of tests across clusters) is not easily satisfied. ${ }^{31}$ This fuels controversy among competing taxonomies.

Conventional psychometric validity of a collection of item or test scores for different constructs thus has three aspects. (a) A factor $f_{l}$ is assumed to account for the intercorrelations among the items or tests within a construct $l$. (b) Item-specific and random error variance are low (intercorrelations among items are high within a cluster). ${ }^{32}$ (c) Factor $f_{l}$ for construct $l$ is independent of factor $f_{l^{\prime}}$ for construct $l^{\prime}$. Criteria (a) and (b) are required for "convergent validity." Criterion (c) is "discriminant validity."

An alternative approach to constructing measurement systems is based on the predictive power of the tests for real world outcomes, that is, on behaviors measured outside of the exam room or observer system. The Hogan Personality Inventory ${ }^{33}$, the California Personality Inventory, and the Minnesota Multiphasic Personality Inventory were all developed with the specific purpose of predicting real-world outcomes. Decisions to retain or drop items during the development of these inventories were based, at least in part, upon the ability of items to predict such outcomes. This approach has an appealing concreteness about it. Instead of relying on abstract a priori notions about domains of personality and subjectively defined latent factors generated from test scores and self and observer personality assessments, it anchors measurements in tangible, real-world outcomes and constructs explicit tests with predictive power. Yet this approach has major problems.

First, all measurements of factor $f_{i, l}$ can claim incremental predictive validity as long as each measurement is subject to error $\left(\varepsilon_{i, l}^{n} \neq 0\right)$. Proxies for $f_{i, l}$ can appear to be separate determinants (or "causes") instead of surrogates for an underlying one-dimensional construct or factor. Thus suppose that model (4) is correct and that a set of measurements display both 
convergent and discriminant validity. As long as there are measurement errors for construct $l$, there is no limit to the number of proxies for $f_{i, l}$ that will show up as statistically significant predictors of an outcome. This is a standard result in the econometrics of measurement error. We develop this point further in Web Appendix A. ${ }^{34}$

A second problem is reverse causality. This is especially problematic when interpreting correlations between personality measurements and outcomes. Outcomes may influence the personality measures as well as the other way around. For example, self-esteem might increase income, and income might increase self-esteem. Measuring personality prior to measuring predicted outcomes does not necessarily obviate this problem. For example, the anticipation of a future pay raise may increase present self-esteem. Heckman, Stixrud, and Urzua (2006) and Urzua (2007) demonstrate the importance of correcting for reverse causality in interpreting the effects of personality tests on a variety of socioeconomic outcomes. Application of econometric techniques for determining the causal effects of factors on outcomes makes a distinctive contribution to psychology. These methods are briefly surveyed in Web Appendix A.

Many psychologists focus on prediction, not causality, out of ignorance of more sophisticated econometric tools. Establishing predictive validity will often be enough to achieve the goal of making good placement decisions. However, for policy analysis, including analyses of new programs designed to augment the skills of the disadvantaged, causal models are needed. $^{35}$

The papers of Heckman, Stixrud, and Urzua (2006), Urzua (2007), and Cunha and Heckman (2008), are frameworks for circumventing the problems that arise in using predictive validity alone to define and measure personality constructs. ${ }^{36}$ These frameworks recognize the problem of measurement error in the proxies for constructs. Constructs are created on the basis 
of how well latent factors predict outcomes. They develop a framework for testing discriminant validity because they allow the factors across different clusters of constructs to be correlated, and can test for correlations across the factors.

They use an extension of factor analysis to represent proxies of low dimensional factors. They test for the number of latent factors required to fit the data and rationalize the proxies. ${ }^{37}$ Generalizing the analysis of Hansen, Heckman, and Mullen (2004), they allow for lifetime experiences and investments to determine in part the coefficients of the factor model and to affect the factor itself. They correct estimates of latent factors on outcomes for the effects of spurious feedback, and separate proxies from factors. The factors are estimated to change over the life cycle as a consequence of experience and investment.

Measurements of latent factors may be corrupted by "faking." There are at least two types of false responses: those arising from impression management and those arising from selfdeception (Paulhus, 1984). For example, individuals who know that their responses on a personality questionnaire will be used to make hiring decisions may deliberately exaggerate their strengths and downplay their weaknesses. ${ }^{38}$ Subconscious motives to see themselves as virtuous may produce the same faking behavior, even when responses are anonymous. Of course, it is possible to fake conscientiousness on a self-report questionnaire whereas it is impossible to fake superior reasoning ability on an IQ test. To a lesser degree, a similar bias may also operate in cognitive tests. Persons who know that their test scores will affect personnel or admissions decisions may try harder. The effects of faking on predictive validity have been well-studied by psychologists, who conclude that distortions have surprisingly minimal effects on prediction of job performance (Hough et al. 1990; Hough and Ones 2002; Ones and Viswesvaran 1998). Correcting for faking using scales designed to measure deliberate lying does not seem to improve 
predictive validity (Morgeson et al. 2007). Nevertheless, when measuring cognitive and personality traits one should standardize for incentives and environment. This leads to the next topic.

\section{A Benchmark Definition of Traits}

Although most personality psychologists rely on tests or observer reports to measure latent factors, behaviors in real world settings are also informative on those traits. If this were not so, the latent traits would be of little interest to economists or psychologists. The outputs of tasks $T_{i, j}$ defined in equation (1) may be test scores, observer reports or productivity measurements in social settings. Test scores are proxies for the latent traits that generate behavior. Thus the measurements of trait $l$ in measurement situation $n, M_{i, l}^{n}$ in equation (3) can be more broadly interpreted as a measure of performance in any situation.

An ongoing debate in the personality literature concerns the existence and stability of latent traits. An extreme view, advocated by Mischel (1968), claims that manifestations of traits are solely situation-specific. Traits do not exist except as manifestations of situations. Any observed stability of traits is solely a consequence of stability of situations. We summarize the evidence on this and related claims in section V. First, we present a framework for thinking about this issue. This framework is equally applicable to personality inventories, IQ test scores or to measurements on conventional economic preferences.

To simplify notation, drop the subscript denoting person $i$. In this notation, $f$ is a vector of latent traits and $f_{l}$ is a particular trait in the list of $L$ traits (extraversion, for example). The manifestation of trait $l, M_{l}^{n}$ as opposed to the trait itself $f_{l}$, is obtained by measurement $n$, $n=1, \ldots, N_{l}$ and may depend on incentives to manifest the trait. Let $R_{l}^{n}$ be the reward for manifesting the trait in situation $n$. Thus if extraversion is a desirable trait in $n$, and is highly 
rewarded, there will be more manifest extraversion in $n$ compared to less highly rewarded situations. Reward can be interpreted very broadly to include the benefits of social approval, the approval of external observers and the like. Other latent traits besides $l$ may affect the manifestation of a trait for $l$. Thus, pursuing the extraversion example, more highly intelligent persons may perceive the benefits of exhibiting extraversion in situation $n$. Let $f_{\sim l}$ be the components of $f$ apart from $f_{l}$. Let $W_{l}^{n}$ denote other variables operating in situation $n$ that affect measured performance for $l$.

Measured traits are imperfect proxies for true traits:

$$
M_{l}^{n}=h_{l}\left(f_{l}, f_{\sim l}, R_{l}^{n}, W_{l}^{n}\right), n=1, \ldots, N_{L}, l=1, \ldots, L .
$$

There may be threshold effects in all variables so the $h_{l}$ function allows for jumps in manifest traits as the arguments of (5) are varied. These functions may vary across individuals.

Mischel (1968) claims that $h_{l}$ does not depend on $f_{l}$ because there is no $f_{l}$ (or for that matter $f_{\sim l}$ ) and indeed that the manifestation $M_{l}^{n}$ is solely a function of situational incentives $R_{l}^{n}$ and context $W_{l}^{n}$. Stability of measured traits is solely a consequence of stability of incentives and context. Some behavioral economists have adopted this interpretation of personality.

Even without taking this extreme position, equation (5) in the general case captures the intuition that it is unwise to equate the measurement of a trait with the trait itself without standardizing incentives and context. It is only meaningful to define measurements on $f_{l}$ at benchmark levels of $R_{l}^{n}, f_{\sim l}$, and $W_{l}^{n}$. Define these benchmarks as $\bar{R}_{l}, \bar{f}_{\sim l}$, and $\bar{W}_{l}$ respectively. At these benchmark values, one can define $f_{l}$ :

$$
\begin{aligned}
& M_{l}^{n}=f_{l}, \quad \text { for } \quad R_{l}^{n}=\bar{R}_{l}, \quad f_{l}=\bar{f}_{l}, \quad f_{\sim l}=\bar{f}_{\sim l}, \quad W_{l}^{n}=\bar{W}_{l}, \\
& n=1, \ldots, N_{l}, \quad l=1, \ldots, L .
\end{aligned}
$$


This produces an operational definition of latent traits across measurement situations.

Framework (5) accounts for the diversity of measurements on the same latent trait. It is flexible enough to capture interactions among the traits and the notion that at high enough levels of certain traits, incentives $\left(R_{l}^{n}\right)$ might not matter whereas at lower levels they might. Thus, if the trait in question is intelligence, scores on IQ tests might depend on the level of conscientiousness of the test taker. People with higher levels of conscientiousness may not respond to incentives on an IQ test, whereas those with lower levels of conscientiousness may be more motivated.

Psychologists have not been careful in characterizing the benchmark states at which standard measurements are taken. This substantially affects the transportability of tests to other environments beyond that of the test-taking environment. ${ }^{39}$ Persons answering a questionnaire on a personality test in a general survey have different incentives to respond than persons who are applying for a job. We review this literature below. First we present a dramatic example of how incentives and personality traits affect the scores on IQ tests.

\section{IQ Scores Reflect Incentives and Measure Both Cognitive and Personality}

\section{Traits}

Notwithstanding the very low correlations between IQ and most measures of personality, performance on intelligence and achievement tests depends in part on certain personality traits of the test taker, as well as their motivation to perform. ${ }^{40}$ A smart child unable to sit still during an exam or uninterested in exerting much effort can produce spuriously low scores on an IQ test. Moreover, many IQ tests also require factual knowledge acquired through schooling and life experience, which are in part determined by the motivation, curiosity, and persistence of the test taker. ${ }^{41}$ Thus, personality can have both direct and indirect effects on IQ test scores. 
Almost 40 years ago, several studies called into question the assumption that IQ tests measure maximal performance (that is, performance reflecting maximal effort). These studies show that among individuals with low IQ scores, performance on IQ tests could be increased up to a full standard deviation by offering incentives such as money or candy, particularly on groupadministered tests and particularly with individuals at the low-end of the IQ spectrum. (Thus incentives $R_{l}^{n}$ in equation (5) are varied.) Engaging in complex thinking is effortful, not automatic (Schmeichel, Vohs, and Baumeister 2003), and therefore motivation to exert effort affects performance. Zigler and Butterfield (1968) found that early intervention (nursery school, for example) for low SES kids may have a beneficial effect on motivation, not on cognitive ability per se. In their study, the benefits of intervention (in comparison to a no-treatment control group) on IQ were not apparent under testing conditions where motivation to perform well were maximized. Raver and Zigler (1997) and Heckman, Stixrud, and Urzua (2006) present further evidence on this point. Table 2 summarizes evidence that extrinsic incentives can substantially improve performance on tests of cognitive ability, especially among low-IQ individuals. ${ }^{42}$

Segal (2006) shows that introducing performance-based cash incentives in a low-stakes administration of the coding speed test of the Armed Services Vocational Battery (ASVAB) increases performance substantially among roughly one-third of participants. Less conscientious men are particularly affected by incentives. Thus in terms of equation (5), other traits $\left(f_{\sim l}\right)$ affect the manifestation of the trait in question $\left(f_{l}\right)$. Segal's work and a large body of related work emphasize heterogeneity in the motivations that affect human performance. Borghans, Meijers, and ter Weel (2006) show that adults spend substantially more time answering IQ questions when rewards are higher, but subjects high in emotional stability and conscientiousness are less affected by these incentives. Similarly, Pailing and Segalowitz (2004) find that an event-related 
potential (ERP) indexing the emotional response to making an error increases in amplitude when incentives are offered for superior test performance. ${ }^{43}$ This effect is smaller for individuals high in conscientiousness and emotional stability. Thus, IQ scores do not accurately reflect maximal intellectual performance for individuals low in the personality traits related to conscientiousness and emotional stability. The performance on the IQ test encodes, in part, how effective persons may be in application of their intelligence, that is, how people are likely to perform in a realworld setting. However, it is far from obvious that motivation on an exam and motivation in a real-world situation are the same.

Like low motivation, test anxiety can significantly impair performance (Hembree, 1988). That is, subjects do worse when they worry excessively about how they are performing and when their autonomic nervous system over-reacts by increasing perspiration, heart rate, and so on. Because individuals who are higher in Big Five neuroticism are more likely to experience test anxiety, there is another reason, beyond incentives, why emotional stability can impact IQ scores (Moutafi, Furnham, and Tsaousis, 2006).

Personality traits can also affect IQ scores indirectly through the knowledge acquired by individuals who are more open to experience, more curious, and more perseverant. Cunha and Heckman (2008) show a correlation between cognitive and personality factors of the order of 0.3. Hansen, Heckman, and Mullen (2004), Heckman, Stixrud, and Urzua (2006), and Urzua (2007) show how schooling and other acquired traits substantially causally affect measured cognitive and personality test scores. Cattell's investment theory (1971) anticipates recent findings that knowledge and specific complex skills depend not only on fluid intelligence but also on the cumulative investment of effort and exposure to learning opportunities. 
How, then, should one interpret a low IQ score? Collectively, the evidence surveyed here and in Table 2 suggests that IQ test performance reflects not only pure intelligence, but also anxiety, other personality traits, knowledge, intrinsic motivation, and reactions to extrinsic incentives to perform well, as indicated in (5). The relative impurity of IQ tests likely varies from test to test and individual to individual. Little effort to date has been made to standardize the context and incentives of tests. The difficulty of creating a pure measure of intelligence suggests that Herrnstein and Murray (1994) likely overestimate the effect of pure intelligence on outcomes such as crime and wages. To capture pure intelligence, it is necessary to adjust for the incentives, motivations, and context in which the measurements are taken, and traits other than intelligence, using the framework of equations (5) and (6). ${ }^{44}$

\section{E. Contextualizing Personality}

Recently, personality psychologists have begun to address the role of context, including rewards and observational frames, on the measurement of personality traits. Bandura (1999), Roberts (2007), the papers in a special issue of the Journal of Personality, December, 2007, and McAdams (2006) discuss this issue. Individuals in different roles (and with different incentives) manifest different traits. Equation (5) captures the effects on measurements of the level of the trait $\left(f_{l}\right)$, the incentives $\left(R_{l}^{n}\right)$ in a situation and the context $\left(W_{l}^{n}\right)$. Interaction terms in equation (5) are called "mechanistic interactionism" (see Ozer, 1986 and Endler, 1982). Emmons, Diener, and Larsen (1986), and Emmons and Diener (1986) present evidence of sorting and reciprocal interaction. McAdams (2006) summarizes this literature.

Although Mischel (1968) started the situational vs. trait debate, Mischel and Shoda (1998) implicitly accept specification (5) in their "if-then" analysis of conditional traits. The situation affects the manifestation of the trait. They conduct experiments that establish the 
existence of stable traits across situations. To date, little systematic empirical analysis within the

framework of equations (5) or (6) has been developed except in papers by economists. ${ }^{45}$ This framework offers a promising way to quantify the effects of situations and latent traits on measurements.

\section{The Evidence On Preference Parameters}

Many economists and some psychologists estimate the traditional preference parameters in economics: time preference, risk aversion and preference for leisure. More recently, altruism and social preferences have been studied. In this section, we review the evidence from the group of psychologists and economists who directly measure these preferences. We discuss the findings of the personality psychologists in the next section. Both types of measurements capture aspects of personality broadly defined. They are two distinct approaches which are only partially integrated at the time of this writing.

At the outset, we note that many of the measurements we survey in this and next section do not standardize for incentive and contextual effects. This lack of standardization creates a serious problem in isolating true traits and making comparisons across studies. In economic choices, market settings play a crucial role in policing behavior. Even if individuals seek to exhibit irrational behavior, they must live within their constraints. In a series of papers, List $(2004,2006,2007)$ has shown how behavior in market settings alters the choices that are made in lab settings where market forces are absent. Different incentives and context act on agents $\left(R_{l}^{n}\right.$ and $W_{l}^{n}$ in (5)).

\section{A. Time Discounting}

Evidence from animal and human experiments suggests that future rewards are discounted non-exponentially as a function of delay. Notwithstanding a vigorous debate about 
the best-fitting and most parsimonious mathematical models for discounting (McClure et al. 2004; Ainslie and Monterosso 2004), there is some consensus in psychology that hyperbolic functions fit data from these experiments better than do exponential functions (Rachlin 2004; Ainslie 1991). However, as noted by many economists, the evidence for hyperbolic discounting is far from solid. ${ }^{46}$

Under hyperbolic discounting, future utility $A$ is discounted to current utility value $V$ by the formula

$$
V=\frac{A}{1+k d}
$$

where $d$ is the delay and $k$ is the discount rate parameter. Under exponential discounting, $V=\frac{A}{(1+\rho)^{d}}$, where $\rho$ is the discount rate.

Several economists have used observational data to estimate discount rates. ${ }^{47,48}$ Frederick, Loewenstein, and O'Donoghue (2002) point out that such field data may be complicated by the effects of factors such as imperfect information on the part of the subject about future rewards or credit constraints. Standard econometric problems of endogeneity and measurement error plague the observational approach. It is therefore potentially problematic to interpret discount rates estimated in this way. These limitations build the case for experimental elicitations, but they have their own set of problems. ${ }^{49}$

The most widely-used experimental approach to the measurement of discount rates poses a series of choices between smaller, immediate and larger, delayed monetary rewards (see Fuchs 1982; Kirby and Marakovic 1996; Green and Myerson 2004; Rachlin 2006; and Thomas and Ward 1984), for example "Would you choose $\$ 1500$ now or $\$ 4000$ in five years?" (Fuchs 1982). These choices are typically among hypothetical items, but it is unclear whether discount rates for 
real and hypothetical rewards are identical. No real world markets are operative. Adjustments for contextual and incentive effects are not made in these studies.

Johnson and Bickel (2002) and Madden et al. (2003) find no within-subject effect of reward type on discount rates, but Kirby (1997) finds higher discount rates for real rewards vs. hypothetical ones. Even when rewards are real, choosing the delayed reward in discount rate procedures does not require the participant to also sustain his or her choice (Reynolds and Schiffbauer 2005). In real life, one must not only choose delayed gratification but also maintain this choice in the face of immediate temptation. Typical discount rate elicitation procedures used by economists are akin to procedures that ask dieters whether they choose to forgo desserts for an entire week without measuring their ability to sustain their initial choice. ${ }^{50}$

Frederick, Loewenstein, and O’Donoghue (2002) survey methods for measuring discount rates. They document that across studies, estimated discount rates of adult respondents range from -6 percent to infinity. Even more worrisome, questions about the discount rate reveal within-subject inconsistencies (Loewenstein and Prelec 1991) and can lead to very different estimates of this parameter in the same population. These irregularities are disturbing and can be traced to three major sources of error: confounds with individual differences unrelated to time preference (risk aversion, for example), framing effects, and other artifacts related to the particular procedure used, and situational influences on the psychological state of the respondent. ${ }^{51}$ No attempt is made to standardize for incentives, market forces, personality, cognitive traits, and context in this literature.

Consider, for example, how an unrelated trait such as numeracy can distort estimates of time preference. ${ }^{52}$ Virtually all methods of estimating time preference assume that respondents are equally numerate, but Peters et al. (2006) show that this assumption is often untrue. 
Furthermore, more numerate individuals are less susceptible to framing effects and draw stronger and more precise affective meaning from numbers and comparisons using numbers. The confound of numeracy may explain why more intelligent (or educated) individuals often display lower discount rates when decisions require complex calculations to compare subtly different delays or reward amounts (for example, de Wit et al. 2007; Dohmen et al., 2007) but does not shed light on why smarter individuals also have lower discount rates when choosing between relatively simple cash sums (Funder and Block 1989) and between non-cash rewards (such as smaller vs. larger candy bars in Mischel and Metzner 1962) ${ }^{53}$. A meta-analysis by Shamosh and Gray (2007) of 24 studies in which both IQ and discount rates were measured shows the two traits are inversely related $(r=-.23)$. The complexity entailed by comparing the present and future values of rewards suggests that the inverse relationship between discount rates and intelligence is not just an artifact of measurement. An individual with poor working memory and low intelligence may not be capable of accurately calculating or even perceiving the value of a deferred reward. At the least, making such calculations is more effortful (that is, costly) for individuals of low cognitive ability. If the cost of making calculations exceeds the expected benefit of such deliberation, the individual may choose by default the immediate, certain reward. Here the line between preference and constraint blurs - is this individual's behavior best explained as a constraint on cognition or a preference? We develop this point further in Section VII.

Discount rates also appear to vary inversely with the size of reward (Green, Fry, and Myerson 1994; Kirby, 1997), and vary with the type of reward offered (Chapman, Nelson, and Hier 1999; Chapman and Coups 1999; Estle et al. 2007; Bickel, Odum, and Madden 1999; Bonato and Boland 1983). Insofar as estimates of discount rates are sensitive to context or 
framing effects, they may fail the definitional requirements for separable economic preferences (see Kahneman, Ritov, and Schkade 1999), but they are consistent with more general preference specifications, as we note in section VII.

Frederick, Loewenstein, and O'Donoghue (2002) argue that "the cumulative evidence raises serious doubts about whether there is, in fact, such a construct—a stable factor that operates identically on, and applies equally to, all sources of utility” (p. 392). Instead, Frederick et al. suggest that time preference is tri-dimensional, comprising three separate underlying motives: impulsivity, the tendency to act spontaneously and without planning, compulsivity; the tendency to stick with plans, and inhibition, the ability to override automatic responses to urges or emotions. However, they do not provide a precise map between $\rho$ and these personality traits, nor do they show how exactly their three traits affect choice behavior.

A parallel effort to define impulsivity and to decompose this trait into its constituent components is underway in the psychology literature. To date, there is no agreement as to what these dimensions are (see Barratt, 1985; Buss and Plomin, 1975; Congdon and Canli, 2005; Eysenck, Easting, and Pearson, 1984; Olson, Schilling, and Bates, 1999; Revelle, 1997; White et al. 1994; Whiteside et al. 2005).

An uninvestigated empirical question is whether estimates of the constituent components that give rise to time preference will prove more useful for economic models than currently used specifications. The science of measuring preferences is almost a century behind the science of measuring IQ.

\section{B. Risk Preference}

The risk preference parameter (also referred to as "risk aversion" or "risk tolerance") represents the curvature of the utility function. Using observational data, this parameter is often 
estimated through Euler equations. Browning, Hansen, and Heckman (1999) survey the literature and review the general framework.

Survey techniques measure risk preferences in a more direct way, with methods parallel to the ones developed to measure time preference. The key difference between time and risk preference is that time preference describes the devaluation of rewards as a function of their delay, whereas risk preference describes the devaluation of rewards as a function of their uncertainty. Of course, in the real world, risk and delay are inextricably confounded. A standard result (Gorman, 1968) shows that, in a separable model, intertemporal substitution and risk aversion are indistinguishable attributes of preference specifications. In addition, all deferred rewards carry with them some risk that they will not in fact be received. All consequences involving risk lie in the future. If they were immediate, there would be no uncertainty to negotiate. Despite the common discounting process, however, Green and Myerson (2004) argue that the two constructs belong to different underlying psychological processes. As evidence, they point out that the two constructs react differently to the same effect: for example, an increase in the size of reward generally decreases the discount on time but increase it on probability. ${ }^{54}$ This is evidence against the standard intertemporally separable model of risk aversion.

Survey questions assessing risk preference usually pose a series of questions involving the choice between a lottery and a certain outcome: "Which would you prefer: $\$ 100$ dollars today, or a 50 percent chance of receiving nothing and a 50 percent chance of receiving \$200?” Two recent studies have introduced measures of risk preferences in field experiments. Harrison, Lau, and Rutstrom (2007) use real stakes to elicit risk preferences on a representative sample of 253 people in Denmark. Dohmen et al. (2005) use a lottery experiment with a representative sample of 450 German adults to validate survey responses on risk preference from the 
Socioeconomic Panel (SOEP). In their study, the general SOEP question about "willingness to take risks, in general" answered on an 11-point scale predicts self-reported risky behavior in the domains of health, driving, financial matters, leisure, and so on better than does a typical lottery question. Also, such a general question is free from framing effects that shape behavior in presence of risk (Kahneman 2003). The findings for general samples suggest that preferences are best measured in ways that do not require a high level of numeracy. As we previously argued for time preference, the effects of numeracy and intelligence may not simply constitute methodological artifacts, but are root explanations for behavior in the face of uncertainty. As for time preference, in fact, there appears to be an inverse relationship between cognitive ability and risk aversion, where higher IQ people have higher risk tolerance (Benjamin, Brown, and Shapiro 2006; Dohmen et al. 2007). ${ }^{55}$

Risk preference also varies with socioeconomic characteristics. However, there is no general consensus on the direction of such differences: some studies find a negative relationship between education and risk aversion (Weiss 1972; Belzil and Leonardi 2006; Ferrer-i-Carbonell 2005; Binswanger 1980, 1981; Guiso and Paiella 2001; and Andersen et al. 2005), while Barsky et al. (1997) find an inverse U-shaped relationship, with risk tolerance peaking at 12 years of education. There are some consistent patterns of a negative relationship between unemployment duration and risk aversion, (see Feinberg 1977, and Kohn and Schooler 1978). Most of the studies find that women are more risk averse than $\operatorname{men}^{56}$ (see Barsky et al. 1997; Donkers, Melenberg, and van Soest 2001; Hartog, Ferrer-i-Carbonell, and Jonker 2002; Jianakoplos and Bernasek 1998; see Eckel and Grossman 2008 for a review), but a few do not find this gender difference (see Andersen et al. 2005; Harbaugh, Krause, and Vesterlund 2002; and Holt and Laury 2002). Parents and their children are similarly risk averse, and this effect is stronger 
among children with fewer siblings and first-born children (Dohmen et al. 2006). Risk aversion dips sharply in adolescence (Steinberg, 2004, 2007) and then throughout adulthood seems to increase with age (Dohmen et al. 2005).

The empirical findings summarized in this section assume that risk preference can be modelled with a single parameter across situations. Yet, like time preference, risk preference may be multidimensional rather than unitary. Weber (2001) shows that risk preference varies by domain, and a scale that assesses risk taking in five different domains shows low correlations across these domains (Weber, Blais, and Betz 2002). One can be quite risk-averse when it comes to financial decisions but risk-loving when it comes to health decisions (Hanoch, Johnson, and Wilke 2006). Weber's risk-return model of risk taking (Weber and Milliman 1997; Weber and Hsee 1998) finds that low correlations among risk taking preference across domains can be explained by domain-specific perceptions of riskiness and return. Perhaps the relatively modest predictive validity of risk aversion for actual risk-taking behaviour (for example, Barsky et al. 1997) might be improved considerably with a multidimensional and domain-specific approach to its measurement.

A behavioral task and self-report measure from the psychology literature are of interest. Lejuez and colleagues $(2002,2003)$ have developed a behavioral task for risk preference. Their Balloon Analogue Risk Task (BART) is a computer game in which participants make repeated choices between keeping a certain smaller monetary reward and taking a chance on an incrementally larger reward. Scores on the BART correlate with real-world risk behaviors such as smoking, stealing, and not wearing a seatbelt. BART scores also correlate with sensation seeking, a trait proposed by Zuckerman (1994) and defined as "the tendency to seek novel, varied, complex, and intense sensations and experiences and the willingness to take risks for the 
sake of such experience. ${ }^{, 57}$ More than 2000 published articles have incorporated sensation seeking self-report questionnaires, and collectively these studies have established that sensation seeking predicts risky driving, substance use and abuse, smoking, drinking, unprotected sex, juvenile delinquency, and adult criminal behavior (see Zuckerman 2007 for a review). This broadens the notion of risk aversion to include the enjoyment of risk, per se, at least over certain ranges. Unfortunately, few, if any studies, have included typical risk preference propositions of the sort relevant to economic decision making when sensation seeking is estimated. ${ }^{58}$ An integration of these two endeavors would be useful.

\section{Preference for Leisure}

There is a large literature on estimating leisure preferences. See Killingsworth (1985), Pencavel (1986), Heckman (1993), and Browning, Hansen, and Heckman (1999) for surveys of

labor supply elasticities. ${ }^{59}$ Pencavel (1986) discusses the evidence on experimental estimates of labor supply functions in field settings.

Survey-based estimates of preferences for leisure are less common, probably because direct measurement is complicated. ${ }^{60}$ Comparable questions that capture the economic concepts often give results that vary substantially in level, although generally different measures are correlated. Difficulties people face in understanding economic trade-offs might be a reason for this. Estimates of leisure demand based on psychological questionnaires often predict outcomes better. One reason why self-report measures of personality have higher predictive validities for outcomes may be their superior reliability and, consequently, lower error variance, but this has not been explicitly investigated. A second advantage of self-report measures is that questions are deliberately phrased to emphasize typical behavior and, thus, responses are less likely affected by situational factors. This results in lower error variance. 
Most omnibus measures of personality include scales closely related to preference for leisure or, more frequently, the obverse trait of preference for work. The widely used Big Five (or NEO-PI-R, Costa and McCrae 1992b), whose components and facets are summarized in Table 1, includes an Achievement Striving subscale of Conscientiousness, which describes ambition, the capacity for hard work, and an inclination toward purposeful behavior. Jackson's Personality Research Form (1974) includes an achievement scale measuring the aspiration to accomplish difficult tasks and to put forth effort to attain excellence, as well as an endurance scale, measuring willingness to work long hours and perseverance in the face of difficulty, and a play scale, measuring the inclination to participate in games, sports, and social activities "just for fun." A recent factor analysis of seven major personality inventories identified industriousness as one of six facets of Conscientiousness (Roberts et al. 2005a).

\section{Altruism and Social Preferences}

There is a large literature in economics on altruism and an emerging literature in economics on social preferences. Papers by Bergstrom (1997) and Laitner (1997) discuss models of interdependent family preferences. Andreoni (1995) shows that pure models of altruism are inconsistent with his evidence. His "warm glow" version of altruism suggests that giving for giving's sake is valued. Part of the difficulty in measuring altruism is that it entails tracing links between multiple agents typically followed over time, and it is difficult to use laboratory experiments to isolate altruism. Villanueva (2005) and Laferrère and Wolff (2006) summarize the mixed evidence on altruism in families.

A recent literature explores social preferences which are distinct from altruism per se. Altruism is based on the assumption that the preferences of one agent depend on the consumption or utility of other agents. Social preferences are preferences that depend on agent's 
evaluations of a social condition (inequality, for example) or the intentions of other agents. Meier (2007) surveys the evidence on other forms of altruism and on pro-social behavior more generally. Fehr and Schmidt (1999) analyze inequality aversion (in which people dislike inequality rather than valuing the consumption or utility of agents per se). Fehr and Gächter (2000), and Falk and Fischbacher (2006) present evidence on reciprocity and conditional cooperation, in which agents act in a pro-social or antisocial manner depending on the behavior of others with whom they interact. Fehr and Schmidt (2006) summarize the theory and empirical support for social preferences. Their research suggests that social preferences distinct from pure altruism may play an important role in shaping individual behaviors. To date, there has been no attempt to relate social preferences to the Big Five personality traits that we discuss next, even though at an intuitive level social preferences should be linked with empathy and outgoingness.

\section{Predictive Power of Personality Traits}

The importance of personality traits can be inferred from the failure of cognitive measures to predict certain outcomes. Heckman and Rubinstein (2001) use evidence from the General Education Development (GED) testing program (an exam-certified alternative high school degree) to demonstrate the quantitative importance of personality traits. GED recipients have the same cognitive ability as high school graduates who do not go on to college, as measured by scores on the Armed Forces Qualifying Test (AFQT). Controlling for cognitive ability, GED recipients actually have lower hourly wages and obtain lower levels of schooling than high school dropouts. GED recipients also have higher job turnover rates, and are more likely to drop out of the army and post secondary schooling (Heckman and LaFontaine 2007). Heckman, Stixrud, and Urzua (2006) show that the power of the personality traits they consider equals or exceeds the predictive power of cognitive traits for schooling, occupational choice, 
wages, health behaviors, teenage pregnancy, and crime. As noted in the introduction, evidence from the Perry Preschool Project suggests that Perry did not raise IQ, but did promote a variety of positive behaviors (see Heckman and Masterov, 2007).

In the psychology literature, there is substantial evidence on the importance of personality traits in predicting socioeconomic outcomes including job performance, health, and academic achievement (Barrick and Mount 1991; Chamorro-Premuzic and Furnham 2005; Hampson et al. 2006; Hogan, Hogan, and Roberts, 1996; Hogan and Holland 2003; Robbins et al. 2006; Roberts et al., 2007, Ones et al. 2007; Schmidt and Hunter 1998). Figure 2 summarizes correlations for the predictive validity of IQ and Big Five personality factors on leadership ratings, job performance, longevity, college grades, and years of education. Observed correlations are presented as well as, where available, true score correlations that are corrected for attenuation due to restriction on range or lack of reliability. ${ }^{61}$ These estimates derive from meta-analyses and reviews in the psychology literature. ${ }^{62}$ Wherever available, estimates from longitudinal studies are favored over cross-sectional estimates. We repeat the qualification of our review of the evidence that we made in Section IV. With the exceptions noted below, little empirical research in the literature standardizes for incentives and context, or directly controls for reverse causality.

Figure 3 shows that IQ surpasses any single Big Five personality factor in the prediction of the two academic outcomes, college grades $(r=.45)$ and years of education $(r=.55)$. Big Five conscientiousness is by far the best personality predictor of grades $(r=.22)$ and, after openness to experience, the second-best personality predictor of years of education $(r=.11){ }^{63}$ Conscientiousness is a slightly better predictor of longevity $(r=.09)$ than is IQ $(r=.06)$. Conscientiousness predicts leadership ratings $(r=.20)$ slightly better than IQ does $(r=.17)$. 
Conscientiousness predicts job performance $(r=.13$; corrected $r=.22)$ better than does any other Big Five factor, but not as well as IQ does $(r=.21$; corrected $r=.55)$. The importance of IQ increases with job complexity, defined as the information processing requirements of the job: cognitive skills are more important for professors, scientists, and senior managers than for semiskilled or unskilled laborers (Schmidt and Hunter 2004) ${ }^{64}$ In contrast, the importance of conscientiousness does not vary much with job complexity (Barrick and Mount 1991).

Contemporary psychologists (for example Chamorro-Premuzic and Furnham 2003; Digman and Takemoto-Chock 1981; Duckworth and Seligman, 2005; Mischel, Shoda, and Peake 1988; Noftle and Robins 2007; Ones et al. 2007; Paunonen and Ashton 2001; Robbins et al. 2006; Salgado 1997; Shoda, Mischel, and Peake 1990; Wolfe and Johnson 1995) and earlier researchers (for example, Hull and Terman 1928; Harris 1940; Wechsler 1940; and Barton Dielman, and Cattell 1972) suggest that self-control, perseverance, and other aspects of conscientiousness as the major personality contributors to success in school and in life. (For a more detailed review of personality, IQ, and academic performance, see Chamorro-Premuzic and Furnham 2005.) ${ }^{65}$ As noted previously, Big Five conscientiousness is conceptually related to risk aversion, leisure preference, and time preference. Aspects of Big Five neuroticism (more helpfully termed by its obverse, Big Five emotional stability) are next in importance. Nyhus and Pons (2005) have shown, for example that emotional stability predicts higher wages, and Salgado (1997) shows that emotional stability and conscientiousness are more predictive of job performance across professions than other Big Five dimensions. As described in more detail below, Heckman, Stixrud, and Urzua (2006) and Judge and Hurst (2007) show that among participants in the NLSY 1979 cohort, positive self-evaluations measured in young adulthood (with self-report questions of self-esteem, locus of control, and related traits) predict income in 
mid-life and, further, enhance the benefits of family socioeconomic status, and academic achievement on mid-life income. Hogan and Holland (2003) have also shown measures emotional stability to be potent and general predictors of job performance (inversely), with predictive validities corrected for range restriction and unreliability of $r=.43$. Whether predictive validities for self-report measures of personality are large enough to warrant their use in personnel selection is a matter of vigorous debate (see Morgeson et al. 2007; Tett and Christiansen 2007; Ones et al. 2007).

\section{A. Limitations of Current Evidence on Predictive Validity}

There are five reasons why effect size estimates summarized in Figure 3 may underestimate the impact of personality traits. First, whereas the benefits of IQ are monotonically increasing (that is, more is always better), the optimal level of most personality traits may lie somewhere between the two extremes (see Benson and Campbell 2007 and LaHuis, Martin and Avis 2005). Indeed, Wiggins and Pincus (1989) and others have speculated that clinically diagnosable personality disorders represent combinations of extreme points (that is, an extreme excess or lack) on the continuum of each of the Big Five factors. Curvilinear relationships are, of course, not well represented by correlation coefficients.

Second, short personality measures that yield a single score for each Big Five domain are too blunt an instrument to capture relationships between personality and outcomes. Stronger relationships between personality and outcomes often emerge when more narrowly defined facets are used (Paunonen and Ashton 2001). For example, Roberts et al. (2005a) show that lower-level facets of Conscientiousness (for example, the traits of industriousness, self-control) have differential relationships with labor market and other outcomes, and, further, that these traits considered individually may predict outcomes better than a broad measure of 
Conscientiousness. An example of the dramatic impact of a very specifically defined and carefully measured personality trait comes from Mischel and colleagues, who show that delay of gratification (measured as the number of seconds children can wait for a larger treat in lieu of a smaller, immediate treat) at age four predicts higher academic and social functioning in adolescence (Mischel, Shoda, and Peake 1988; Shoda, Mischel, and Peake 1990). The correlations between time preference and SAT scores over a decade later are dramatic $(r=.42$ for SAT verbal and $r=.57$ for SAT math; Mischel, Shoda, and Rodriguez 1989).

Hogan (2005) makes a related point regarding the specificity and appropriateness of outcome variables: "Researchers often fail to align predictors with criteria; this results in using measures of conscientiousness to predict service orientation, or measures of extraversion to predict training performance..." (p. 333). This argument is consistent with the operation of comparative advantage in the labor market and in a variety of other areas of social life. In some tasks, certain traits may be useful; in other tasks, they may not be useful.

Third, personality in large-sample studies is almost invariably measured by brief, selfreport questionnaires, and this approach yields less reliable and less precise estimates of the effects of personality on outcomes than do IQ tests. Dunning, Heath, and Suls (2004) show that the limitations of self-report questionnaires extend beyond vulnerability to faking and include the tendency of most individuals to overrate their skills. Despite general recognition of these limitations and the handicap they present for assessing the importance of personality traits, few novel measurement approaches have been validated for many traits of interest—and none that would be feasible in the sort of large-scale data set favored by economists (see Wittman 2002). Thus, whereas multi-source, multi-method approaches to personality measurement are superior, they are difficult if not impossible to implement in many research contexts. To the extent that IQ 
is more accurately measured than personality, estimates of the effects of personality on outcomes will be disproportionately attenuated (see Duckworth and Seligman 2005). Accounting for measurement error is empirically important in using psychometric measurements in empirical work. Cunha and Heckman (2008) estimate substantial measurement error components in both cognitive and noncognitive test scores.

A fourth limitation of the estimates in Figure 3 is that they do not capture interaction effects. It is possible, for example, that specific personality traits moderate the effect of cognitive skills and resources on outcomes. Consider the following evidence from the literature. Judge and colleagues identify a low-dimensional factor called core self-evaluations, ${ }^{66}$ encompassing high self-esteem, high generalized self-efficacy, internal locus of control, and high emotional stability (Judge, Locke, and Durham 1997; Judge and Bono 2001). Judge and Hurst (2007) analyze data from the National Longitudinal Study of Youth (NLSY79). They find that high SES, strong academic performance, and educational attainment in adolescence and young adulthood predict higher incomes later in life only among participants who were above-average in core selfevaluations. In contrast, adolescents who were below-average in core self-evaluations do not capitalize on these resources. Judge and colleagues speculate that high core self-evaluations lead to several advantageous behaviors, including looking for more challenging jobs, persisting longer on difficult tasks, and maintaining motivation in the face of failure. ${ }^{67}$

Finally, standard measures of predictive power are effect size and variance explained. However, $R^{2}$, or goodness of fit measures, are only one way to measure the importance of variables. ${ }^{68}$ Heckman, Stixrud, and Urzua (2006) develop a different measure of predictive power based not on variance explained, but on the response of outcomes to a change in the variable. They examine the effect of moving people from different percentiles in the latent factor 
distributions of cognitive and personality skills on the following outcomes: (a) participation in and completion of schooling; (b) wages; (c) crime; (d) teenage pregnancy; (e) occupational choice, and (f) participation in risky behaviors. Their measure does not depend on the scale of the variable - just the change in its rank in an overall distribution. ${ }^{69}$ They find that personality traits have lower predictive power (in the sense of $R^{2}$ ) than cognitive traits but that moving from the top decile to the bottom decile on either cognitive or personality traits has comparable effects on all outcomes although there are important differences by gender. Cunha and Heckman (2008); Heckman, Stixrud, and Urzua (2006) and Urzua (2007) show the importance of measurement error on both cognitive and personality constructs. Their emphasis on establishing causal rather than merely predictive effects of personality, and in accounting for measurement error is a distinctive feature of the recent literature on personality in economics. ${ }^{70}$

\section{Changing Preference Parameters and Psychological Variables}

Given the impact of personality traits on life outcomes, it is important to know how much they can change. If they change, to what extent do environments and investments influence the developmental trajectories of personality traits? $?^{71}$

The malleability of personality can be defined and measured in several ways: Mean-level change refers to change over time in absolute levels of a trait and is measured by changes in scores over time. Rank-order change, in contrast, refers to changes in the ordinal ranking of a trait in a population and is measured by test-retest rank correlations. Mean-level and rank-order change capture independent effects (Block and Haan 1971). For example, cognitive abilities exhibit dramatic mean-level change from early childhood through adolescence, but, over the same period, strong rank-order stability. Rank-order may change dramatically without any resulting mean-level change if a subpopulation shows an increase on a trait while an equal 
proportion of the population decreases to offset it.

An extreme but common view among psychologists is that dramatic rank-order or meanlevel change in personality is nearly impossible after early adulthood. The speculation of William James (1890) that "in most of us, by the age of thirty, the character has set like plaster, and will never soften again" (pp. 125-126) is widely held (see Costa and McCrae 1994; McCrae and Costa 1990, 1994, 1996, 2003). Mounting evidence suggests that the set-like-plaster view is not correct.

A second useful dichotomy contrasts normative change, defined as changes that are typical of the average individual in a given population, and caused either by biological programming (ontogenic) or by predictable changes in social roles (sociogenic), and nonnormative change, encompassing both intentional change, caused by deliberate, self-directed efforts, deliberately chosen changes in social roles and atypical life events (trauma, for example) $)^{72}$. More relevant to the current review is intentional change-can investments be made by the person or the parent that change ability or preferences?

\section{A. Mean Level Changes}

During the early years of life, mean-level changes in traits are obvious and dramatic. For example, children become dramatically more capable of self-control as they move from infancy into toddler and preschool years (McCabe, Cunnington, and Brooks-Gunn 2004; Mischel and Metzner 1962; Vaughn, Kopp, and Krakow 1984; Posner and Rothbart 2000). But mean-level changes in traits are also apparent, albeit less extreme, later in life. In a 2006 meta-analysis of longitudinal studies, Roberts, Walton, and Viechtbauer (2006) examine cumulative lifetime change in Big Five openness, conscientiousness, extraversion, and agreeableness; they split Big Five extraversion into social dominance and social vitality. Figure 4a shows that people typically 
become more socially dominant (a facet of Extraversion), conscientious, and emotionally stable across the life course, whereas social vitality and openness to experience rise early in life and then fall in old age. Surprisingly, after childhood, the greatest mean-level change in most personality traits takes place not during the tumultuous years of adolescence, but rather in young adulthood. An exception is the trait of sensation seeking, discussed earlier as a trait related to risk aversion. There is a dramatic peak in sensation seeking during adolescence that has been associated with synchronous changes in brain structure and function (Spear 2000a,b).

In contrast, a longitudinal study of adult intellectual development shows mean-level declines in cognitive skills, particularly cognitive processing speed, after age 55 or so (Schaie 1994). The top panel of Figure $4 \mathrm{~b}$ shows mean-level changes in cognitive skills using a longitudinal analysis, and the bottom panel of Figure $4 \mathrm{~b}$ shows mean-level changes using a cross-sectional analysis ${ }^{73}$. Fluid intelligence decreases much more dramatically than does crystallized intelligence, and crystallized intelligence (acquired skills and knowledge) rises over the life course (Horn 1970). Figure 4c presents a schematic of the lifetime development of the two types of intelligences. The importance of crystallized intelligence would explain why an 18year old undergraduate taking organic chemistry for the first time might be surpassed by a chemistry professor thrice his age, despite the superior fluid intelligence of the student. It also explains why most of us would rather use an experienced cardiac surgeon who has seen hundreds of cases just like ours to perform our surgery, rather than an exceptionally bright young surgeon with minimal experience.

\section{B. Rank-Order Change in Cognitive and Personality Skills}

Rank-order stability in personality increases steadily over the lifespan. Figure 5a shows graphs of rank order stability of personality by age. A meta-analysis by Roberts and DelVecchio 
(2000) summarizes longitudinal studies where the average lag between assessments was at least a year and averaged 6.8 years. It shows that test-retest stability estimates rise from $r=.35$ for birth-2.9 years to $r=.52$ for 3-5.9 years to $r=.45$ for 6-11.9 years to $r=.47$ for 12 to 17.9 years. They show that rank-order stability estimates for personality plateau far from unity, at $r=.74$, about the same level as terminal stability estimates for IQ. However, personality does not reach this plateau until at least age 50; whereas IQ reaches this plateau by age six or eight (Schuerger and Witt 1989; Hopkins and Bracht 1975). Figure 5b shows rank order stability of IQ over broad age ranges. Hartog (2001) reviews the evidence on rank order stability in economic preferences.

\section{Mechanisms of Change for Cognitive and Personality Traits}

What mechanisms underlie stability and change in personality? Why do most of us mature into more responsible, agreeable, confident, and emotionally stable individuals as we age? Why do our personality traits, relative to others in our age-group, steadily stabilize as we approach our fifties? If, as McCrae and colleagues have claimed, normative changes reflect genetically programmed processes, investment should not affect change. The current literature in psychology claims that genetic factors are largely responsible for stability in personality in adulthood whereas environmental factors are mostly responsible for change (Blonigen et al., 2006; Plomin and Nesselroade 1990). ${ }^{74}$ In a longitudinal study of twins surveyed at age 20 and then again at age 30 , about 80 percent of the variance of the stable component of personality was attributed to genetic factors (McGue, Bacon, and Lykken 1993). In the same study, change in personality was mostly attributed to environmental factors. Helson et al. (2002), for example, has documented the substantial influence that social roles and cultural milieu can have on personality development. This is consistent with the economic model of investment and the response of manifest traits to incentives. However, there is recent evidence suggesting that environmental 
factors, and in particular stable social roles, also contribute to stability in personality and that genetic factors can contribute to change (see Roberts, Wood, and Caspi 2008 for a review).

Research on IQ also points to the enduring effects of genes, which are with us all of our lives, in contrast to more transient effects of environmental influences, which depend on a multitude of unstable variables, including social roles, levels of physical maturity and decline,, and historical and cultural milieu. ${ }^{75}$ Increases in the heritability of IQ from childhood (about 40 percent) to adulthood (estimates range from 60 percent to 80 percent) are well-documented in behavioral genetics studies and likely reflect increasing control of the individual (vs. parents) over environment (Bergen, Gardner, and Kendler 2007; McGue et al. 1993; Plomin et al. 2002). ${ }^{76}$ Heritability estimates for Big Five traits are relatively stable across the life course at about 40 to 60 percent (Bouchard and Loehlin 2001). ${ }^{77}$ Behavioral genetics studies typically estimate the effect of parental environments to be near zero, but Turkheimer et al. (2003) find estimates from such studies to be biased downward by the over-representation of middle and upper-class families. Krueger and colleagues have recently demonstrated that other moderators may influence the heritability of traits (see Krueger et al., 2008). Among poor families, Turkheimer et al. find that 60 percent of the variance in IQ is accounted for by shared environment and heritability estimates are almost nil, whereas among affluent families, the result is reversed.

Genes exert their influence in part through the selection and evocation of environments that are compatible with one's genotype — a phenomenon sometimes referred to as "geneenvironment correlation" or "nature via nurture" (see Rutter 2006). As individuals move from childhood to adulthood, they have more control over their environments, and thus geneenvironment correlation becomes more important because shared environments become less 
common. $^{78}$

Substantial but temporary influence from environment is a basic assumption of the Dickens-Flynn model reconciling the high heritability of IQ and massive gains of IQ between generations (Dickens and Flynn 2001). ${ }^{79}$ The relatively short half-life of common environmental influences may also explain why adopted children resemble their biological parents more and more and their adopted parents less and less as they grow older (Scarr, Weinberg, and Waldman 1993). ${ }^{80}$ Lizzeri and Siniscalchi (2006) develop an economic model of parenting that explains the evidence on twins raised apart that shows conditions under which parents will differentially affect their children.

It is important to note that the family studies of genetic influence measure only the effects of shared environments, which become less similar as children age. Thus even identical twins may be motivated to seek out different environments over time (Rutter 2006). Recent evidence that first born children grow up, on average, to have three points higher IQ than their younger siblings reinforces the point that sharing parents does not necessarily imply identical environments in childhood (Kristensen and Bjerkedal 2007).

What other than preprogrammed genetic influences might account for mean-level changes in personality? Personality change in adulthood may be precipitated by major shifts in social roles (for example, getting a job for the first time, becoming a parent). Clausen and Gilens (1990) claim that female labor force participation increases self-confidence. Gottschalk (2005) presents experimental evidence that women forced to work due to welfare reform showed gains in self-confidence and self-esteem. Roberts (1997) reports an increase of social dominance and Roberts and Chapman (2000) a decrease in neuroticism for working women. Others show that marital and family experiences shape personality (Helson and Picano 1990, Roberts, Helson, and 
Klohnen 2002). ${ }^{81}$

Cognitive ability can also be affected by environmental factors. Cahan and Cohen (1989) use a quasi-experimental paradigm comparing children who differ in both age and schooling to show that schooling increases intelligence test scores independently of age. ${ }^{82}$ Schooler and colleagues show that complex (that is, cognitively demanding) work increases intellectual functioning among adults and vice versa (Schooler, Mulatu, and Oates 1999; Kohn and Schooler 1978). If social role changes are experienced by most people in a population at the same time, we will observe the effects as mean-level changes in personality. If, on the other hand, these social roles are not assumed synchronously, we will observe rank-order changes. One difficulty with many of these studies is the problem of reverse causality discussed in Section III and analyzed in Hansen, Heckman, and Mullen (2004) and Heckman, Stixrud, and Urzua (2006). Changes in personality may drive social role changes rather than the other way around. However, the experimental analysis of Gottschalk (2005) suggests genuine causal effect of work on personality traits.

Are the effects of environment on personality change long-lasting? Do changes endure after the environmental cause is removed? At the moment, the prevailing view in psychology is relatively pessimistic. McGue, Bacon, and Lykken (1993) suggest that only permanent changes in environment (for example, a social role like parenthood) might budge personality: "Environmental factors do not exert cumulative long-lasting influences and that, even when substantial, environmental factors do not normally lead, in adulthood, to a long-term redirection to the individual course of personality development... Environmental factors are most likely to influence behavioral stability when they are consistently and persistently experienced" (pp. 105106). However, there is insufficient evidence from longitudinal studies to confirm this 
viewpoint, and the analysis of the Perry Preschool study by Heckman et al. (2007) strongly suggests that long-term personality factors can be altered by interventions. Finally, it is important to note individual differences in developmental trajectories: conscientiousness, agreeableness, and emotional stability not only increase with age, but also correlate with personality consistency (Caspi, Roberts, and Shiner 2005).

The enduring effects of environment are greater earlier in life. Duyme, Dumaret, and Tomkiewicz (1999) studied children with IQs below 86 who were adopted between the ages of four and six into stable homes. In adolescence, children adopted into high SES homes gained an average of 19.5 IQ points; children adopted into low SES homes showed an average gain of 7.7 IQ points. In studies of Romanian children taken from impoverished orphanages and placed into middle-class British homes, the long-term salutary effects of adoption on cognitive ability were dramatic when infants were placed before they reached six months, and markedly less so when adoption was delayed until later ages (Beckett et al. 2006). Notably, children adopted at different ages between six to 42 months did not differ at age 11 from each other in the terms of cognitive ability, with all children demonstrating an average deficit of 15 IQ points relative to children who had been adopted earlier in life. The effects of low nutrition had no effect on cognitive outcomes at age 11, suggesting a prominent role for psychological deprivation. As Beckett and colleagues point out, these findings are consistent with the existence of a very early critical or sensitive period for intellectual development (in which particular environmental stimuli are necessary for normative axonal rewiring (see Uylings, 2006 and Rutter, 2006, for reviews) ${ }^{83}$ Knudsen et al. (2006) and Cunha and Heckman (2007) summarize this evidence and relate it to models of investment in economics. 
Cunha and Heckman (2007) summarize the evidence on the impact of parental investment on the evolution of cognitive and personality skills. Their paper in this issue and their extension of that paper with Schennach establish evidence on sensitive periods in the development of the child. ${ }^{84}$ In their framework, the latent traits are time (or age) subscripted: $f_{i, t}$. Each of the measurement equations or variables is time subscripted. The traits evolve by equations of motion over the life cycle $T$ :

$$
f_{i, t+1}=\psi\left(f_{i, t}, I N_{i, t}\right), \quad t=1, \ldots, T,
$$

where $I N_{i, t}$ is a vector of experience related to inputs which can include the parental and school environments, experiences in the workplace, and the like. The initial condition $f_{i, 0}$ reflects genetic material and the in utero environment that determines the initial stock of traits.

Both cognitive and personality skills can be affected by parental investment and schooling, which are components of $I N_{i, t}$. Sensitive periods for cognitive skills come earlier than sensitive periods for personality skills. Sensitive periods are periods in which investment has especially high productivity for a trait (see Cunha and Heckman, 2007). Cognitive and personality skills cross-fertilize each other with high stocks of each skill at one age improving the productivity of investments at later ages. ${ }^{85}$ The evidence of cross-fertilization from personality skills to cognitive skills is stronger than evidence for the cross-fertilization of cognitive skills to personality skills. Both cognitive and personality skills affect adult outcomes but they have different relative importance in explaining different outcomes. See Cunha and Heckman (2008) and Cunha, Heckman, and Schennach (2007) for descriptions of the methods used to estimate the production relationships. These methods also control for the problem of reverse causality in the psychological measurements. 
The accomplishments of psychotherapy also support the possibility of intentional, meanlevel, and rank-order change. In a 1980 meta-analysis, Smith, Glass, and Miller summarized 575 controlled studies, concluding that individuals who undergo psychotherapy are about 0.85 standard deviations better on outcome measures than those who do not. The large benefits of therapy are not permanent, however: the effect of psychotherapy over control conditions falls to about half a standard deviation two years after therapy is concluded. Moreover, it is not clear that the effects of psychotherapy on individuals who seek change generalize to individuals who are not actively seeking treatment for a condition that causes them distress. ${ }^{86}$

More evidence on the possibility of intentional change comes from the psychological literature on expertise. Ericsson, Krampe, and Tesch-Romer (1993) demonstrate across domains as diverse as chess, musical performance, and digit span memory, that thousands of hours of sustained, deliberate practice lead to dramatic improvements in skill. Ericsson points out that the top performers in nearly every field do not reach world-class levels of skill until at least ten years of deliberate practice. Ericsson also points out that because well-designed practice is the key to skill development. ${ }^{87}$

Early interventions, such as enriched childcare centers coupled with home visitations, have been successful in alleviating some of the initial disadvantages of children born into adverse conditions. See Cunha et al. (2006) and Cunha and Heckman (2007) for evidence on these interventions. As noted in the introduction to this paper, while these interventions were originally designed to improve the cognitive skills of children, their success has mostly been in boosting personality skills. For example, the Perry Preschool Program, an enriched early childhood intervention evaluated by random assignment where treatments and controls are followed to age 40, did not boost IQ but raised achievement test scores, schooling, and social 
skills. It raised personality skills but not cognitive skills, at least as measured by IQ. Effects were not uniform across gender groups (Heckman, 2004; Heckman, Stixrud, and Urzua, 2006). See the evidence in Cunha et al. (2006) and Heckman et al (2007).

\section{Stability of Economic Preference Parameters}

Less is known about the stability of economic preferences. To our knowledge, no longitudinal study has measured the mean-level or rank-order stability of time preference over the life cycle (Frederick, Loewenstein, and O'Donoghue. 2002). A handful of cross-sectional studies using relatively small samples have examined mean-level stability, and their findings are mixed. Green, Fry, and Myerson (1994) and Harrison, Lau, and Williams (2002) find that discount rates are lower among older individuals. On the other hand, Chesson and Viscusi (2000) claim to find that older adults have higher discount rates than younger adults. Chao et al. (2007), de Wit et al. (2007), and Coller and Williams (1999) find no relationship between age and discount rate. Finally, Read and Read (2004) find a curvilinear relationship in which older people discount more than younger people, and middle-aged people discount less than either group. Sahm (2007) shows that risk aversion increases with age.

In summary, the answer to the question of whether change in personality is possible must be a definitive yes, both in terms of mean-level and rank-order change. However, change may be more difficult later in the life cycle, change may be more enduring for some (such as more emotionally stable individuals) than for others, change may require persistent and consistent environmental pressure (as opposed to transient pressure from short-term interventions), and there are powerful forces for stability (such as genes and habit) which make change difficult. 


\section{Frameworks for Integrating Personality and Economics}

This section attempts to integrate the main lessons summarized in the preceding sections into formal economic models. As noted in section IV, preference anomalies have attracted a lot of attention in the recent literature in behavioral economics. ${ }^{88}$ However, choice is generated by preferences, expectations, and constraints, and psychology has something to say about each of these aspects of agent decision making.

We show how psychological variables, which define capacities and constraints, can enter standard choice models. Some traits can be enhanced through investment and experience. Traits may be divisible so that more of a trait used in one activity may reduce the supply of traits to other activities. Some traits may be public goods, available at the same level to all tasks. We create a taxonomy of traits to motivate future research on the economics of personality.

Bowles and Gintis (1976), Mueser (1979), Bowles, Gintis, and Osborne (2001), Hartog (2001), and Mueller and Plug (2006) consider how specific traits affect earnings capacities. Our discussion is more comprehensive than theirs because we consider how traits affect performance in many distinct areas of economic and social life. We also speculate about the relationship of the Big Five personality factors to conventional economic preference parameters. As yet, no tight link has been established. Cognition and personality likely both affect conventional preference parameters. Despite a hundred years of intelligence testing, IQ remains to be systematically integrated into economic theory apart from its direct effect on earnings.

\section{A. Psychological Variables as Constraints}

Capacities may be physical (beauty and strength, for example), cognitive (abstract reasoning) and those related to personality. Capacities determine, for example, how effectively persons process information, cope with uncertainty, adjust to setbacks, envision counterfactual 
states, project into the future as well as their sense of pride in their work. These capacities affect learning, social engagement and even the definition of self. They are in part acquired, and there is evidence that aspects of these capacities are heritable.

The conventional neoclassical model of economics postulates quasiconcave preferences embedded in a model with uncertainty and constraints. A large literature analyzes this model under a variety of constraints, market arrangements and expectation schemes (see Mas-Colell, Whinston, and Green, 1995 for an example). Versions of the model emphasize how information revelation in different market settings affects agent choices. Preferences postulated a priori play a central role in this theory as they do in most research in behavioral economics.

However, individual differences in personality and cognition shape the constraints of individuals and hence their choices. To show how far one can go in developing models that recognize the centrality of constraints to economic choice theory, it is instructive to consider a simple model without standard preferences where constraints alone (including expectations of feasible states) shape choices. A constraint-driven model need not produce a unique choice outcome for all persons with the same constraints. ${ }^{89}$ In this framework, agents have no preferences and act like molecules in a Brownian motion constrained only by choice sets. As the choice sets change, the constrained molecules must change their choices to respect the boundaries created by the constraints. As emphasized by Becker (1962) and Sanderson (1974), with sufficient generality in the specification of the constraint set, one can generate all of the predictions of neoclassical choice theory from constraints and not preferences.

Following Thurstone (1927), Block and Marschak (1960), Bock and Jones (1968), and McFadden $(1974,1981)$, write the utility of agent $i$ for choice $l$ as $U_{i, l}$. In terms of the literature in psychology, $U_{i, l}$ is the motivation for choice (goal) $l$ by agent $i$. There is a distribution of 
utilities across consumers. Choice sets, $B_{i}$, differ among persons depending on their capacities. These capacities are determined by agent cognitive and personality traits as well as the usual time and material constraints. In models with uncertainty, agents form expectations of constraint sets. Agent $i$ chooses $\hat{l}_{i}$ as the maximal element in the choice set $B_{i}$ :

$$
\hat{l}_{i}=\underset{l \in B_{i}}{\operatorname{argmax}}\left\{U_{i, l}\right\} .
$$

Consider a familiar model which writes $U_{i, l}=V_{i, l}+\varepsilon_{i, l}$, where $V_{i, l}$ is agent $i$ valuation for $l$ and $\varepsilon_{i, l}$ is a random "taste" shock. When $V_{i, l}=V_{l}$, and $\varepsilon_{i, l}$ is iid extreme value type 1 , the probability that $l$ is selected from choice set $B_{i}$ is

$$
\begin{aligned}
\operatorname{Pr}\left(l \mid B_{i}\right) & =\frac{\exp \left(V_{l}\right)}{\sum_{j \in B_{i}} \exp \left(V_{j}\right)} \text { for } l \in B_{i}, \\
& =0, \text { for } l \notin B_{i} .
\end{aligned}
$$

If agents have zero mean scale preference among the choices $\left(V_{l}=0\right)$ so that all choices (goals) have the same mean utility, we obtain a version of Becker's (1962) model of rational random behavior as extended by Sanderson (1974) where choices are generated by random shocks and the budget set determines choice behavior. Under an iid assumption for preference shocks, all possible choices are equally likely. ${ }^{90}$

Depending on how the constraints are determined, one can capture a variety of aspects of choice behaviour. Thus a shy person may limit her options in a way an extravert does not. An intelligent person may have a much richer choice set not only because of greater earnings capacity but also because of much greater imagination. Much like greater pixel resolution in imaging machines, those with higher IQ may resolve reality in a more fine-grained and less biased way. The negative relationship between IQ and risk aversion noted in section IV may be 
due, in part, to the greater resolution of reality (removal of components of uncertainty) by the more intelligent. ${ }^{91}$ We capture the effect of these traits on the choice sets, which may also depend on material endowments. Applied to intertemporal settings, this framework captures the phenomenon of high time preference as an inability of an agent to imagine future states or as an inability to accurately measure future states. ${ }^{92,93}$

\section{B. Incorporating Personality and Cognitive Ability into Conventional Economic}

\section{Models: A Simple Framework for Organizing the Evidence}

How should one incorporate psychological traits into conventional economic models? One could think of them as public goods, freely available to all activities or tasks undertaken by agents. This is the approach implicitly adopted by most personality psychologists. One could also think of psychological traits as excludable private goods. More of a trait used in one activity means less of the trait available for use in other activities.

In addition, one might augment, complement or override the supply of a trait to any activity by supplying more time, or energy, to the activity in which the trait is used. Thus a trait that is a public good may be more evident in a given activity if more time or energy is allocated to the activity. On the other hand, "energy," $e$, which can be vector valued, may be used to moderate the manifestation of the trait (for example, energy may be spent controlling anger in a given activity). Individuals differ in their endowment vector of the trait $\bar{f}$ or in terms of the energy (possibly including time) denoted $\bar{e}$. Thus there may be a time constraint as in Becker (1965) or more generally there may be energy constraints (constraints on effort capacity).

To develop these concepts and their consequences, we sketch a simple one-period model of consumer choice under certainty. We consider models with uncertainty in the next subsection. The framework developed in this subsection is rich enough to make some useful distinctions. 
Following Becker (1965), assume that there are $J+1$ activities with outputs $Z_{j}, j=1, \ldots, J+1$ undertaken by the agent. We add one activity to account for market earnings. $Z_{j}$ is produced by combining tasks, $T_{j}$, defined in section II, with purchased market goods, $X_{j}$. We augment the task functions defined by equation (1) to include levels of energy, and time, in vector $e^{j}$ :

$$
T_{j}=h_{j}\left(f^{j}, e^{j}\right) \quad j=1, \ldots, J+1 .
$$

$f^{j}$ is to be distinguished from $f_{j}$, the $j^{\text {th }}$ component of vector $f$. There is a parallel notation for $e^{j}$ which may also be a vector valued (for example, time, energy). Thus the first component of $e, e_{1}$, could be time; the second component effort, and so on. $e^{1}$ is the amount of the vector allocated to the first task. The more time or energy devoted to a task, the greater the output from the task. For a fixed input of psychological traits, higher levels of $e^{j}$ may raise the output of the task. It may also happen that unless a minimum amount of time or energy is devoted to a task, there is no productivity in the task. Thus if $e^{j}=0$, the trait $f^{j}$ may be switched off. However, if some traits have negative productivity in some tasks more energy may be allocated to those tasks to offset the negative trait. The effect of a trait in a task will depend on the bundle of other inputs used in the task. It is necessary to identify these other inputs to identify the traits used in any activity.

Output in activity $Z_{j}$ is

$$
Z_{j}=\varphi_{j}\left(T_{j}, X_{j}\right) \quad j=1, \ldots, J+1 .
$$

The outputs in activity $j$ depend on the task output $T_{j}$ and the goods input $X_{j}$. Agents have preferences over $Z_{j}$ and $e^{j}$. The effort expended in an activity may have psychic costs or benefits. There may be psychic costs in using $e^{j}$ to suppress the expression of a trait. 
Preferences may also depend on $f$ as well as other variables which we keep implicit. The utility function is

$$
U=U\left(Z_{1}, \ldots, Z_{J}, e^{1}, \ldots, e^{J+1}, f\right)
$$

It captures the motivation of the agents for the outputs and "energy." As previously noted, personality psychologists do not typically study motivation. ${ }^{94}$ As embodied in utility functions, motivation is central to most economic models of choice. Income is return on asset flow $Y$ plus labor earnings which we denote $Z_{J+1}=\varphi_{J+1}\left(T_{J+1}, X_{J+1}\right)$. The budget constraint for goods is thus

$$
\sum_{j=1}^{J+1} P_{j} X_{j}=Y+Z_{J+1}
$$

$Z_{J+1}$ is a hedonic earnings function which prices out traits and energy in the market, and produces a flow of income. $^{95}$

It is possible to distinguish two different cases for $f$. For psychological traits, we can distinguish the case where $f$ is a public good, $f^{j}=\bar{f}$ for all $j=1, \ldots, J+1$, from the case where it is a private good, $\sum_{j=1}^{J+1} f^{j}=\bar{f}$. In the former case, the same psychological traits enter as inputs into all tasks and activities. In the latter case, the traits applied to different tasks are excludable and rivalrous. More traits applied in one activity means fewer traits in other activities. People are not stuck with their personality in all activities. Some components of $f$ may be public and others private. Thus extraversion and conscientiousness may be private goods that are more productive in some activities than others and the limited and divisible supply of these traits will be allocated according to preferences and productivity. Openness to experience may be a public good. One can classify all traits by this schema. One could consider all possible combinations of public and private good possibilities for all of the traits. For simplicity, we consider the pure 
private goods case and the pure public goods case. A similar distinction could be made for the energy inputs, but this seems less natural. To focus on main cases, we assume that $e$ is a private good. Thus we analyze the two cases displayed in the table:

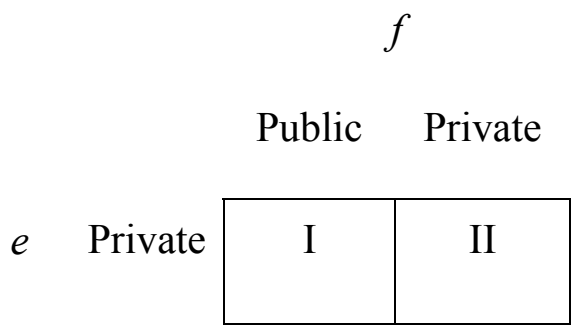

In case I, the additional constraint operating on the consumer beyond the budget constraint (12) is

$$
f^{j}=\bar{f}, \quad \sum_{j=1}^{J+1} e^{j}=\bar{e}, \quad \text { for all } j=1, \ldots, J+1 .
$$

In case II, the operative constraints are

$$
\sum_{j=1}^{J+1} f^{j}=\bar{f}, \quad \sum_{j=1}^{J+1} e^{j}=\bar{e}
$$

\section{a. Case I: Traits as Public Goods}

In case I, different bundles of $\bar{f}$ across persons create comparative advantages for agents in different tasks and thus produce comparative advantages in different activities. These endowments affect consumption patterns of agents and the derived demand for $X_{j}$ through scale and complementary effects in the production of activities and through demand effects in preferences. Case I is a version of Michael's (1973) model of environmental variables in a household production framework. ${ }^{96}$ 
For analytical simplicity, suppose that $Z_{j}$ and $T_{j}, j=1, \ldots, J+1$, display constant returns to scale in non-public inputs. The assumption of constant returns neutralizes any scale effects in the determination of the shadow prices of tasks and activities. Traits may have negative productivities. Persons with higher levels of traits with negative productivity require the allocation of more energy and time to produce any given task. Thus hot tempered people exert greater effort in controlling themselves in some activities.

In terms of the technologies (9), when $f$ is a public good, we assume constant returns to scale in $e^{j}$ but that $f^{j}=\bar{f}$ is a fixed, environmental variable. Different levels of $\bar{f}$ produce different productivities in different tasks. Feeding $\bar{f}$ into the activity functions (10), which are also assumed to be constant returns to scale, we can analyze the agent's problem of allocating effort among tasks and goods among activities using the analysis of Michael (1973). Financial and energy resources are not changed by $\bar{f}$ except for its effect on $Z_{J+l}$. Holding energy and money resources fixed, changes in $\bar{f}$ produce reallocations across budget categories.

Thus if $\bar{f}$ raises the productivity of inputs in task $j$, it reduces the shadow price of activity $j$. This has the usual income and substitution effects. The income effects produce a greater demand for all normal activities and sets in motion an increase in the derived demand for the inputs used in the activities. Since in general $\bar{f}$ appears as an input in multiple activities, increases in $\bar{f}$ will set off a chain of substitution effects among the activities. Depending on the preferences (motivations) over the $Z_{j}, j=1, \ldots, J+1$, demands for inputs may increase or decrease.

It is instructive to reason through several cases. Consider an increase in conscientiousness. This will likely increase earnings (via $Z_{J+1}$ ), and will enhance productivity in some tasks intensive in conscientiousness and activities based on those tasks more than other 
tasks and activities. The increased income will support more of all activities. The differential shift in productivity across tasks and activities will reduce the prices of activities that are more intensive in the use of conscientiousness. If the demands for those activities are price elastic compared to the demands for the less conscientiousness-intensive activities, the demand for the inputs used in those activities will increase. If the demands are relatively inelastic, the demands will decrease because of the greater productivity for the inputs.

If a trait reduces productivity, the chain of logic just presented runs in reverse. With increases in, for example, neuroticism, shadow prices of activities intensive in that trait will increase. Labor earnings will tend to decrease. In the price-elastic case, consumers will tend to substitute away from activities intensive in the trait and the demand for inputs will decrease. In the inelastic case, input demands will increase as agents substitute goods and energy inputs into the activities that are inelastically demanded.

The same level of the traits is found in all activities, but in general, energy or time will be allocated differentially among activities. A person who allocates more energy or time to a task will manifest more of the trait. ${ }^{97}$ If inputs are complementary, at the same scale of output more of the task will be demanded. Unless one controls for these inputs, one may fail to capture the uniformity of traits across tasks and activities. In all of these cases, purchase patterns of market goods will provide information on endowments and allocation of energy and traits. ${ }^{98}$

\section{b. Case II: Traits as Private Goods}

The case when traits are private goods produces the possibility of different levels of traits being used in different tasks and activities. Responses of activity levels to changes in rewards across activities will be more price-elastic when traits can be allocated across activities than when traits are fixed. Equiproportionate expansions in $(\bar{f}, \bar{e})$ differentially expand the 
consumption possibility set for activities intensive in $(f, e)$ and reduce their shadow prices, producing substitution effects in task production and activity consumption that promote consumption in activities intensive in the traits. Because of the ability of agents to reallocate traits across tasks and activities, an increase in endowment produces a stronger effect on consumption of $f$-intensive activities than in the public goods case. This greater elasticity of response to endowment is a consequence of the LeChatelier Principle (Samuelson, 1947). The public goods case imposes more constraints on the system than the private goods case. Compared to the case of public goods for traits, agents will reduce their allocation of the trait from activities where their productivity is negative and will spend less effort $(e)$ in overriding the effects of negative traits in productivity. ${ }^{99}$ The trait will be shifted into less costly activities and less energy will be spent controlling it. ${ }^{100}$ In this case, in different tasks and activities, different traits will in general be observed. This will produce a low correlation in traits across activities.

The evidence summarized in sections IV and V of this paper would seem to favor case II, since different levels of traits are often found in different activities. However, since most of the estimates reviewed in this paper do not adjust for the inputs that affect the manifestation of the traits, one must be cautious in reaching this conclusion. Such adjustments are indicated by the theory but are not yet standard in economics or psychology.

The roles of time and energy in amplifying or reducing the effects of the traits in activities needs to be systematically explored to make the theory empirically operational as are the effects of traits on the purchase of related goods (for example, shy people may seek to live in secluded areas, houses with high walls and seek jobs with little human contact). In the private goods specification of the model (case II), the motivation for the supply of traits to different activities depends on preferences (utility rewards $U$ ), on productivity in $Z_{j}$, and in productivity 
in the tasks $T_{j}$. In this framework, it is possible to formalize many of the currently disparate concepts of personality psychology. However, much more empirical research is required to make the framework just sketched operational. It would be very informative to estimate both versions of the model and to test between them.

We now turn to more general economic models with risk aversion, intertemporal choice, and investment. For simplicity, we assume that personality, other psychological traits and energy are public goods. The private goods version of the models follows from a direct application of analysis of this section.

\section{Integrating Psychology into More General Economic Models}

Economic theory at the single agent level separates two distinct aspects of behavior and decision making: preferences and constraints. Included among the constraints are (a) information acquisition constraints; (b) static budget constraints and endowments that affect the flow of resources available for consumption in any period; and (c) dynamic constraints connected with asset, skill and trait formation. The constraints facing agents are also determined by available market arrangements and trading opportunities. Psychology is potentially informative about all aspects of agent decision making.

Preferences are central to conventional economic choice models. In their most general form, we may write utility for an agent with decision horizon $T$ over bundles of goods (attributes), $X_{t}, t=1, \ldots, T$, in an environment of perfect certainty with cognitive and personality attributes $f$ as

$$
U\left(X_{1}, \ldots, X_{T} ; f\right)
$$

where it is assumed that $U$ is neoclassical. ${ }^{101}$ At this level of generality, cognitive and personality traits can affect all aspects of choice for all goods including the valuation of leisure, 
the intertemporal tradeoffs among goods, and risk aversion. A general non-separable intertemporal preference function is consistent with substantial departures from standard utility theory such as hyperbolic discounting (Phelps and Pollak 1968; Ainslie 1991; Laibson 1998) and a variety of "exotic" or nonstandard preferences as discussed in, for example, Backus, Routledge, and Zin (2005) and Hansen (2005). Preference specifications (13) are consistent with different rates of time preference for different goods and across different periods as is found in the literature reviewed in Section IV. ${ }^{102}$

Few economists would embrace the high level of generality of specification (13). Fruitful economic models are more tightly structured. Specification (13) can characterize a one-shot model of lifetime decision making under certainty. Agents choose their lifetime consumption bundles at the beginning of life and are fully committed to those choices.

A basic problem with these specifications is time inconsistency. ${ }^{103}$ In open markets, persons are not committed to their initial desired choices. After period 1, there is ambiguity about the appropriate representation of the remaining lifecycle utility function. One possibility is (13) with the first period choices as fixed arguments. Then, agents will stick to the lifetime program they initially select. Such an approach seems artificial because each period, people start anew and are free to make new decisions from a fresh time perspective. However, compulsive personality types may stick to the same plans no matter what, as long as they are feasible. Recall that compulsivity is one facet of the Big Five.

More generally, agents may look at future decisions differently in period 2 than they did in period 1 . Let $U^{t}$ be the utility of the agent at stage $t$ for the remainder of life $U^{t}=G^{t}\left(X_{t}, \ldots, X_{T} ; f\right)$. Without further restrictions, there is no reason why in period $t$, the agent is compelled to value the utilities of previous period consumption bundles or account for 
past consumption behavior in the way done prior to period $t$ in evaluating future consumption streams. The problem of preferences changing over time is distinct from the problem of revised information sets although both produce possible departures from initial decisions based on (13). ${ }^{104}$ In both cases, decisions made in early periods affect resources available to later periods and, retrospectively, there may be regret about initial consumption choices. Economists have traditionally addressed this problem by specializing (13). The conventional specification of the general preference function (8) assumes a constant rate of discount $\rho$ for utility across periods:

$$
U\left(X_{1}, \ldots, X_{T}, f\right)=\sum_{t=1}^{T} \frac{1}{(1+\rho)^{t-1}} U\left(X_{t}, f\right) .
$$

Specification (14) is not required to achieve time consistency of choices. ${ }^{105}$ This is an important point, because there is a lot of evidence that speaks against (14) as previously noted in section IV. Notice that (14) is just a special case of equation (13), which is also a standard model of economic preferences. Discounting is implicit in specification (13), which generates goods-specific discounting that depends on future and past consumption choices, a phenomenon ruled out by (14). A more general form of discounting than specification (14) that is consistent with (13) is

$$
U\left(X_{1}, \ldots, X_{T}, f\right)=\sum_{t=1}^{T} \prod_{j=2}^{t}\left(\frac{1}{1+\rho_{j}}\right) U\left(X_{t}, f\right),
$$

where discount rates may vary with age. Even more generally, both preferences and discount rates may vary with time-dependent variables (for example, children, health, mood, personality variables, and cognition). ${ }^{106}$ Following our analysis in section VI, factor $f$ can evolve over time. Let $f_{t}$ denote personality and cognitive traits at age $t$. We can use $U_{t}\left(X_{t}, f_{t}\right)$ in place of $U\left(X_{t}, f\right)$, allowing for personal traits to evolve over time, and we can allow for utility in period $t$ itself to change, even after controlling for $f_{t}$ and $X_{t}$. The analysis of Becker and Mulligan (1997) 
and Mulligan (1997) models the evolution of the discount rate through investment decisions. Becker and Murphy (1988) model the evolution of preferences for addiction where $f_{t}$ is a stock of addictive capital.

A wide variety of special cases of lifetime preferences are subsumed in specification (13). Personality factors like deliberation, future time perspective, and the capacity to inhibit impulses likely determine discount factors or preferences more generally. So may aspects of cognitive ability. Loewenstein et al. (2001) discuss how decisions are affected by moods and emotions, which are influenced by personality variables. There is some evidence that higher IQ persons have lower discount rates (see Frederick 2005 and Dohmen et al. 2007).

The standard model of social interaction in economics is interaction through markets (See Arrow and Hahn 1971). More recently, economists have begun to analyze interactions in more general settings. They consider interactions in learning, in workplace productivity and in consumption. ${ }^{107}$

This aspect of human interaction is not captured by specifications (13)-(15) unless the $X_{t}$ include outcomes, choices or utilities of other persons. As noted previously in section IV, a large literature in economics discusses the implications of altruism (see Becker, 1981 and Laferrère and Wolff, 2006, for a survey). Fehr and Gächter (2000) discuss the consequences of social preferences for economic decisions. Models of social preferences have been developed by Fehr and Schmidt (1999) and Falk and Fischbacher (2006). See the surveys by Fehr and Schmidt (2006) and Meier (2007). One of the major findings of personality psychology noted in section $\mathrm{V}$ is that sociability, empathy, and the capacity to get along with others are important predictors of success in many activities. These traits are not the same as altruism or social preferences, but 
they are facets related to Big Five agreeableness and extraversion. It would be useful to clarify the relationships among these measurements.

Sociability and empathy may affect preferences for group activity which may be a source of pleasure (or displeasure) for some and which may also affect productivity in group activities in the workplace or in learning environments. Dohmen et al. (2008) present evidence on how trust, positive reciprocity, and negative reciprocity relate to Big Five personality traits. These and other personality traits play dual roles. They are a source of pleasure and they can also be a source of productivity in certain contexts. Agents making choices under any of the standard preference schemes, including those that recognize social interactions, are constrained in their information, the resources required to support consumption and in their ability to accumulate financial assets and skills.

Uncertainty and risk are essential aspects of life. Economists have devoted much attention to the specification of the preferences of agents and the effect of uncertainty on choice (see Mas-Colell, Whinston, and Green 1995). Revisions of information sets over time are another reason why agents may deviate from initial choices apart from time inconsistency.

Alternative specifications of information and preference are used in the literature. Individuals who are more intelligent or more open to experience (that is, more intellectually curious and motivated to learn) may acquire information more cheaply. Other personality traits may affect the basic attribute spaces perceived by agents.

The conventional model of uncertainty in economics is the expected utility model. Break $X$ into values that occur in different states $s=1, \ldots, S_{t},\left(X_{11}, \ldots, X_{1 s}, \ldots, X_{1 S_{t}}\right)$. Expected utility represents preferences by

$$
U(X)=\sum_{t=1}^{T} \sum_{s=1}^{S_{t}} P_{t, s} U\left(X_{t, s}\right), \text { where } \sum_{s=1}^{S_{t}} P_{t, s}=1, t=1, \ldots, T
$$


where $X_{t, s}$ is a state $s$, time $t$-specific bundle of traits and $P_{t, s}$ is the probability that state $s$ occurs in period $t$.

There is considerable empirical evidence against this model. Many departures from it have been proposed to rationalize the available evidence. ${ }^{108}$ Some departures break the additive separability assumption and assume a variety of alternative preference structures. A more general specification is based on (13) or its "exotic preference" specializations augmented to include as arguments different states of nature at each time period $\left(X_{t, s}\right)$ and probability distributions over these states of nature. These models allow for much richer specifications of the information sets on which agents act than is permitted in the expected utility model.

Personality factors may affect the arrival and processing of information. People not open to experience fail to learn from it. Impulsive people who do not act with deliberation may process information inefficiently (Frederick 2005). Persons with greater ability to imagine the future or imagine outcomes reduce the intrinsic uncertainty in their environments and may be less risk averse, or more risk averse, depending on whether the imagined outcome is more favorable or less favorable. Personality traits affect openness to experience (willingness to learn), risk aversion (anxiety), and imagination about future states not yet experienced (creativity). Persons with higher IQs appear to be more willing to take risks and are more patient (Dohmen et al. 2007), perhaps because they are better able to envision future consequences.

There are far richer models of decision making under uncertainty in economics than the standard expected utility model or models based on decision making under uncertainty generated from objective distributions. These specifications allow for preferences over the temporal resolution of uncertainty about states of the world (Kreps and Porteus 1978; Epstein and Zin 1991), uncertainty about distributions over states of the world (ambiguity) and different types of 
risk and uncertainty aversion in preferences (see Starmer 2000). These models enrich conventional economic theory by taking into consideration how agents react to uncertain events and how they process information. ${ }^{109}$ These richer theories of decision making under uncertainty expand the scope for introducing personality variables into economics. ${ }^{110}$

Personality traits are likely to prove useful in economic models of decision making under ambiguity. ${ }^{111}$ Individuals may differ in their capacities to deal with poorly defined situations. Greater intelligence may help define situations, but person with greater self control, openness to experience, lower levels of anxiety and those who seek excitement may better cope with ambiguity.

Personality traits may also affect the resources available to agents. As emphasized by Bowles, Gintis, and Osborne (2001), certain personality and character traits may be more highly valued than others in the labor market (trustworthiness, perseverance, outgoingness, for example). Borghans, ter Weel and Weinberg (2006) show that technological and organizational changes have increased the importance of people skills in the workplace. They present evidence for Germany and the United States that the increased importance of people skills has affected the labor-market outcomes of blacks and women. They find that the relative employment of women is higher in occupations in which people tasks are more important in Britain, Germany and the United States. The reverse is true for racial, ethnic, cultural, and linguistic minorities in the United States. They also show that the rapid increase in the importance of people tasks over this time period helps explain the increase in women's wages relative to men and the stagnation in wages of black workers relative to white workers. Diligent or trustworthy employees require less supervision. More generally, different personality and cognitive traits may be more highly valued in some activities than in others. In any activity, whether it is learning, information 
processing or performance of a workplace task, those who exert higher levels of effort will be more productive.

Comparative advantage in the labor market is analyzed in the models of Roy (1951), Mandelbrot (1961, 1962), Tinbergen (1956), Rosen (1974), Sattinger (1979, 1993), Willis and Rosen (1979), Heckman and Sedlacek (1985), and Teulings (1995; 2005). Borghans, ter Weel, and Weinberg (2007) develop a model in which personality traits are included in an assignment model. Write the productivity of a person in occupation (pursuit) $j$ at time $t$ as $Y_{j, t}=\alpha_{j, t}\left(f_{t}^{j}, e_{t}^{j}\right)$, $j=1, \ldots, J_{t}$, where we adjoin $t$ subscripts to the trait and energy levels. Different occupations or tasks require (or weight) different traits differently. (See Hogan, 2005, and Hogan and Hogan, 2007.) Thus, for example, extraversion is an essential trait for a salesman but not a lighthouse keeper or a truck driver. An individual who tries harder at any task will typically be more productive, although in certain workplace norms that enforce effort standards, the loner who makes more effort may be less productive, at least in terms of group cohesiveness. ${ }^{112}$

In subsection B, we analyzed specifications of market productivity functions that are used in the efficiency wage literature (see Weiss 1991). Market output depends on psychological traits plus effort and energy. Agents operating under different incentive schemes will manifest different effort. More generally, as noted in subsection B and section IV, the expression or manifestation of personality traits will depend, in part, on the context in which the individual is placed. At issue is the situational specificity of personality traits.

If agents choose or are assigned to tasks on the basis of maximal output $Y_{j, t}$ and pursuit of one occupation precludes pursuit of other occupations, the occupation (task) selected at time $t$ among the $J_{t}$ possible assignments at time $t$ is $j_{t}^{*}$, defined as 


$$
j_{t}^{*}=\underset{j_{t}}{\arg \max }\left\{Y_{j, t}\right\}_{t=1}^{J_{t}} .
$$

In this case, $Y_{i, j_{t}^{*}}$ corresponds to $Z_{J+1, t}$ for the period $t$ as introduced in subsection C. This framework captures the notion of comparative advantage in the labor market where agents sort into sectors based on their comparative productivity. Productivity determined by skills and personality traits affects the bundle of goods that the agent can buy. The phenomena of comparative advantage and differential skill requirements in different tasks helps to explain why some personality traits are predictive in certain activities but not in others (for evidence see Hogan, Hogan, and Roberts 1996). Hogan (2005) and Hogan and Hogan (2007) show the predictive power of personality traits in different occupations. Different employers may place different weights on different characteristics, and they may have different values in different settings. ${ }^{113}$

Over time, persons may also accumulate assets and skills, and may change their personality characteristics and cognitive traits. Preference parameters affect asset and skill accumulation. In section VI, we presented evidence that cognitive and personality traits can be changed (see Cunha and Heckman 2007 and Fraley and Roberts 2005). Both are influenced by experience and current stocks of the characteristics and other determinants. To formalize these notions, define $C_{t}$ as a capacity vector that includes $f_{t}$ and $e_{t}$ but encompasses a wider notion of capacities. Motivation can be affected by intelligence and other capacities of human beings (see Cunha and Heckman 2008). Interventions can affect preferences, information, opportunity sets, and the formation of skills and preferences. Personality and cognitive ability evolve over time through investment, through learning by doing or through other life experiences (see Cunha and Heckman 2007; Cunha, Heckman, and Schennach 2007). Among the characteristics or capacities $C_{t}$ can be health, motivation, personality traits and ability (Heckman 2007). Using the 
technology of skill formation developed by Cunha and Heckman (2007, 2008), capacities evolve via the following recursive technology

$$
C_{t+1}=\tau\left(C_{t}, I N_{t}\right), t=1, \ldots, T-1, C_{0}=c_{0}
$$

where $c_{0}$ is an initial condition for capacities and $I N_{t}$ is investment at stage $t$ and where $\tau$ is concave in $I N_{t}$, and is assumed to be differentiable in $C_{t}$ and $I N_{t}$. In one version of this theory, $f_{t}=C_{t}$ and cognitive and personality skills can evolve over time. ${ }^{114}$ Characteristics may be selfproductive $\left(\frac{\partial \tau\left(C_{t}, I N_{t}\right)}{\partial C_{t}}>0\right)$. Investment, which can include experience and other inputs, may affect the evolution of abilities and personality, that is, $\left(\frac{\partial \tau\left(C_{t}, I N_{t}\right)}{\partial I N_{t}}>0\right)$.

\section{Linking Preference and Constraint Parameters to Psychological Variables}

It is tempting to relate the personality traits in Table 1 to conventional economic preference parameters. This task is complicated by the fact that Table 1 omits cognition. We previously cited evidence relating IQ to risk preference and time preference. In this subsection, we speculate about the relationship between personality measures and conventional preference parameters. It is an area ripe for future research and our comments are designed to foster it.

The Big Five captures traits that seem relevant but are not exclusive determinants of economic preference parameters. Moreover, a single agent economic model cannot fully capture the operation of traits that foster social interactions. Positive social interactions can produce benefits in terms of learning and information processing. Participation in social groups provides a form of insurance and may promote risk taking (through insurance), even if it does not change risk aversion. Many economic models of contracting emphasize unobserved effort (a component of $e$ ), as an important dimension of economic transactions in the presence of imperfect 
information (see Salanié 1997). Empirical work in contract theory would be facilitated if preference parameters could be extracted from psychological questionnaires that predict effort.

For the same time input, some individuals may put in more effort in a task (a component of $\left.T_{j}, j=1, \ldots, J+1\right)$ and will be more productive than other individuals at the task whether the task is a job, learning in school or acquiring information. Persons for whom the utility cost of effort is low, and hence exert more effort, will be more productive in a variety of activities. Moreover, effort or energy levels (and other personality traits) can be affected by incentives confronting agents. Thus, behavior is affected by incentives and is not necessarily constant across settings.

In Table 1, "warmth" (a facet under extraversion) may be a productive trait in some settings, but it may be unproductive in certain settings (for example, an assembly line, on the battlefield or in a seminar). Fantasy (under Openness) can be counterproductive in routine tasks but very productive in creative work, providing that the person is also self-disciplined and open to criticism. There is wisdom in considering traits that have domain-specific productivities. Such productivities are associated with comparative advantage in the labor market. In addition, different incentives and monitoring schemes can produce different behaviors (the measures in equation (3) for the same person placed in different settings, for example).

Do the traits discussed by personality psychology cause us to rethink the standard economic model? The evidence on the predictive power of sociability, effort and conscientiousness and the evidence on altruism and other pro-social preferences should lead to a reemphasis of traditional theory. Social interactions tend to be neglected in standard economic theory, although there is a lot of recent research on this topic (see Durlauf and Young 2001, Brock and Durlauf 2001, and the evidence in Fehr and Schimdt, 2006). 
Is it possible that conventional economic preference parameters fully explain all of the personality traits uncovered by psychologists? It seems implausible that conventional leisure preference, risk aversion, and time preference parameters explain all of the traits identified in Table 1. For one thing, it is likely that these parameters are produced both by cognition and personality as we have previously noted. However, certain traits associated with Big Five conscientiousness might be rationalized by basic preference parameters. A low taste for leisure and a low discount rate would contribute to making persons more conscientious. However, the Big Five traits alone cannot explain diligence unless the person has some goal (or goals) or preferences motivating effort and self-discipline in a particular situation. Conventional economic models do not explain the origin of motives (goals). Most of the traits in Table 1 (for example, hostility, warmth, anxiety, trust) are less easily explained by standard economic preferences.

\section{Summary and Suggestions for Future Research}

Whereas the significance of personality traits for success in many aspects of life has long been appreciated at an intuitive level, it was not until recently that a substantial body of empirical analysis has documented this intuition. However, recognizing the importance of traits other than intelligence is not enough. It is also essential to identify which traits are important for which outcomes. Such an understanding not only leads to better measures and richer models, but ultimately provides direction for policy and intervention. Economists are not alone in their interest in the description, prediction, and explanation of human behavior. Psychologists, too, have approached these challenges. Economists can profitably leverage research from psychology 
on the measurement, prediction, and malleability of personality traits organized in the widelyaccepted Big Five taxonomy.

We summarize this paper by collecting our responses to the questions posed in the introduction.

1. Cognitive and personality traits are conceptually distinct if one defines cognitive traits to mean general intelligence and specific cognitive abilities. Aspects of personalityshyness, sociability, time preference, impulsivity, extraversion, agreeableness, empathy, sense of humor, and so on—involve cognitive processes but can be separated from raw problem solving abilities for abstract problems.

2. Distinguishing cognitive and personality traits empirically is a difficult task. Measurements of IQ and achievement are affected not only by the knowledge of the test taker, but also by their motivation. Responses on self-report personality questionnaires are affected by strategic responses of the persons being examined which depend, in part, on their perceptions of gain from a response and hence their basic intelligence. Econometric methods have been developed to isolate "pure" intelligence and personality from the effects of environment and experience and to account for measurement error. Their application will enable both psychologists and economists to isolate relevant psychological traits as well as test among competing specifications of how personality traits should enter economic models.

3. We distinguish a priori definitions of personality traits constructed using factor analyses from predictive definitions. Definitions of personality traits based on internal consistency of clusters of test scores are widely used in personality psychology. The tests used in these exercises are devised on a priori grounds to "tap" certain trait spaces that are intuited to be important. Clusters of traits arrived at through factor analysis are less appealing than 
definitions based on the predictive power of tests in real world settings. Each approach has its limitations.

4. The concordance between the measures of personality psychology and the parameters of economic theory is far from perfect. Personality psychology instructs us that many traits, even those beyond altruism and social preferences, are important factors that should be given more emphasis in the economic theory of preferences and constraints. Motivation and effort deserve a renewed emphasis applied to broader aspects of social life than just the labor market. Economists explicitly model motivation through preferences. The evidence suggests that performance on tests can be affected by incentives but only for certain personality types. Economists have long emphasized that organizations can succeed by aligning the interests of the workers with those of managers. This can be achieved by selecting persons with compatible personality traits (for example, on the basis of trustworthiness, cooperativeness, and the like) or by giving incentives to workers of each personality type or by a mixture of the two strategies. However, implementing both types of strategies in the same workplace may be counterproductive because of envy and other social effects.

While the lessons from personality psychology are provocative, they have not yet changed the way most economists go about their business. Recent attacks by psychologists on conventional preference specifications in economics have not been productive because the straw men attacked - expected utility and additively separable models for intertemporal choice - have long been abandoned by economists at the frontier of knowledge. What is needed are more focused studies that suggest specific generalizations of standard models that are empirically fruitful for a range of questions and that have empirical content. Both preferences and 
constraints should be analyzed. Implementing the simple models presented in section VII would be a good first start.

An example of how economic theory can be changed in a fundamental way by learning lessons from personality psychology is the recent work on multidimensional screening that adds personality skills to traditional screening and signaling models and produces a fundamental reformulation of signaling theory (Araujo, Gottlieb, and Moreira, 2007).

5. Many economists and psychologists assume that preference and personality parameters are fixed early in life. The evidence suggests otherwise. Both cognitive and personality traits evolve, albeit at different rates at different ages. Rank-order stability of cognitive skills emerges much earlier than rank-order stability of personality skills. Recent research shows how cognitive and personality skills are affected by parental investments and life experiences. While an assumption of complete stability is analytically convenient, it is not found in the data. Evidence of change in preferences suggests that consistent life cycle planning may be difficult. Agents may, or may not, know if their future preferences will be like their current preferences.

In addition, many psychological measurement schemes assume that the persons being assessed face common choice environments. Our analysis shows that contexts and incentives affect manifest personality traits (effort, for example) and may also affect self-reported traits. This point has important lessons for the measurement and interpretation of personality traits that have not yet made their way into psychological or economic survey-based schemes. It would be very informative to measure personality and cognitive traits under a broader array of different incentive arrangements than have been explored to date, and to benchmark measurements of personality and preference traits at common baselines and tools exist to make these adjustments. 
There is a lot of room for cooperation and exchange of findings and methods between personality psychology and economics. We conclude by suggesting some avenues for future research.

I. Economic preference measures should be subject to the same psychometric standards as personality measures. These include: evidence of internal reliability, test-retest stability (over short periods), convergent validity, discriminant validity, and predictive validity. Subjecting economic preference measures to these standards will increase their validity and improve their ability to predict outcomes. At the same time, psychologists should better recognize that the contexts and incentives faced by agents affect measurements of both cognitive and personality traits.

II. Economic preferences are likely multidimensional. Time preference, for example, may have different components (for example, the inability to inhibit an impulse, the tendency not to consider or imagine the future, comfort with ambiguity, and the like). A hierarchical view (as there is for IQ) may organize a large, currently disorganized literature and unite inconsistent findings across studies and low intercorrelations among measures in a given study. In addition, recognition that certain traits may be allocated differently across tasks, and adjusting for this, will likely improve consistency of the evidence across studies.

III. Econometric methods that account for measurement error and that anchor measurements in real world behavior hold substantial promise in both fields. Econometric methods can move the study of personality and its effects from purely predictive analyses to causal models. Econometric methods also hold promise in modeling the formation and evolution of traits over the life cycle. 
IV. New studies should incorporate validated personality, IQ, and preference measures, as well as outcome measures. Prospective, longitudinal designs are best suited to this task. They should measure volatility of traits at a given age (depending on contexts and incentives faced by agents) as well as the effects of experience on the evolution of personality. An open question, not fully addressed in this paper, is the situational and cultural specificity of personality measures. More careful measurements are required to resolve this issue. The evidence presented here is consistent with stability of traits with age but not their constancy. At a point in time, incentives and situations affect levels of performance, but personality is not entirely situation-specific.

V. A topic not addressed in this paper but important for future work is the relation of cognitive and personality traits to neural substrates and biological factors. ${ }^{115}$ Such a mapping would establish a firm basis for distinguishing among these classes of traits, and also clarify distinctions among personality traits. The evidence assembled thus far suggests that the executive function is localized to the prefrontal cortex and its afferent and efferent connections (Miller and Cohen, 2001). Fear is localized to the amygdala (Calder, Lawrence, and Young, 2001). Recently, the interest of neuroscientists has been extended to time preference (Glimcher, Kable, and Louie, 2007; McClure et al., 2004).

While much remains to be discovered, the evidence presented here suggests that the systematic empirical and theoretical study of personality is likely to be very fruitful for economics. Personality traits are predictive of socioeconomic success. They can be influenced by interventions and investment more readily than IQ, at least after the early years. A deeper understanding of personality traits promises to enrich economic theory and to understand the sources of, and solutions for, human inequality. 


\section{References}

Ackerman, Phillip L. and Eric D. Heggestad. 1997. "Intelligence, Personality, and Interests:

Evidence for Overlapping Traits." Psychological Bulletin 121(2):219-45.

Ainslie, George. 1991. "Derivation of Rational Economic Behavior from Hyperbolic Discount." American Economic Review 81(2):334-40.

Ainslie, George and John Monterosso. 2004. "A Marketplace in the Brain?" Science 306(5695):421-3.

Allport, Gordon W. and Henry S. Odbert. 1936. "Traitnames. A Psycho-Lexical Study." Psychological Monographs. $47: 171$.

Alvarez, Julie A. and Eugene Emory. 2006. "Executive Function and the Frontal Lobes: A MetaAnalytic Review." Neuropsychology Review 16(1):17-42.

American Educational Research Association, American Psychological Association, National Council on Measurement in Education and Joint Committee on Standards for Educational and Psychological Testing. 1999. Standards for Educational and Psychological Testing. Washington, DC: American Educational Research Association.

American Psychological Association and Gary R. VandenBos. 2007. APA Dictionary of Psychology. Washington, DC: American Psychological Association.

Andersen, Steffen, Glenn W. Harrison, Morten Igel Lau, and E. Elisabet Rutstrom. 2005. "Eliciting Risk and Time Preferences." CEBR Discussion Paper 2005-16. Copenhagen, Denmark: Centre for Economic and Business Research.

Andreoni, James. 1995. "Warm-Glow Versus Cold-Prickle: The Effects of Positive and Negative Framing on Cooperation in Experiments." The Quarterly Journal of Economics 110(1):121. 
Araujo, Aloisio, Daniel Gottlieb, and Humberto Moreira. 2007. "A Model of Mixed Signals with Applications to Countersignaling and the GED." RAND Journal of Economics Forthcoming.

Ardila, Alfredo, David Pined, and Monica Rosselli. 2000. "Correlation between Intelligence Test Scores and Executive Function Measures." Archives of Clinical Neuropsychology 15(1):31-6.

Arrow, Kenneth J. and Frank Hahn. 1971. General Competitive Analysis. San Francisco: Holden-Day.

Ayllon, Teodoro and Kathy Kelly. 1972. "Effects of Reinforcement on Standardized Test Performance." Journal of Applied Behavior Analysis 5(4):477-84.

Backus, David K., Bryan R. Routledge, and Stanley E. Zin. 2005. "Exotic Preferences for Macroeconomists." In NBER Macroeconomics Annual 2004, ed. Mark Gertler and Kenneth S. Rogoff, 319-90. Cambridge, MA: MIT Press.

Bandura, Albert. 1999. "A Social Cognitive Theory of Personality." In Handbook of Personality: Theory and Research, ed. Lawrence A. Pervin and Oliver P. John, 154-96. New York, NY: Guilford Press.

Barratt, Ernest S. 1985. "Impulsive Subtraits: Arousal and Information Processing." In Motivation, Emotion and Personality, ed. Spence, Janet T. and Izard, Carroll E., 137-46. New York: Elsevier Science Publishing Company.

Barrick, Murray R. and Michael K. Mount. 1991. "The Big Five Personality Dimensions and Job Performance: A Meta-Analysis." Personnel Psychology 44(1):1-26. 
Barsky, Robert B., F. Thomas Juster, Miles S. Kimball and Matthew D. Shapiro. 1997.

"Preference Parameters and Behavioral Heterogeneity: An Experimental Approach in the Health and Retirement Study." Quarterly Journal of Economics 112(2):537-79.

Barton, Keith, Ted E. Dielman, and Raymond B. Cattell. 1972. "Personality and IQ Measures as Predictors of School Achievement." Journal of Educational Psychology 63(4):398-404.

Baumeister, Roy F., Ellen Bratslavsky, Mark Muraven, and Dianne M. Tice. 1998. "Ego Depletion: Is the Active Self a Limited Resource?" Journal of Personality and Social Psychology 74(5):1252-65.

Becker, Gary S. 1962. "Irrational Behavior and Economic Theory." Journal of Political Economy 70:1-13. 1965. "A Theory of the Allocation of Time." The Economic Journal 75(299):493517. 1981. A Treatise on the Family. Cambridge, Mass: Harvard University Press. Becker, Gary S. and Casey B. Mulligan. 1997. "The Endogenous Determination of Time Preference." Quarterly Journal of Economics 112(3):729-58.

Becker, Gary S. and Kevin M. Murphy. 1988. "A Theory of Rational Addiction." Journal of Political Economy 96(4):675-700.

Beckett, Celia, Barbara Maughan, Michael Rutter, Jenny Castle, Emma Colvert, Christine Groothues, Jana Kreppner, Suzanne Stevens, Thomas G. O'Connor, and Edmund J. S. Sonuga-Barke. 2006. "Do the Effects of Early Severe Deprivation on Cognition Persist into Early Adolescence? Findings from the English and Romanian Adoptees Study." Child Development 77(3):696-711. 
Belzil, Christian and Marco Leonardi. 2006. "Can Risk Aversion Explain Schooling

Attainments? Evidence from Italy." IZA Discussion Paper 2123. Bonn, Germany: Institute for the Study of Labor (IZA).

Benhabib, Jess, Alberto Bisin, and Andrew Schotter. 2004. "Hyperbolic Discounting and SelfControl: An Experimental Analysis." Unpublished manuscript. New York University.

Benjamin, Daniel J., Sebastian A. Brown, and Jesse M. Shapiro. 2006. "Who is 'Behavioral'? Cognitive Ability and Anomalous Preferences." Unpublished manuscript, Cornell University. Ithaca, NY.

Benson, Michael J. and John P. Campbell. 2007. "To be, Or Not to be, Linear: An Expanded Representation of Personality and its Relationship to Leadership Performance." International Journal of Selection and Assessment 15(2):232-49.

Bergen, Sarah E., Charles O. Gardner, and Kenneth S. Kendler. 2007. "Age-Related Changes in Heritability of Behavioral Phenotypes Over Adolescence and Young Adulthood: A MetaAnalysis." Twin Research and Human Genetics 10(3):423-33.

Bergstrom, Ted C. 1997. "A Survey of the Theories of the Family." In Handbook of Population and Family Economics, ed. Mark R. Rosenzweig and Oded Stark, 21-80. Amsterdam: North Holland.

Besharov, Gregory and Bentley Coffey. 2003. "Reconsidering the Experimental Evidence for Quasi-Hyperbolic Discounting." Unpublished manuscript. Duke University, Department of Economics.

Bickel, Warren K., Amy L. Odum and Gregory J. Madden. 1999. "Impulsivity and Cigarette Smoking: Delay Discounting in Current, Never, and Ex-Smokers." Psychopharmacology $146(4): 447-54$ 
Binswanger, Hans P. 1980. "Attitudes Toward Risk: Experimental Measurement in Rural India." American Journal of Agricultural Economics 62(3):395-407. . 1981. "Attitudes Toward Risk: Theoretical Implications of an Experiment in Rural India." Economic Journal 91(364):867-90.

Blair, Clancy. 2006. "How Similar are Fluid Cognition and General Intelligence? A Developmental Neuroscience Perspective on Fluid Cognition as an Aspect of Human Cognitive Ability." Behavioral and Brain Sciences 29(2):109-60.

Blair, Clancy, David Gamson, Steven Thorne, and David Baker. 2005. "Rising Mean IQ: Cognitive Demand of Mathematics Education for Young." Intelligence 33(1):93-106. Block, H. D. and Jacob Marschak. 1960. "Random Orderings and Stochastic Theories of Responses." In Contributions to Probability Statistics: Essays in Honor of Harold Hotelling, ed. Ingram Olkin, 97-132. Stanford, CA: Stanford University Press.

Block, Jack. 1995. "A Contrarian View of the Five-Factor Approach to Personality Description." Psychological Bulletin 117(2):187-215.

Block, Jack and Norma Haan. 1971. Lives through Time. Berkeley: Bancroft Books.

Blonigen, Daniel M., Brian M. Hicks, Robert F. Krueger, Christopher J. Patrick, and William G. Iacono. 2006. "Continuity and Change in Psychopathic Traits as Measured Via NormalRange Personality: A Longitudinal-Biometric Study." Journal of Abnormal Psychology 115(1):85-95.

Boake, Corwin. 2002. "From the Binet-Simon to the Wechsler-Bellevue: Tracing the History of Intelligence Testing." Journal of Clinical and Experimental Neuropsychology 24(3):383405. 
Bock, Richard D. and Lyle V. Jones. 1968. The Measurement and Prediction of Judgment and Choice. San Francisco: Holden-Day.

Bonato, Daniela P. and Fred J. Boland. 1983. "Delay of Gratification in Obese Children." Addictive Behaviors 8(1):71-4.

Borghans, Lex and Bart H. H. Golsteyn. 2006. "Time Discounting and the Body Mass Index: Evidence from the Netherlands." Economics and Human Biology 4(1):39-61. . 2007. "Time Discounting, Imagination, and Human Capital Investment Decisions." Unpublished manuscript. Maastricht University.

Borghans, Lex, Huub Meijers and Bas ter Weel. 2006. "The Role of Noncognitive Skills in Explaining Cognitive Test Scores." Working paper Maastricht University:

Borghans, Lex, Bas ter Weel, and Bruce A. Weinberg. 2006. People People: Social Capital and the Labor-Market Outcomes of Underrepresented Groups. Cambridge, MA: National Bureau of Economic Research, Inc, NBER Working Papers: 11985. . 2007. "Interpersonal Styles and Labor Market Outcomes." Unpublished manuscript. Maastricht University.

Bouchard, Thomas J. and John C. Loehlin. 2001. "Genes, Evolution and Personality." Behavior Genetics 31(3):243-73.

Bowles, Samuel and Herbert Gintis. 1976. Schooling in Capitalist America: Educational Reform and the Contradictions of Economic Life. New York: Basic Books.

Bowles, Samuel, Herbert Gintis, and Melissa Osborne. 2001. "The Determinants of Earnings: A Behavioral Approach." Journal of Economic Literature 39(4):1137-76. 
Breuning, Stephen E. and William F. Zella. 1978. "Effects of Individualized Incentives on Norm-Referenced IQ Test Performance of High School Students in Special Education Classes." Journal of School Psychology 16(3):220-6.

Brock, William A. and Steven N. Durlauf. 2001. "Interactions-Based Models." In Handbook of Econometrics, ed. James J. Heckman and Edward Leamer, 3463-568. New York: NorthHolland.

Browning, Martin, Lars Peter Hansen, and James J. Heckman. 1999. "Micro Data and General Equilibrium Models." In Handbook of Macroeconomics, ed. John B. Taylor and Michael Woodford, 543-633. Elsevier.

Browning, Martin and Costas Meghir. 1991. "The Effects of Male and Female Labor Supply on Commodity Demands." Econometrica 59(4):925-951.

Buss, Arnold H. and Robert Plomin. 1975. A Temperament Theory of Personality Development. New York: Wiley.

Cahan, Sorel and Nora Cohen. 1989. "Age Versus Schooling Effects on Intelligence Development." Child Development 60(5):1239-49.

Calder, Andrew J., Andrew D. Lawrence, and Andrew W. Young. 2001. "Neuropsychology of Fear and Loathing." Nature Reviews Neuroscience 2(5):352-63.

Camerer, Colin and George F. Loewenstein. 2004. "Behavioral Economics: Past, Present and Future." In Advances in Behavioral Economics, ed. Colin Camerer, George F. Loewenstein and Matthew Rabin, 1-61. New York: Russell Sage Foundation.

Camerer, Colin, George F. Loewenstein, and Drazen Prelec. 2005. "Neuroeconomics: How Neuroscience can Inform Economics." Journal of Economic Literature 43(1):9-64. 
Camerer, Colin, George F. Loewenstein, and Matthew Rabin. 2004. Advances in Behavioral Economics. New York: Russell Sage Foundation.

Campbell, Donald T. and Donald W. Fiske. 1959. "Convergent and Discriminant Validation by the Multitrait-Multimethod Matrix." Psychological Bulletin 56(2):81-105.

Canli, Turhan. 2006. Biology of Personality and Individual Differences. New York: Guilford Press.

Carroll, John B. 1993. Human Cognitive Abilities: A Survey of Factor-Analytic Studies. New York: Cambridge University Press.

Caspi, Avshalom. 2000. "The Child is Father of the Man: Personality Continuities from Childhood to Adulthood." Journal of Personality and Social Psychology 78(1):158-72.

Caspi, Avshalom, Joseph McClay, Terrie E. Moffitt, Jonathan Mill, Judy Martin, Ian W. Craig, Alan Taylor and Richie Poulton. 2002. "Role of Genotype in the Cycle of Violence in Maltreated Children." Science 297(5582):851-4.

Caspi, Avshalom, Brent W. Roberts, and Rebecca L. Shiner. 2005. "Personality Development: Stability and Change." Annual Review of Psychology 56(1):453-84.

Caspi, Avshalom, Karen Sugden, Terrie E. Moffitt, Alan Taylor, Ian W. Craig, HonaLee Harrington, Joseph McClay, Jonathan Mill, Judy Martin, Antony Braithwaite and Richie Poulton. 2003. "Influence of Life Stress on Depression: Moderation by a Polymorphism in the 5-HTT Gene." Science 301(5631):386-9.

Cattell, James McKeen. 1890. "Mental Tests and Measurements." Mind 15(59):373-81.

Cattell, Raymond B. 1971. Abilities: Their Structure, Growth, and Action. Boston: Houghton Mifflin. . 1987. Intelligence: Its Structure, Growth and Action. Amsterdam: North-Holland. 
Chamorro-Premuzic, Tomas and Adrian Furnham. 2003. "Personality Predicts Academic Performance: Evidence from Two Longitudinal University Samples." Journal of Research in Personality 37(4):319-38. 2005. Personality and Intellectual Competence. Mahwah, N.J: L. Erlbaum Associates.

Chao, Li-Wei, Helena Szrek, Nuno Sousa Pereira, and Mark V. Pauly. 2007. "Time Preference and Its Relationship with Age, Health, and Longevity Expectations." CETE Discussion Papers 0706. Universidade do Porto, Faculdade de Economia do Porto.

Chapman, Gretchen B. and Elliot J. Coups. 1999. "Time Preferences and Preventive Health Behavior: Acceptance of the Influenza Vaccine." Medical Decision Making 19(3):30714.

Chapman, Gretchen B., Richard Nelson, and Daniel B. Hier. 1999. "Familiarity and Time Preferences: Decision Making about Treatments for Migraine Headaches and Crohn's Disease." Journal of Experimental Psychology: Applied 5(1):17-34.

Chesson, Harrell and W. Kip Viscusi. 2000. "The Heterogeneity of Time-Risk Tradeoffs." Journal of Behavioral Decision Making 13(2):251-8.

Clausen, John A. and Martin Gilens. 1990. "Personality and Labor Force Participation Across the Life Course: A Longitudinal Study of Women's Careers." Sociological Forum 5(4):595618.

Clingman, Joy and Robert L. Fowler. 1976. "The Effects of Primary Reward on the I.Q. Performance of Grade-School Children as a Function of Initial I.Q. Level." Journal of Applied Behavior Analysis 9(1):19-23. 
Cloninger, C. Robert. 1987. "A Systematic Method for Clinical Description and Classification of Personality Variants: A Proposal." Archives of General Psychiatry 44(6):573-88.

Coller, Maribeth and Melonie B. Williams. 1999. "Eliciting Individual Discount Rates." Experimental Economics 2(2):107-27.

Colquitt, Jason A., Jeffrey A. LePine, and Raymond A. Noe. 2000. "Toward an Integrative Theory of Training Motivation: A Meta-Analytic Path Analysis of 20 Years of Research." Journal of Applied Psychology 85(5):678-707.

Congdon, Eliza and Turhan Canli. 2005. "The Endophenotype of Impulsivity: Reaching Consilience through Behavioral, Genetic, and Neuroimaging Approaches." Behavioral and Cognitive Neuroscience Reviews 4(4):262-81.

Conti, Gabriella and Stephen Pudney. 2007. "The Dynamics of Cognitive Development." Unpublished manuscript,. University of Essex, Institute for Social and Economic Research.

Costa, Paul T. and Robert R. McCrae. 1988. "From Catalog to Classification: Murray's Needs and the Five-Factor Model." Journal of Personality and Social Psychology 55(2):258-65. . 1992a. "Four Ways Five Factors are Basic." Personality and Individual Differences 13(6):653-65. . 1992b. Revised NEO Personality Inventory (NEO PI-R) and NEO Five-Factor Inventory (NEO-FFI). Odessa, FL: Psychological Assessment Resources. . 1994. "Set Like Plaster? Evidence for the Stability of Adult Personality." In Can Personality Change? ed. Todd F. Heatherton and Joel Lee Weinberger, 21-40. Washington, DC: American Psychological Association. 
Cragg, John G. and Stephen G. Donald. 1997. "Inferring the Rank of a Matrix." Journal of Econometrics 76(1-2):223-50.

Csikszentmihalyi, Mihaly. 1996. Creativity: Flow and the Psychology of Discovery and Invention. New York: Harper Collins Publishers.

Cudek, Robert and Robert C. MacCallum. 2007. Factor Analysis at 100: Historical Developments and Future Directions. Mahwah, NJ: Lawrence Erlbaum Associates. Cunha, Flavio and James J. Heckman. 2007. "The Technology of Skill Formation." American Economic Review 97(2):31-47. 2008. "Formulating, Identifying and Estimating the Technology of Cognitive and Noncognitive Skill Formation." Journal of Human Resources. Forthcoming. Cunha, Flavio, James J. Heckman, Lance J. Lochner, and Dimitriy V. Masterov. 2006. "Interpreting the Evidence on Life Cycle Skill Formation." In Handbook of the Economics of Education, ed. Eric A. Hanushek and Frank Welch, 697-812. Amsterdam: North-Holland.

Cunha, Flavio, James J. Heckman, and Susanne M. Schennach. 2007. "Estimating the Technology of Cognitive and Noncognitive Skill Formation." Unpublished manuscript, University of Chicago, Department of Economics.

Damasio, Antonio R. 1994. Descartes' Error: Emotion, Reason, and the Human Brain. New York: Putnam.

de Wit, Harriet, Janine D. Flory, Ashley Acheson, Michael McCloskey and Stephen B. Manuck. 2007. "IQ and Nonplanning Impulsivity are Independently Associated with Delay Discounting in Middle-Aged Adults." Personality and Individual Differences 42(1):11121. 
Devlin, Bernie, Michael Daniels and Kathryn Roeder. 1997. "The Heritability of IQ." Nature 388(6641):468-71.

DeYoung, Colin G. 2007. "Between Facets and Domains: Ten Aspects of the Big Five." Journal of Personality and Social Psychology

Dickens, William T. and James R. Flynn. 2001. "Heritability Estimates Versus Large

Environmental Effects: The IQ Paradox Resolved." Psychological Review 108(2):346-69.

Digman, John M. 1990. "Personality Structure: Emergence of the Five-Factor Model." Annual Review of Psychology 41:417-40.

. 1997. "Higher-Order Factors of the Big Five." Journal of Personality and Social Psychology 73(6):1246-56.

Digman, John M. and Naomi K. Takemoto-Chock. 1981. "Factors in the Natural Language of Personality: Re-Analysis, Comparison, and Interpretation of Six Major Studies." Multivariate Behavioral Research 16(2):149-70.

Dohmen, Thomas, Armin Falk, David Huffman, and Uwe Sunde. 2006. "The Intergenerational Transmission of Risk and Trust Attitudes." IZA Discussion Papers 2380. Bonn, Germany: Institute for the Study of Labor. . 2007. "Are Risk Aversion and Impatience Related to Cognitive Ability?" IZA

Discussion Paper 2735. Bonn, Germany: Institute for the Study of Labor. . 2008. "On Representative Trust and Recipcrocity: Prevalence and Determinants." Economic Inquiry In press.

Dohmen, Thomas, Armin Falk, David Huffman, Uwe Sunde, Jürgen Schupp, and Gert G. Wagner. 2005. "Individual Risk Attitudes : New Evidence from a Large, Representative, 
Experimentally-Validated Survey." Discussion Papers of DIW Berlin 511. Berlin, Germany: German Institute for Economic Research.

Donkers, Bas, Bertrand Melenberg, and Arthur van Soest. 2001. "Estimating Risk Attitudes using Lotteries: A Large Sample Approach." Journal of Risk and Uncertainty 22(2):16595.

Dreber, Anna and Moshe Hoffman. 2007. "Fingers Indicate Risk Preferences are Partly Predetermined." Unpublished manuscript. Stockholm School of Economics, Stockholm, Sweden.

Du, Wanjiang, Leonard Green, and Joel Myerson. 2002. "Cross-Cultural Comparisons of Discounting Delayed and Probabilistic Rewards." Psychological Record 52(4):479-92.

Duckworth, Angela L. 2007. "Unpublished Dataset." Philadelphia, PA. University of Pennsylvania.

Duckworth, Angela L. and Martin E. P. Seligman. 2005. "Self-Discipline Outdoes IQ in Predicting Academic Performance of." Psychological Science 16(12):939-44.

Duncan, Greg J. and Rachel Dunifon. 1998. "'Soft-Skills" and Long-Run Labor Market Success." In Research in Labor Economics, ed. Solomon W. Polachek, 123-49. Stamford, CT: JAI Press.

Dunning, David, Chip Heath, and Jerry M. Suls. 2004. "Flawed Self-Assessment: Implications for Health, Education, and the Workplace." Psychological Science in the Public Interest 5(3):69-106.

Durlauf, Steven N. and Marcel Fafchamps. 2005. "Social Capital." In Handbook of Economic Growth, ed. Steven N. Durlauf and Philippe Aghion, 1639-99. Amsterdam: Elsevier. Durlauf, Steven N. and H. Peyton Young. 2001. Social Dynamics. Cambridge, MA: MIT Press. 
Duyme, Michel, Annick-Camille Dumaret, and Stanislaw Tomkiewicz. 1999. "How can we Boost IQs of "Dull Children"? A Late Adoption Study." Proceedings of the National Academy of Sciences 96(15):8790-4.

Eckel, Catherine C. and Philip J. Grossman. 2008. "Men, Women and Risk Aversion: Experimental Evidence." In Handbook of Experimental Economic Results, ed. Charles Plott and Vernon Smith, Amsterdam: Elsevier.

Edlund, Calvin V. 1972. "The Effect on the Behavior of Children, as Reflected in the IQ Scores, when Reinforced After each Correct Response." Journal of Applied Behavior Analysis 5(3):317-9.

Ellsberg, Daniel. 1961. "Risk, Ambiguity, and the Savage Axioms." The Quarterly Journal of Economics 75(4):643-69.

Emmons, Robert A. and E. D. Diener. 1986. "An Interactional Approach to the Study of Personality and Emotion." Journal of Personality 54(2):371-84.

Emmons, Robert A., E. D. Diener and Randy J. Larsen. 1986. "Choice and Avoidance of Everyday Situations and Affect Congruence: Two Models of Reciprocal Interactionism." Journal of Personality and Social Psychology 51(4):815-26.

Endler, Norman S. 1982. "Interactionism: A Personality Model, but Not Yet a Theory." Nebraska Symposium on Motivation :155-200.

Epstein, Larry G. and Michel Le Breton. 1993. "Dynamically Consistent Beliefs must be Bayesian." Journal of Economic Theory 61(1):1-22.

Epstein, Larry G. and Stanley E. Zin. 1991. "Substitution, Risk Aversion, and the Temporal Behavior of Consumption and Asset Returns: An Empirical Analysis." Journal of Political Economy 99(2):263-86. 
Ericsson, K. Anders, Ralf T. Krampe, and Clemens Tesch-Romer. 1993. "The Role of Deliberate Practice in the Acquisition of Expert Performance." Psychological Review 100(3):363406.

Ericsson, K. Anders and Paul Ward. 2007. "Capturing the Naturally Occurring Superior Performance of Experts in the Laboratory: Toward a Science of Expert and Exceptional Performance." Current Directions in Psychological Science 16(6):346-50.

Estle, Sara J., Leonard Green, Joel Myerson, and Daniel D. Holt. 2007. "Discounting of Monetary and Directly Consumable Rewards." Psychological Science 18(1):58-63.

Euwals, Rob and Arthur van Soest. 1999. "Desired and Actual Labour Supply of Unmarried Men and Women in the Netherlands." Labour Economics 6(1):95-118.

Eysenck, Hans Jurgen. 1991. "Dimensions of Personality: 16, 5 Or 3 ? Criteria for a Taxonomic Paradigm." Personality and Individual Differences 12(8):773-90.

Eysenck, Sybil B., G. Easting, and Paul R. Pearson. 1984. "Age Norms for Impulsiveness, Venturesomeness and Empathy in Children." Personality and Individual Differences 5(3):315-21.

Falk, Armin and Urs Fischbacher. 2006. "A Theory of Reciprocity." Games and Economic Behavior 54(2):293-315.

Falmagne, Jean-Claude. 1985. Elements of Psychophysical Theory. New York: Oxford University Press.

Fehr, Ernst and Simon Gächter. 2000. "Fairness and Retaliation: The Economics of Reciprocity." Journal of Economic Perspectives 14(3):159-81.

Fehr, Ernst and Klaus M. Schmidt. 1999. "A Theory of Fairness, Competition, and Cooperation." Quarterly Journal of Economics 114(3):817-68. 
2006. "The Economics of Fairness, Reciprocity and Altruism - Experimental

Evidence and New Theories." In Handbook on the Economics of Giving, Recipcrocity and Altruism, ed. Serge-Christophe Kolm and Jean Mercier Ythier, 615-91. Amsterdam: Elsevier.

Feinberg, Robert M. 1977. "Risk Aversion, Risk, and the Duration of Unemployment." Review of Economics and Statistics 59(3):264-71.

Ferrer-i-Carbonell, Ada. 2005. "Income and Well-being: An Empirical Analysis of the Comparison Income Effect." Journal of Public Economics 89(5):997-1019.

Flynn, James Robert. 2007. What is Intelligence? Beyond the Flynn Effect. New York: Cambridge University Press.

Fraley, R. Chris and Brent W. Roberts. 2005. "Patterns of Continuity: A Dynamic Model for Conceptualizing the Stability of Individual Differences in Psychological Constructs Across the Life Course." Psychological Review 112(1):60-74.

Frederick, Shane. 2005. "Cognitive Reflection and Decision Making." Journal of Economic Perspectives 19(4):25-42.

Frederick, Shane, George F. Loewenstein, and Ted O'Donoghue. 2002. "Time Discounting and Time Preference: A Critical Review." Journal of Economic Literature 40(2):351-401.

Fuchs, Victor R. 1982. "Time Preference and Health: An Explorative Study." In Economic Aspects of Health, ed. Victor R. Fuchs, 93-120. Chicago, IL: University of Chicago Press. Fudenberg, Drew. 2006. "Advancing Beyond Advances in Behavioral Economics." Journal of Economic Literature 44(3):694. 
Funder, David C. and Jack Block. 1989. "The Role of Ego-Control, Ego-Resiliency, and IQ in Delay of Gratification in Adolescence." Journal of Personality and Social Psychology 57(6):1041-50.

Gailliot, Matthew T., Roy F. Baumeister, C. Nathan DeWall, Jon K. Maner, E. Ashby Plant, Dianne M. Tice, Lauren E. Brewer and Brandon J. Schmeichel. 2007. "Self-Control Relies on Glucose as a Limited Energy Source: Willpower is More than a Metaphor." Journal of Personality and Social Psychology 92(2):325-36.

Galton, Francis. 1883. Inquiries into Human Faculty and its Development. London, UK: Macmillan and Company.

Gardner, Howard. 2004. Frames of Mind: The Theory of Multiple Intelligences. New York, NY: Basic Books.

Gately, Dermot. 1980. "Individual Discount Rates and the Purchase and Utilization of Energyusing Durables: Comment." The Bell Journal of Economics 11(1):373-4.

Gilboa, Itzhak and David Schmeidler. 1993. "Updating Ambiguous Beliefs." Journal of Economic Theory 59(1):33-49.

Gillham, Jane E. and Karen J. Reivich. 1999. "Prevention of Depressive Symptoms in School Children: A Research Update." Psychological Science 10(5):461-2.

Glimcher, Paul William, Joseph Kable, and Kenway Louie. 2007. "Neuroeconomic Studies of Impulsivity: Now Or just as Soon as Possible?" American Economic Review 97(2):142-7.

Goff, Maynard and Phillip L. Ackerman. 1992. "Personality-Intelligence Relations: Assessment of Typical Intellectual Engagement." Journal of Educational Psychology 84(4):537-52. 
Goldberg, Lewis R. 1971. "A Historical Survey of Personality Scales and Inventories." In Advances in Psychological Assessment, ed. Paul McReynolds, 293-336. Palo Alto, CA: Science and Behavior Books.

Goldberg, Lewis R., John A. Johnson, Herbert W. Eber, Robert Hogan, Michael C. Ashton, C. Robert Cloninger, and Harrison G. Gough. 2006. "The International Personality Item Pool and the Future of Public-Domain Personality Measures." Journal of Research in Personality 40(1):84-96.

Goldberger, Arthur Stanley. 1968. Topics in Regression Analysis. New York: Macmillan.

Goldsmith, H. Hill, Arnold H. Buss, Robert Plomin, Mary Klevjord Rothbart, Alexander Thomas, Stella Chess, Robert A. Hinde, and Robert B. McCall. 1987. "Roundtable: What is Temperament? Four Approaches." Child Development 58(2):505-29.

Gorman, W. M. 1968. "The Structure of Utility Functions." Review of Economic Studies 35(4):367-90.

Gottfredson, Linda S. 2002. "G: Highly General and Highly Practical." In The General Factor of Intelligence: How General is it? ed. Robert J. Sternberg and Elena L. Grigorenko, 33180. Mahwah, NJ: Lawrence Erlbaum Associates Publishers.

Gottschalk, Peter. 2005. "Can Work Alter Welfare Recipients' Beliefs?" Journal of Policy Analysis and Management 24(3):485-98.

Gough, Harrison G. and Alfred B. Heilbrun. 1983. The Adjective Check List Manual. Palo Alto, CA: Consulting Psychologists Press.

Green, Leonard, Astrid F. Fry and Joel Myerson. 1994. "Discounting of Delayed Rewards: A Life-Span Comparison." Psychological Science 5(1):33-6. 
Green, Leonard and Joel Myerson. 2004. "A Discounting Framework for Choice with Delayed and Probabilistic Rewards." Psychological Bulletin 130(5):769-92.

Guiso, Luigi and Monica Paiella. 2001. "Risk Aversion, Wealth and Background Risk." CEPR Discussion Papers 2728. London, UK: Centre for Economic Policy Research. Keywords: Background Risk; Heterogeneous Preferences; Prudence; Risk Aversion; Publication Type: Working Paper; Update Code: 200404

Haavelmo, Trygve. 1944. "The Probability Approach in Econometrics." Econometrica 12(Supplement):- and 1-115.

Hamermesh, Daniel S. and Jeff E. Biddle. 1994. "Beauty and the Labor Market." American Economic Review 84(5):1174-94.

Hamermesh, Daniel S., Xin Meng, and Junsen Zhang. 2002. "Dress for Success--does Primping Pay?" Labour Economics 9(3):361-73.

Hampson, Sarah E., Lewis R. Goldberg, Thomas M. Vogt, and Joan P. Dubanoski. 2006. "Forty Years on: Teachers' Assessments of Children's Personality Traits Predict Self-Reported Health Behaviors and Outcomes at Midlife." Health Psychology 25(1):57-64.

Hanoch, Yaniv, Joseph G. Johnson, and Andreas Wilke. 2006. "Domain Specificity in Experimental Measures and Participant Recruitment: An Application to Risk-Taking Behavior." Psychological Science 17(4):300-4.

Hansen, Karsten T., James J. Heckman, and Kathleen J. Mullen. 2004. "The Effect of Schooling and Ability on Achievement Test Scores." Journal of Econometrics 121(1-2):39-98.

Hansen, Lars Peter. 2005. "Comment on "Exotic Preferences for Macroeconomics" by D. K. Backus, B. R. Routledge and S. E. Zin." In NBER Macroeconomics Annual, ed. Mark Gertler and Kenneth Rogoff, 391-405. Cambridge, MA: MIT Press. 
. 2007. "Beliefs, Doubts and Learning: Valuing Macroeconomic Risk." American Economic Review 97(2):1-30.

Hansen, Lars Peter and Thomas J. Sargent. 2008. Robustness. Princeton, NJ: Princeton University Press.

Harbaugh, William T., Kate Krause, and Lise Vesterlund. 2002. "Risk Attitudes of Children and Adults: Choices Over Small and Large Probability Gains and Losses." Experimental Economics 5(1):53-84.

Harris, Daniel. 1940. "Factors Affecting College Grades: A Review of the Literature, 19301937." Psychological Bulletin 37(3):125-66.

Harrison, Glenn W. and Morten Igel Lau. 2005. "Is the Evidence for Hyperbolic Discounting in Humans Just An Experimental Artefact?" CEBR Discussion Paper 2005-1. Centre for Business and Economic Research.

Harrison, Glenn W., Morten Igel Lau, and E. Elisabet Rutstrom. 2007. "Estimating Risk Attitudes in Denmark: A Field Experiment." Scandinavian Journal of Economics 109(2):341-68.

Harrison, Glenn W., Morten Igel Lau, and Melonie B. Williams. 2002. "Estimating Individual Discount Rates in Denmark: A Field Experiment." American Economic Review 92(5):1606-17.

Harrison, Glenn W. and John A. List. 2004. "Field Experiments." Journal of Economic Literature 42(4):1009-55.

Hartog, Joop. 1980. "Earnings and Capability Requirements." Review of Economics and Statistics 62(2):230-40. 
. 2001. "On Human Capital and Individual Capabilities." Review of Income and

Wealth 47(4):515-40.

Hartog, Joop, Ada Ferrer-i-Carbonell, and Nicole Jonker. 2002. "Linking Measured Risk

Aversion to Individual Characteristics." Kyklos 55(1):3-26.

Hartog, Joop, Justin van der Sluis, and Mirjam van Praag. 2007. "Returns to Intelligence:

Entrepreneurs Versus Employees." Unpublished manuscript, University of Amsterdam.

Hausman, Jerry A. 1979. "Individual Discount Rates and the Purchase and Utilization of Energyusing Durables." Bell Journal of Economics 10(1):33-54.

Heckman, James J. 1974. "Effects of Child-Care Programs on Women's Work Effort." Journal of Political Economy 82(2):S136-63.

. 1976. "A Life-Cycle Model of Earnings, Learning, and Consumption." Journal of Political Economy 84(4, Part 2):S11-44.

. 1993. "What has been Learned about Labor Supply in the Past Twenty Years?"

American Economic Review 83(2):116-21.

. 2004. "Lessons from the Technology of Skill Formation." Annals of the New York

Academy of Science (1038):179-200.

. 2005. "The Scientific Model of Causality." Sociological Methodology 35(1):1-97.

. 2007. "The Economics, Technology and Neuroscience of Human Capability

Formation." Proceedings of the National Academy of Sciences 104(3):13250-5.

Heckman, James J. and Paul A. LaFontaine. 2007. "The American High School Graduation Rate: Trends and Levels." NBER Working Papers 13670. Forthcoming, Quarterly Journal of Economics 
Heckman, James J. and Dimitriy V. Masterov. 2007. "The Productivity Argument for Investing in Young Children." Review of Agricultural Economics 29(3):446-93.

Heckman, James J., Seong H. Moon, Rodrigo R. Pinto, Peter Savelyev, Lawrence Schweinhart, Azeem Shaikh, and Adam M. Yavitz. 2007. "The Perry Preschool Project: A Reanalysis." Unpublished manuscript. University of Chicago, Department of Economics.

Heckman, James J. and Yona Rubinstein. 2001. "The Importance of Noncognitive Skills: Lessons from the GED Testing Program." American Economic Review 91(2):145-9.

Heckman, James J. and Guilherme L. Sedlacek. 1985. "Heterogeneity, Aggregation, and Market Wage Functions: An Empirical Model of Self-Selection in the Labor Market." Journal of Political Economy 93(6):1077-125.

Heckman, James J., Jora Stixrud, and Sergio Urzua. 2006. "The Effects of Cognitive and Noncognitive Abilities on Labor Market." Journal of Labor Economics 24(3):411-82.

Heckman, James J. and Edward J. Vytlacil. 2007a. "Econometric Evaluation of Social Programs, Part I: Causal Models." In Handbook of Econometrics, ed. James J. Heckman and E. Leamer, 4779-874. Amsterdam: Elsevier. . 2007b. "Econometric Evaluation of Social Programs, Part II: Using the Marginal Treatment Effect to Organize Alternative Economic Estimators to Evaluate Social Programs and to Forecast their Effects in New Environments." ed. James J. Heckman and Edward Leamer, Amsterdam: North-Holland.

Heitz, Richard P., Nash Unsworth and Randall W. Engle. 2005. "Working Memory Capacity, Attention Control, and Fluid Intelligence." In Handbook of Understanding and Measuring Intelligence, ed. Oliver Wilhelm and Randall W. Engle, 61-77. Thousand Oaks, CA: Sage Publications, Inc. 
Helson, Ravenna, Virginia S. Y. Kwan, Oliver P. John, and Constance Jones. 2002. "The Growing Evidence for Personality Change in Adulthood: Findings from Research with Personality Inventories." Journal of Research in Personality 36(4):287-306.

Helson, Ravenna and James Picano. 1990. "Is the Traditional Role Bad for Women?" Journal of Personality and Social Psychology 59(2):311-20.

Hembree, Ray. 1988. "Correlates, Causes, Effects, and Treatment of Test Anxiety." Review of Educational Research 58(1):47-77.

Henderson, James Mitchell, and Richard E. Quandt. 1958. Microeconomic Theory: A Mathematical Approach. New York: McGraw-Hill.

Herrnstein, Richard J. and Charles A. Murray. 1994. The Bell Curve: Intelligence and Class Structure in American Life. New York: Free Press.

Hofstee, Willem K., Boele de Raad, and Lewis R. Goldberg. 1992. "Integration of the Big Five and Circumplex Approaches to Trait Structure." Journal of Personality and Social Psychology 63(1):146-63.

Hogan, Joyce and Brent Holland. 2003. "Using Theory to Evaluate Personality and JobPerformance Relations: A Socioanalytic Perspective." Journal of Applied Psychology 88(1):100-12.

Hogan, Robert. 2005. "In Defense of Personality Measurement: New Wine for Old Whiners." Human Performance 18(4):331-41.

Hogan, Robert and Joyce Hogan. 2007. Hogan Personality Inventory Manual, Third Edition. Tulsa, OK: Hogan Assessment Systems.

Hogan, Robert, Joyce Hogan, and Brent W. Roberts. 1996. "Personality Measurement and Employment Decisions: Questions and Answers." American Psychologist 51(5):469-77. 
Holland, Paul W. 1986. "Statistics and Causal Inference." Journal of the American Statistical Association 81(396):945-60.

Holt, Charles A. and Susan K. Laury. 2002. "Risk Aversion and Incentive Effects." American Economic Review 92(5):1644-55.

Holt, Michael M. and Tom R. Hobbs. 1979. "The Effects of Token Reinforcement, Feedback and Response Cost on Standardized Test Performance." Behaviour Research and Therapy $17(1): 81-3$.

Hopkins, Kenneth D. and Glenn H. Bracht. 1975. "Ten-Year Stability of Verbal and Nonverbal IQ Scores." American Educational Research Journal 12(4):469-77.

Horn, John L. 1970. "Organization of Data on Life-Span Development of Human Abilities." In Life-Span Developmental Psychology: Research and Theory, ed. Lise R. Goulet and Paul B. Baltes, 423-66. New York: Academic Press.

Horn, John L. and John J. McArdle. 2007. "Understanding Human Intelligence in Factor Analysis since Spearman." In Factor Analysis at 100: Historical Developments and Future Directions, ed. Robert Cudek and Robert C. MacCallum, Mahwah, NJ: Lawrence Erlbaum Associates.

Hough, Leaetta M., Newell K. Eaton, Marvin D. Dunnette, John D. Kamp, and Rodney A. McCloy. 1990. "Criterion-Related Validities of Personality Constructs and the Effect of Response Distortion on those Validities." Journal of Applied Psychology 75(5):581-95.

Hough, Leaetta M. and Deniz S. Ones. 2002. "The Structure, Measurement, Validity, and use of Personality Variables in Industrial, Work, and Organizational Psychology." In Handbook of Industrial, Work and Organizational Psychology, Volume 1: Personnel Psychology, 
ed. Neil Anderson, Deniz S. Ones, Handan Kepir Sinangil and Chockalingam

Viswesvaran, 233-77. Thousand Oaks, CA: Sage Publications, Inc.

Hull, Clark Leonard and Lewis Madison Terman. 1928. Aptitude Testing. Yonkers-on-Hudson, N.Y: World Book Company.

Humphreys, Lloyd G. and Thomas Taber. 1973. "Postdiction Study of the Graduate Record Examination and Eight Semesters of College Grades." Journal of Educational Measurement 10(3):179-84.

Jackson, Douglas Northrop. 1974. Personality Research Form Manual. Goshen, N.Y: Research Psychologists Press.

James, William. 1890. The Principles of Psychology. New York, NY: H. Holt and Company. Jensen, Arthur R. 1980. Bias in Mental Testing. New York: Free Press. 1998. The g Factor: The Science of Mental Ability. Westport, CT: Praeger.

Jianakoplos, Nancy Ammon, and Alexandra Bernasek. 1998. "Are Women More Risk Averse?" Economic Inquiry 36(4):620-30.

John, Oliver P. 1990. "The "Big Five" Factor Taxonomy: Dimensions of Personality in the Natural Language and in Questionnaires." In Handbook of Personality: Theory and Research, ed. Lawrence A. Pervin and Oliver P. John, 66-100. New York, NY: Guilford Press.

John, Oliver P., Avshalom Caspi, Richard W. Robins, and Terrie E. Moffitt. 1994. "The "Little Five": Exploring the Nomological Network of the Five-Factor Model of Personality in Adolescent Boys." Child Development 65(1):160-78. 
John, Oliver P. and Sanjay Srivastava. 1999. "The Big Five Trait Taxonomy: History, Measurement and Theoretical." In Handbook of Personality: Theory and Research, ed. Lawrence A. Pervin and Oliver P. John, 102-38. New York: The Guilford Press.

Johnsen, Thore H. and John B. Donaldson. 1985. "The Structure of Intertemporal Preferences Under Uncertainty and Time Consistent Plans." Econometrica 53(6):1451-8.

Johnson, Matthew W. and Warren K. Bickel. 2002. "Within-Subject Comparison of Real and Hypothetical Money Rewards in Delay Discounting." Journal of the Experimental Analysis of Behavior 77(2):129-46.

Judge, Timothy A. and Joyce E. Bono. 2001. "Relationship of Core Self-Evaluations Traits-Self-Esteem, Generalized Self-Efficacy, Locus of Control, and Emotional Stability--with Job Satisfaction and Job Performance: A Meta-Analysis." Journal of Applied Psychology 86(1):80-92.

Judge, Timothy A. and Charlice Hurst. 2007. "Capitalizing on One's Advantages: Role of Core Self-Evaluations." Journal of Applied Psychology 92(5):1212-27.

Judge, Timothy A., Edwin A. Locke, and Cathy C. Durham. 1997. "The Dispositional Causes of Job Satisfaction: A Core Evaluation Approach." Research in Organizational Behavior 19:151-88.

Kahneman, Daniel. 2003. "Maps of Bounded Rationality: Psychology for Behavioral Economics." American Economic Review 93(5):1449-75.

Kahneman, Daniel, Ilana Ritov, and David A. Schkade. 1999. "Economic Preferences Or Attitude Expressions? an Analysis of Dollar Responses to Public Issues." Journal of Risk and Uncertainty 19(1):203-35. 
Kaplan, Robert M. and Dennis P. Saccuzzo. 1997. Psychological Testing: Principles, Applications, and Issues. Pacific Grove, CA: Brooks/Cole Pub. Co.

Killingsworth, Mark R. 1985. "Substitution and Output Effects on Labor Demand: Theory and Policy Applications." Journal of Human Resources 20(1):142-52.

Kirby, Kris N. 1997. "Bidding on the Future: Evidence Against Normative Discounting of Delayed Rewards." Journal of Experimental Psychology: General 126(1):54-70.

Kirby, Kris N. and Nino N. Marakovic. 1996. "Delay-Discounting Probabilistic Rewards: Rates Decrease as Amounts Increase." Psychonomic Bulletin \& Review 3(1):100-4.

Knudsen, Eric I., James J. Heckman, Judy L. Cameron, and Jack Shonkoff. 2006. "Economic, Neurobiological, and Behavioral Perspectives on Building America's Future Workforce." Proceedings of the National Academy of Sciences 103(27):10155-62.

Kohn, Melvin L. and Carmi Schooler. 1978. "The Reciprocal Effects of the Substantive Complexity of Work and Intellectual Flexibility: A Longitudinal Assessment." The American Journal of Sociology 84(1):24-52.

Kreps, David M. and Evan L. Porteus. 1978. "Temporal Resolution of Uncertainty and Dynamic Choice Theory." Econometrica 46(1):185-200.

Kristensen, Petter and Tor Bjerkedal. 2007. "Explaining the Relation between Birth Order and Intelligence." Science 316(5832):1717.

Krueger, Alan B. and David A. Schkade. 2007. "Sorting in the Labor Market: Do Gregarious Workers Flock to Interactive Jobs?" NBER Working Papers 13032. Cambridge, MA: National Bureau of Economic Research. 
Krueger, Robert F., Susan South, Wendy Johnson, and William G. Iacono. 2008. "The Heritability of Personality is Not always 50\%: Gene-Environment Interactions and Correlations between Personality and Parenting." Journal of Personality Forthcoming.

Kyllonen, Patrick C., Alyssa M. Walters, and James C. Kaufman. 2005. "Noncognitive Constructs and their Assessment in Graduate Education: A Review." Educational Assessment 10(3):153-84.

Laferrère, Anne and François-Charles Wolff. 2006. "Microeconomic Models of Family Transfers." In Handbook on the Economics of Giving, Reciprocity and Altruism, ed. Serge-Christophe Kolm and Jean Mercier Ythier, 889-969. Amsterdam: Elsevier. LaHuis, David M., Nicholas R. Martin, and John M. Avis. 2005. "Investigating Nonlinear Conscientiousness-Job Performance Relations for Clerical Employees." Human Performance 18(3):199-212.

Laibson, David I. 1998. "Life-Cycle Consumption and Hyperbolic Discount Functions." European Economic Review 42(3-5):861-71.

Laitner, John. 1997. "Intergenerational and Interhousehold Economic Links." In Handbook of Population and Family Economics, ed. Mark R. Rosenzweig and Oded Stark, 189-238. Amsterdam: Elsevier.

Larson, Gerald E., Dennis P. Saccuzzo, and James Brown. 1994. "Motivation: Cause Or Confound in Information processing/intelligence Correlations?" Acta Psychologica $85(1): 25-37$.

Larson, Lisa M., Patrick J. Rottinghaus, and Fred H. Borgen. 2002. "Meta-Analyses of Big Six Interests and Big Five Personality Factors." Journal of Vocational Behavior 61(2):21739. 
Lejuez, C. W., Will M. Aklin, Michael J. Zvolensky, and Christina M. Pedulla. 2003.

"Evaluation of the Balloon Analogue Risk Task (BART) as a Predictor of Adolescent Real-World Risk-Taking Behaviours." Journal of Adolescence 26(4):475-9.

Lejuez, C. W., Jennifer P. Read, Christopher W. Kahler, Jerry B. Richards, Susan E. Ramsey, Gregory L. Stuart, David R. Strong, and Richard A. Brown. 2002. "Evaluation of a Behavioral Measure of Risk Taking: The Balloon Analogue Risk Task (BART)." Journal of Experimental Psychology: Applied 8(2):75-84.

Levitt, Steven D. and John A. List. 2007a. "Viewpoint: On the Generalizability of Lab Behaviour to the Field." Canadian Journal of Economics 40(2):347-70. . 2007b. "What do Laboratory Experiments Measuring Social Preferences Reveal about the Real World?" Journal of Economic Perspectives 21(2):153-74.

Lin, Pangchieh and Lloyd G. Humphreys. 1977. "Predictions of Academic Performance in Graduate and Professional School." Applied Psychological Measurement 1(2):249-57.

List, John A. 2004. "Testing Neoclassical Competitive Theory in Multilateral Decentralized Markets." Journal of Political Economy 112(5):1131-56. . 2006. "Friend Or Foe? A Natural Experiment of the Prisoner's Dilemma." Review of Economics and Statistics 88(3):463-71. . 2007. "On the Interpretation of Giving in Dictator Games." Journal of Political Economy 115(3):482-93.

Lizzeri, Alessandro and Marciano Siniscalchi. 2006. "Parental Guidance and Supervised Learning." Northwestern University, Center for Mathematical Studies in Economics and Management Science. 
Loewenstein, George F. and Drazen Prelec. 1991. "Negative Time Preference." The American Economic Review 81(2):347-52.

Loewenstein, George F., Elke U. Weber, Christopher K. Hsee, and Ned Welch. 2001. "Risk as Feelings." Psychological Bulletin 127(2):267-86.

Lord, Frederic M. and Melvin R. Novick. 1968. Statistical Theories of Mental Test Scores. Reading, MA: Addison-Wesley Publishing Company.

Low, K. S. Douglas and James Rounds. 2006. "Vocational Interests." In Comprehensive Handbook of Personality and Psychopathology, ed. Michel Hersen and Jay C. Thomas, 251-67. Hoboken, NJ: John Wiley and Sons.

Lubinski, David. 2004. "Introduction to the Special Section on Cognitive Abilities: 100 Years After Spearman's (1904) "'General Intelligence," Objectively Determined and Measured'." Journal of Personality and Social Psychology 86(1):96-111.

Lykken, David T. 2007. "A More Accurate Estimate of Heritability." Twin Research and Human Genetics 10(1):168-73.

Madden, Gregory J., Andrea M. Begotka, Bethany R. Raiff, and Lana L. Kastern. 2003. "Delay Discounting of Real and Hypothetical Rewards." Experimental and Clinical Psychopharmacology 11(2):139-45.

Mandelbrot, Benoit B. 1961. "Stable Paretian Random Functions and the Multiplicative Variation of Income." Econometrica 29(4):517-43. . 1962. "Paretian Distributions and Income Maximization." Quarterly Journal of Economics 76(1):57-85.

Marschak, Jacob. 1953. "Economic Measurements for Policy and Prediction." In Studies in Econometric Method, ed. W. Hood and T. Koopmans, 1-26. New York: Wiley. 
. 1960. "Binary Choice Constraints and Random Utility Indicators." In

Mathematical Methods in the Social Sciences: Proceedings of the First Stanford

Symposium, ed. Kenneth Arrow, Samuel Karlin and Patrick Suppes, 312-29. Stanford,

CA: Stanford University Press.

Mas-Colell, Andreu, Michael Dennis Whinston, and Jerry R. Green. 1995. Microeconomic

Theory. New York: Oxford University Press.

Mayer, John D. and Peter Salovey. 1997. "What is Emotional Intelligence?" In Emotional

Development and Emotional Intelligence: Educational Implications, ed. Peter Salovey and David J. Sluyter, 3-34. New York, NY: Basic Books.

McAdams, Dan P. 2006. The Person: A New Introduction to Personality Psychology. Hoboken, NJ: J. Wiley \& Sons.

McAdams, Dan P. and Jennifer L. Pals. 2006. "A New Big Five: Fundamental Principles for an Integrative Science of Personality." American Psychologist 61(3):204-17.

McCabe, Lisa A., Marisol Cunnington, and Jeanne Brooks-Gunn. 2004. "The Development of Self-Regulation in Young Children: Individual Characteristics and Environmental Contexts." In Handbook of Self-Regulation: Research, Theory, and Applications, ed. Roy F. Baumeister and Kathleen D. Vohs, 340-56. New York, NY: Guilford Press.

McClelland, David C. 1973. "Testing for Competence rather than for 'Intelligence'." American Psychologist 28(1):1-14.

McClelland, David C., Richard Koestner, and Joel Weinberger. 1989. "How do Self-Attributed and Implicit Motives Differ?" Psychological Review 96(4):690-702.

McClure, Samuel M., David I. Laibson, George F. Loewenstein, and Jonathan D. Cohen. 2004. Science 306(5695):503-7. 
McCrae, Robert R. and Paul T. Costa. 1990. Personality in Adulthood. New York: Guilford Press.

. 1994. "The Stability of Personality: Observation and Evaluations." Current Directions in Psychological Science 3(6):173-5.

. 1996. "Toward a New Generation of Personality Theories: Theoretical Contexts for the Five-Factor Model." In The Five-Factor Model of Personality: Theoretical Perspectives, ed. Jerry S. Wiggins, 51-87. New York, NY: Guilford Press. 2003. Personality in Adulthood: A Five-Factor Theory Perspective. New York: Guilford Press.

McFadden, Daniel. 1974. "Conditional Logit Analysis of Qualitative Choice Behavior." In Frontiers in Econometrics, ed. Paul Zarembka, 105-42. New York: Academic Press. . 1981. "Econometric Models of Probabilistic Choice." In Structural Analysis of Discrete Data with Econometric Applications, ed. Charles F. Manski and Daniel McFadden, 198-272. Cambridge, MA: MIT Press.

McGue, Matt, Steven Bacon, and David T. Lykken. 1993. "Personality Stability and Change in Early Adulthood: A Behavioral Genetic Analysis." Developmental Psychology 29(1):96109.

McGue, Matt, Thomas J. Bouchard, William G. Iacono, and David T. Lykken. 1993. "Behavioral Genetics of Cognitive Ability: A Life-Span Perspective." In Nature, Nurture and Psychology, ed. Robert Plomin and Gerald E. McClearn, 59-76. Washington, DC: American Psychological Association. 
Meier, Stephan. 2007. "A Survey of Economic Theories and Field Evidence on Pro-Social Behavior." In Economics and Psychology: A Promising New Field, ed. Bruno S. Frey and Alois Stutzer, 51-88. Cambridge, MA: MIT Press.

Mershon, Bryan and Richard L. Gorsuch. 1988. "Number of Factors in the Personality Sphere: Does Increase in Factors Increase Predictability of Real-Life Criteria?" Journal of Personality and Social Psychology 55(4):675-80.

Michael, Robert T. 1973. "Education in Nonmarket Production." Journal of Political Economy 81(2):306-27.

Miller, Earl K. and Jonathan D. Cohen. 2001. "An Integrative Theory of Prefrontal Cortex Function." Annual Review of Neuroscience 24(1):167-202.

Mischel, Walter. 1968. Personality and Assessment. New York: Wiley.

Mischel, Walter and Ralph Metzner. 1962. "Preference for Delayed Reward as a Function of Age, Intelligence, and Length of Delay Interval." The Journal of Abnormal and Social Psychology 64(6):425-31.

Mischel, Walter and Yuichi Shoda. 1998. "Reconciling Processing Dynamics and Personality Dispositions." Annual Review of Psychology 49:229-58.

Mischel, Walter, Yuichi Shoda, and Philip K. Peake. 1988. "The Nature of Adolescent Competencies Predicted by Preschool Delay of Gratification." Journal of Personality and Social Psychology 54(4):687-96.

Mischel, Walter, Yuichi Shoda ,and Monica L. Rodriguez. 1989. "Delay of Gratification in Children." Science 244(4907):933-8. 
Moffitt, Terrie E., Avshalom Caspi, and Michael Rutter. 2005. "Strategy for Investigating Interactions between Measured Genes and Measured Environments." Archives of General Psychiatry 62(5):473-81.

Morgeson, Frederick P., Michael A. Campion, Robert L. Dipboye, John R. Hollenbeck, Kevin Murphy, and Neal Schmitt. 2007. "Reconsidering the use of Personality Tests in Personnel Selection Contexts." Personnel Psychology 60(3):683-729.

Moutafi, Joanna, Adrian Furnham, and Ioannis Tsaousis. 2006. "Is the Relationship between Intelligence and Trait Neuroticism Mediated by Test Anxiety?" Personality and Individual Differences 40(3):587-97.

Mueller, Gerrit and Erik Plug. 2006. "Estimating the Effect of Personality on Male and Female Earnings." Industrial and Labor Relations Review 60(1):3-22.

Mueser, Peter R. 1979. "The Effects of Noncognitive Traits." In Who Gets Ahead? the Determinants of Economic Success in America, ed. Christopher Jencks, Susan Bartlett, Mary Corcoran, James Crouse, David Eaglesfield, Gregory Jackson, Kent McClelland, Peter Mueser, Michael Olneck, Joseph Schwartz, Sherry Ward and Jill Williams, 122-58. New York, NY: Basic Books.

Mulligan, Casey B. 1997. Parental Priorities and Economic Inequality. Chicago: University of Chicago Press.

Murray, Henry Alexander. 1938. Explorations in Personality: A Clinical and Experimental Study of Fifty Men of College Age. New York, London: Oxford University Press.

Neisser, Ulric Chair, Gwyneth Boodoo, Thomas J. Bouchard, A. Wade Boykin, Nathan Brody, Stephen J. Ceci, Diane F. Halpern, John C. Loehlin, Robert Perloff, Robert J. Sternberg 
and Susana Urbina. 1996. "Intelligence: Knowns and Unknowns." American Psychologist 51(2):77-101.

Newman, Denise L., Avshalom Caspi, Terrie E. Moffitt, and Phil A. Silva. 1997. "Antecedents of Adult Interpersonal Functioning: Effects of Individual Differences in Age 3 Temperament." Developmental Psychology 33(2):206-17.

Noftle, Erik E. and Richard W. Robins. 2007. "Personality Predictors of Academic Outcomes: Big Five Correlates of GPA and SAT Scores." Journal of Personality and Social Psychology 93(1):116-30.

Nyhus, Ellen K. and Empar Pons. 2005. "The Effects of Personality on Earnings." Journal of Economic Psychology 26(3):363-84.

Olson, Sheryl L., Elizabeth M. Schilling, and John E. Bates. 1999. "Measurement of Impulsivity: Construct Coherence, Longitudinal Stability, and Relationship with Externalizing Problems in Middle Childhood and Adolescence." Journal of Abnormal Child Psychology 27(2):151-65.

Ones, Deniz S., Stephan Dilchert, Chockalingam Viswesvaran, and Timothy A. Judge. 2007. "In Support of Personality Assessment in Organizational Settings." Personnel Psychology In press.

Ones, Deniz S. and Chockalingam Viswesvaran. 1998. "The Effects of Social Desirability and Faking on Personality and Integrity Assessment for Personnel Selection." Human Performance 11(2-3):245-69.

Ozer, Daniel J. 1986. Consistency in Personality: A Methodological Framework. Berlin ; New York: Springer-Verlag. 
Pailing, Patricia E. and Sidney J. Segalowitz. 2004. "The Error-Related Negativity as a State and Trait Measure: Motivation, Personality, and ERPs in Response to Errors." Psychophysiology 41(1):84-95.

Paulhus, Delroy L. 1984. "Two-Component Models of Socially Desirable Responding." Journal of Personality and Social Psychology 46(3):598-609.

Paunonen, Sampo V. and Michael C. Ashton. 2001. "Big Five Predictors of Academic Achievement." Journal of Research in Personality 35(1):78-90.

Pencavel, John H. 1986. "Labor Supply of Men: A Survey." In Handbook of Labor Economics, ed. Orley Ashenfelter and Richard Layard, 3-102. Amsterdam: North-Holland.

Perkins, David N. and Shari Tishman. 2001. "Dispositional Aspects of Intelligence." In Intelligence and Personality: Bridging the Gap in Theory and Measurement, ed. Janet M. Collis and Samuel Messick, 233-57. Mahwah, NJ: Lawrence Erlbaum Associates.

Peters, Ellen, Daniel Vastfjall, Paul Slovic, C. K. Mertz, Ketti Mazzocco, and Stephan Dickert. 2006. "Numeracy and Decision Making." Psychological Science 17(5):407-13.

Phelps, Edmund S. and Robert A. Pollak. 1968. "On Second-Best National Saving and GameEquilibrium Growth." Review of Economic Studies 35(2):185-99.

Phelps, Elizabeth A. 2006. "Emotion and Cognition: Insights from Studies of the Human Amygdala." Annual Review of Psychology 57:27-53.

Plomin, Robert, John C. DeFries, Ian W. Craig and Peter McGuffin. 2002. Behavioral Genetics in the Postgenomic Era. Washington, D.C.: American Psychological Association.

Plomin, Robert and John R. Nesselroade. 1990. "Behavioral Genetics and Personality Change." Journal of Personality 58(1):191-220. 
Pollak, Robert A. and Michael L. Wachter. 1975. "The Relevance of the Household Production Function and its Implications for the Allocation of Time." The Journal of Political Economy 83(2):255-78.

Posner, Michael I. and Mary K. Rothbart. 2000. "Developing Mechanisms of Self-Regulation." Development and Psychopathology 12(3):427-41.

Putnam, Samuel P., Lesa K. Ellis and Mary K. Rothbart. 2001. "The Structure of Temperament from Infancy through Adolescence." In Advances in Research on Temperament, ed. Andrzej Eliasz and Alois Angleitner, 165-82. Lengerich, Germany: Pabst Science Publishers.

Rachlin, Howard. 2004. The Science of Self-Control. Cambridge, MA: Harvard University Press. . 2006. "Notes on Discounting." Journal of the Experimental Analysis of Behavior 85(3):425-35.

Raven, John C. 1962. Advanced Progressive Matrices: Sets I and II. London: H.K. Lewis.

Raver, C. Cybele and Edward F. Zigler. 1997. "Social Competence: An Untapped Dimension in Evaluating Head Start's Success." Early Childhood Research Quarterly 12(4):363-85.

Read, Daniel and Nicoleta Liliana Read. 2004. "Time Discounting Over the Lifespan." Organizational Behavior and Human Decision Processes 94(1):22-32.

Revelle, William. 1997. "Extraversion and Impulsivity: The Lost Dimension?" In The Scientific Study of Human Nature: Tribute to Hans J. Eysenck at Eighty, ed. Helmuth Nyborg, 189212. Amsterdam: Pergamon/Elsevier Science.

Reynolds, Brady and Ryan Schiffbauer. 2005. "Delay of Gratification and Delay Discounting: A Unifying Feedback Model of Delay-Related Impulsive Behavior." Psychological Record 55(3):439-60. 
Rindermann, Heiner. 2007. "The g-Factor of International Cognitive Ability Comparisons: The Homogeneity of Results in PISA, TIMSS, PIRLS and IQ-Tests Across Nations." European Journal of Personality 21(5):667-706.

Robbins, Steven B., Jeff Allen, Alex Casillas, Christina Hamme Peterson, and Huy Le. 2006. "Unraveling the Differential Effects of Motivational and Skills, Social, and SelfManagement Measures from Traditional Predictors of College Outcomes." Journal of Educational Psychology 98(3):598-616.

Roberts, Brent W. 1997. "Plaster Or Plasticity: Are Adult Work Experiences Associated with Personality Change in Women?" Journal of Personality 65(2):205-32. . 2007. "Contextualizing Personality Psychology." Journal of Personality 75(6):1071-82.

Roberts, Brent W. and Christopher N. Chapman. 2000. "Change in Dispositional Well-being and its Relation to Role Quality: A 30-Year Longitudinal Study." Journal of Research in Personality 34(1):26-41.

Roberts, Brent W., Oleksandr S. Chernyshenko, Stephen Stark, and Lewis R. Goldberg. 2005a. "The Structure of Conscientiousness: An Empirical Investigation Based on Seven Major Personality Questionnaires." Personnel Psychology 58(1):103-39.

Roberts, Brent W. and Wendy F. DelVecchio. 2000. "The Rank-Order Consistency of Personality Traits from Childhood to Old Age: A Quantitative Review of Longitudinal Studies." Psychological Bulletin 126(1):3-25.

Roberts, Brent W., Peter Harms, Jennifer L. Smith, Dustin Wood, and Michelle Webb. 2006. "Using Multiple Methods in Personality Psychology." In Handbook of Multimethod 
Measurement in Psychology, ed. Michael Eid and Ed Diener, 321-35. Washington, DC: American Psychological Association.

Roberts, Brent W., Ravenna Helson, and Eva C. Klohnen. 2002. "Personality Development and Growth in Women Across 30 Years: Three Perspectives." Journal of Personality 70(1):79-102.

Roberts, Brent W., Nathan R. Kuncel, Rebecca L. Shiner, Avshalom Caspi, and Lewis R. Goldberg. 2007. "The Power of Personality: The Comparative Validity of Personality Traits, Socioeconomic Status, and Cognitive Ability for Predicting Important Life Outcomes." Perspectives on Psychological Science 2(4):313-45.

Roberts, Brent W., Kate E. Walton, and Wolfgang Viechtbauer. 2006. "Patterns of Mean-Level Change in Personality Traits Across the Life Course: A Meta-Analysis of Longitudinal Studies." Psychological Bulletin 132(1):1-25.

Roberts, Brent W., Dustin Wood, and Avshalom Caspi. 2008. "Personality Development." In Handbook of Personality: Theory and Research, ed. Oliver P. John, Richard W. Robins and Lawrence A. Pervin, New York, NY: Guilford Press.

Roberts, Richard D., Pippa M. Markham, Gerald Matthews, and Moshe Zeidner. 2005 b.

"Assessing Intelligence: Past, Present, and Future." In Handbook of Understanding and Measuring Intelligence, ed. Oliver Wilhelm and Randall W. Engle, 333-60. Thousand Oaks, CA: Sage Publications, Inc.

Rosen, Sherwin. 1974. "Hedonic Prices and Implicit Markets: Product Differentiation in Pure Competition." Journal of Political Economy 82(1):34-55. 
Rothbart, Mary K., Stephan A. Ahadi, and David E. Evans. 2000. "Temperament and Personality: Origins and Outcomes." Journal of Personality and Social Psychology $78(1): 122-35$.

Roy, A. D. 1951. "Some Thoughts on the Distribution of Earnings." Oxford Economic Papers $3(2): 135-46$.

Ruderman, Henry, Mark D. Levine, and James E. McMahon. 1987. "The Behavior of the Market for Energy Efficiency in Residential Appliances Including Heating and Cooling Equipment." Energy Journal 8(1):101-24.

Rutter, Michael. 2006. "Implications of Resilience Concepts for Scientific Understanding." In Resilience in Children, ed. Barry M. Lester, Ann Masten and Bruce McEwen, 1-12. Malden, MA: Blackwell Publishing.

Sahm, Claudia R. 2007. "Does Risk Tolerance Change?" Unpublished manuscript, Department of Economics. University of Michigan.

Salanié, Bernard. 1997. The Economics of Contracts: A Primer. Cambridge, MA: MIT Press. Salgado, Jesus F. 1997. "The Five Factor Model of Personality and Job Performance in the European Community." Journal of Applied Psychology 82(1):30-43.

Samuelson, Paul A. 1937. "A Note on Measurement of Utility." The Review of Economic Studies $4(2): 155-61$. 1947. Foundations of Economic Analysis. Cambridge: Harvard University Press. Sanderson, Warren. 1974. "Does the Theory of Demand Need the Maximum Principle?" In Nations and Households in Economic Growth: Essays in Honor of Moses Ambramovitz, ed. Moses Abramovitz, Paul A. David and Melvin W. Reder, 173-221. New York, NY: Academic Press. 
Sattinger, Michael. 1979. "Differential Rents and the Distribution of Earnings." Oxford Economic Papers 31(1):60-71. . 1993. "Assignment Models of the Distribution of Earnings." Journal of Economic Literature 31(2):831-80.

Scarr, Sandra, Richard A. Weinberg, and Irwin D. Waldman. 1993. "IQ Correlations in Transracial Adoptive Families." Intelligence 17(4):541-56.

Schaie, Klaus Warner. 1994. "The Course of Adult Intellectual Development." American Psychologist 49(4):304-13.

Schmeichel, Brandon J., Kathleen D. Vohs, and Roy F. Baumeister. 2003. "Intellectual Performance and Ego Depletion: Role of the Self in Logical Reasoning and Other Information Processing." Journal of Personality and Social Psychology 85(1):33-46.

Schmidt, Frank L. and John E. Hunter. 1998. "The Validity and Utility of Selection Methods in Personnel Psychology: Practical and Theoretical Implications of 85 Years of Research Findings." Psychological Bulletin 124(2):262-74. . 2004. "General Mental Ability in the World of Work: Occupational Attainment and Job Performance." Journal of Personality and Social Psychology 86(1):162-73.

Schooler, Carmi, Mesfin Samuel Mulatu and Gary Oates. 1999. "The Continuing Effects of Substantively Complex Work on the Intellectual Functioning of Older Workers." Psychology and Aging 14(3):483-506.

Schuck, Sabrina E. B. and Francis M. Crinella. 2005. "Why Children with ADHD do Not have Low IQs." Journal of Learning Disabilities 38(3):262-80.

Schuerger, James M. and Anita C. Witt. 1989. "The Temporal Stability of Individually Tested Intelligence." Journal of Clinical Psychology 45(2):294-302. 
Schulkin, Jay. 2007. "Effort and Will: A Cognitive Neuroscience Perspective." Mind and Matter 5:111-26.

Schwartz, Shalom H. 1992. "The Universal Content and Structure of Values: Theoretical Advances and Empirical Tests in 20 Countries." Advances in Experimental Social Psychology 25:1-62.

Schweinhart, Lawrence J., Jeanne Montie, Zongping Xiang, W. Steven Barnett, Clive R. Belfield, and Milagros Nores. 2005. Lifetime Effects: The High/Scope Perry Preschool Study through Age 40. Ypsilanti, MI: High/Scope Press.

Segal, Carmit. 2006. "Motivation, Test Scores and Economic Success." Working paper. Harvard Business School.

Shamosh, Noah and Jeremy R. Gray. 2007. "Delay Discounting and Intelligence: A MetaAnalysis." Unpublished manuscript. Department of Psychology, Yale University.

Shiner, Rebecca L. 1998. "How Shall we Speak of Children's Personalities in Middle Childhood? A Preliminary Taxonomy." Psychological Bulletin 124(3):308-32.

Shiner, Rebecca L. and Avshalom Caspi. 2003. "Personality Differences in Childhood and Adolescence: Measurement." Journal of Child Psychology and Psychiatry 44(1):2-32.

Shoda, Yuichi, Walter Mischel and Philip K. Peake. 1990. "Predicting Adolescent Cognitive and Self-Regulatory Competencies from Preschool Delay of Gratification: Identifying Diagnostic Conditions." Developmental Psychology 26(6):978-86.

Siegler, Robert S. 1992. "The Other Alfred Binet." Developmental Psychology 28(2):179-90. Siniscalchi, Marciano. 2006. "Dynamic Choice Under Ambiguity." Unpublished manuscript. Northwestern University, Department of Economics. 
Smith, Mary Lee, Gene V. Glass, and Thomas I. Miller. 1980. The Benefits of Psychotherapy. Baltimore: Johns Hopkins University Press.

Spear, Linda Patia. 2000a. "The Adolescent Brain and Age-Related Behavioral Manifestations." Neuroscience \& Biobehavioral Reviews 24(4):417-63. . 2000b. "Neurobehavioral Changes in Adolescence." Current Directions in Psychological Science 9(4):111-4.

Spearman, Charles. 1904. "'General Intelligence,' Objectively Determined and Measured." American Journal of Psychology 15:201-93. 1927. The Abilities of Man; their Nature and Measurement. New York: The Macmillan Company.

Stankov, Lazar. 2005. "G Factor: Issues of Design and Interpretation." In Handbook of Understanding and Measuring Intelligence, ed. Oliver Wilhelm and Randall W. Engle, 279-93. Thousand Oaks, CA: Sage Publications, Inc.

Stanovich, Keith E. 1999. Who is Rational? : Studies of Individual Differences in Reasoning. Mahwah, N.J: Lawrence Erlbaum Associates.

Starmer, Chris. 2000. "Developments in Non-Expected Utility Theory: The Hunt for a Descriptive." Journal of Economic Literature 38(2):332-82.

Steinberg, Laurence. 2004. "Risk Taking in Adolescence: What Changes, and Why?" Annals of the New York Academy of Sciences 1021(1):51-8. . 2007. "Risk Taking in Adolescence: New Perspectives from Brain and Behavioral Science." Current Directions in Psychological Science 16(2):55-9.

Sternberg, Robert J. 2000. Practical Intelligence in Everyday Life. New York, NY: Cambridge University Press. 
2001. "Successful Intelligence: Understanding what Spearman had rather than what

He Studied." In Intelligence and Personality: Bridging the Gap in Theory and

Measurement, ed. Janet M. Collis and Samuel Messick, 347-73. Mahwah, NJ: Lawrence

Erlbaum Associates.

Strotz, Robert H. 1955. "Myopia and Inconsistency in Dynamic Utility Maximization." The Review of Economic Studies 23(3):165-80.

Tellegen, Auke. 1985. "Structures of Mood and Personality and their Relevance to Assessing Anxiety, with an Emphasis on Self-Report." In Anxiety and the Anxiety Disorders, ed. A. Hussain Tuma and Jack D. Maser, 681-706. Hillsdale, NJ: Lawrence Erlbaum Associates. Terman, Lewis Madison. 1916. The Measurement of Intelligence: An Explanation of and a Complete Guide for the use of the Stanford Revision and Extension of the Binet-Simon Intelligence Scale. Boston: Houghton Mifflin Co.

Terman, Lewis Madison and Maud A. Merrill. 1960. Stanford-Binet Intelligence Scale: Manual for the Third Revision Form L-M. Boston: Houghton Mifflin.

Tett, R. P. and N. D. Christiansen. 2007. "Personality Tests at the Crossroads: A Response to Morgeson, Campion, Dipboye, Hollenbeck, Murphy and Schmidt." Personnel Psychology In press.

Teulings, Coen N. 1995. "The Wage Distribution in a Model of the Assignment of Skills to Jobs." Journal of Political Economy 103(2):280-315. 2005. "Comparative Advantage, Relative Wages, and the Accumulation of Human Capital." Journal of Political Economy 113(2):425-61. 
Thomas, Ewart A. and Wanda E. Ward. 1984. "Time Orientation, Time Preference and Spending Behavior." Department of Psychology Research Report 1296A. Palo Alto, CA: Stanford University.

Thurstone, Lewis. 1927. "A Law of Comparative Judgement." Psychological Review 34:273-86. Tinbergen, Jan. 1956. "On the Theory of Income Distribution." Weltwirtschaftliches Archiv 77:155-73.

Turkheimer, Eric, Andreana Haley, Mary Waldron, Brian D'Onofrio and Irving I. Gottesman. 2003. "Socioeconomic Status Modifies Heritability of IQ in Young Children." Psychological Science 14(6):623-8.

Tversky, Amos. 1972a. "Choice by Elimination." Journal of Mathematical Psychology 9(4):34167. . 1972b. "Elimination by Aspects: A Theory of Choice." Psychological Review 79(4):281-99.

Urzua, Sergio. 2007. "Racial Labor Market Gaps: The Role of Abilities and Schooling Choices." Journal of Human Resources Forthcoming.

Uylings, Harry B. M. 2006. "Development of the Human Cortex and the Concept of "Critical" Or "Sensitive" Periods." Language Learning 56(Suppl 1):59-90.

van Praag,Bernard M. S. 1985. "Linking Economics with Psychology: An Economist's View." Journal of Economic Psychology 6(3):289-311.

van Praag,Bernard M. S. and J. van Weeren. 1988. "Memory and Anticipation Processes and their Significance for Social Security and Income Inequality." In Applied Behavioural Economics. Volume 2. ed. Shlomo Maital, 731-51. New York, NY: New York University Press. 
Various. 2007. "Monographs for the Society for Research in Child Development." Volume 72, number 3 .

Vaughn, Brian E., Claire B. Kopp, and Joanne B. Krakow. 1984. "The Emergence and Consolidation of Self-Control from Eighteen to Thirty Months of Age: Normative Trends and Individual Differences." Child Development 55(3):990-1004.

Villanueva, Ernesto. 2005. "Inter Vivos Transfers and Bequests in Three OECD Countries." Economic Policy (43):505-49.

Viswesvaran, Chockalingam and Deniz S. Ones. 1999. "Meta-Analyses of Fakability Estimates: Implications for Personality Measurement." Educational and Psychological Measurement 59(2):197-210.

Webb, Edward. 1915. "Character and Intelligence." British Journal of Psychology 1(3):1-99.

Weber, Elke U. 2001. "Personality and Risk Taking." In International Encyclopedia of the Social and Behavioral Sciences, ed. Neil J. Smelser and Paul B. Baltes, 11274-6. Oxford: Pergamon.

Weber, Elke U., AnnRenee Blais, and Nancy E. Betz. 2002. "A Domain-Specific Risk-Attitude Scale: Measuring Risk Perceptions and Risk Behaviors." Journal of Behavioral Decision Making 15(4):263-90.

Weber, Elke U. and Christopher Hsee. 1998. "Cross-Cultural Differences in Risk Perception, but Cross-Cultural Similarities in Attitudes Towards Perceived Risk." Management Science 44(9):1205-17.

Weber, Elke U. and Richard A. Milliman. 1997. "Perceived Risk Attitudes: Relating Risk Perception to Risky Choice." Management Science 43(2):123-44. 
Wechsler, David. 1939. The Measurement of Adult Intelligence. Baltimore, MD: Williams \& Wilkins Co.

. 1940. "Nonintellective Factors in General Intelligence." Psychological Bulletin

$37: 444-5$.

Weiss, Andrew. 1991. Efficiency Wages: Models of Unemployment, Layoffs, and Wage

Dispersion. New York, NY: Clarendon Press.

Weiss, Yoram. 1972. "The Risk Element in Occupational and Educational Choices." Journal of Political Economy 80(6):1203-13.

Welsh, Marilyn C., Bruce F. Pennington, and Dena B. Groisser. 1991. "A NormativeDevelopmental Study of Executive Function: A Window on Prefrontal Function in Children." Developmental Neuropsychology 7(2):131-49.

White, Jennifer L., Terrie E. Moffitt, Avshalom Caspi, Dawn Jeglum Bartusch, Douglas J. Needles, and Magda Stouthamer-Loeber. 1994. "Measuring Impulsivity and Examining its Relationship to Delinquency." Journal of Abnormal Psychology 103(2):192-205.

Whiteside, Stephen P., Donald R. Lynam, Joshua D. Miller, and Sarah K. Reynolds. 2005. "Validation of the UPPS Impulsive Behaviour Scale: A Four-Factor Model of Impulsivity." European Journal of Personality 19(7):559-74.

Wiggins, Jerry S. and Aaron L. Pincus. 1989. "Conceptions of Personality Disorders and Dimensions of Personality." Psychological Assessment 1(4):305-16.

Willingham, Warren W. 1985. Success in College: The Role of Personal Qualities and Academic Ability. New York, NY: College Entrance Examination Board.

Willis, Robert J. and Sherwin Rosen. 1979. "Education and Self-Selection." Journal of Political Economy 87(5, Part 2):S7-S36. 
Wittmann, Werner W. 2002. "Work Motivation and Level of Performance: A Disappointing Relationship?" Unpublished manuscript. University of Mannheim. Presented: XXV International Congress of Applied psychology Singapore, July 2002 at the Symposium "Integrative Approaches to Work Motivation: Ability and Non-ability Determinants of Regulatory Processes, Learning, and Performance"

Wolfe, Raymond N. and Scott D. Johnson. 1995. "Personality as a Predictor of College Performance." Educational and Psychological Measurement 55(2):177-85.

Wong, Maria M. and Mihaly Csikszentmihalyi. 1991. "Motivation and Academic Achievement: The Effects of Personality Traits and the Quality of Experience." Journal of Personality 59(3):539-74.

Zigler, Edward F. and Earl C. Butterfield. 1968. "Motivational Aspects of Changes in IQ Test Performance of Culturally Deprived Nursery School Children." Child Development 39(1):1-14.

Zuckerman, Marvin. 1994. Behavioral Expressions and Biosocial Bases of Sensation Seeking. New York, NY: Cambridge University Press. 2007. Sensation Seeking and Risky Behavior. Washington, DC: American Psychological Association. 


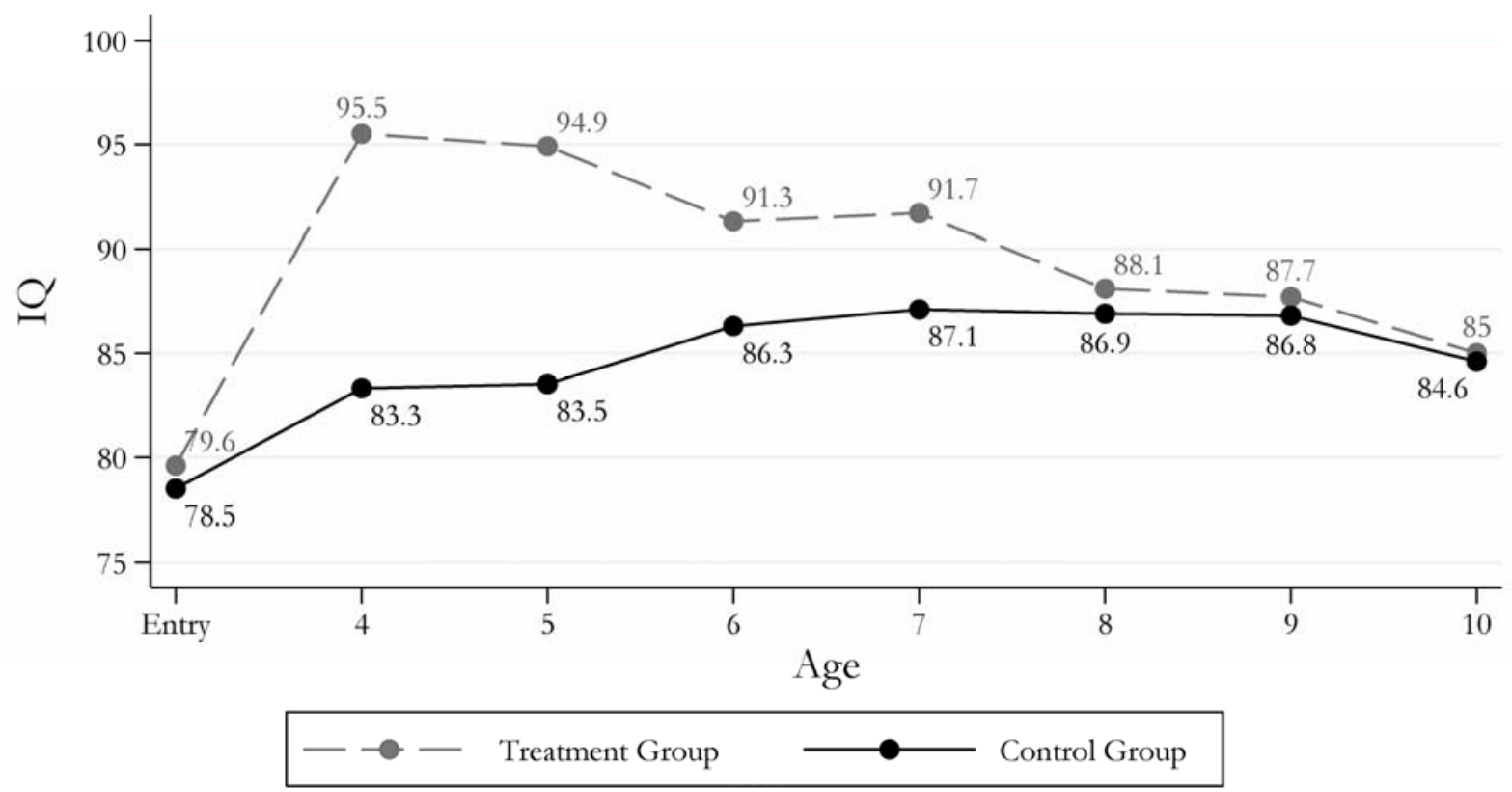

Figure 1

Perry Preschool Program: IQ, by Age and Treatment Group

IQ measured on the Stanford Binet Intelligence Scale (Terman and Merrill, 1960). Test was administered at program entry and each of the ages indicated. Source: Heckman and Masterov (2007). 


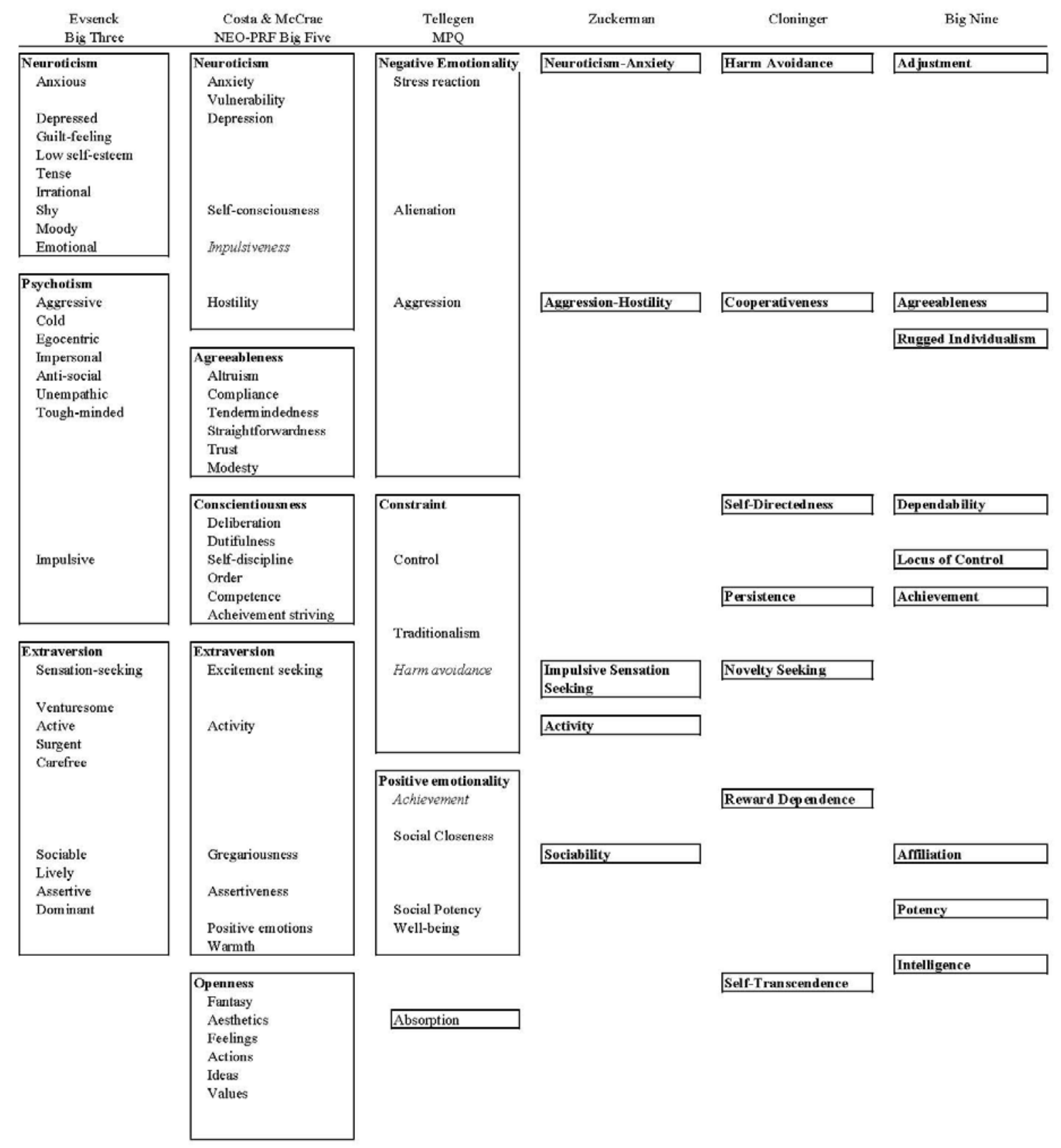

Figure 2

Competing taxonomies of personality

Note: Figure reproduced from Bouchard and Loehlin (2001), with kind permission from Springer Science and Business Media. 
Table 1

The Big Five domains and their facets

\begin{tabular}{|c|c|c|c|}
\hline Factor & Facets & $\begin{array}{l}\text { Definition of } \\
\text { Factor }\end{array}$ & $\begin{array}{l}\mathrm{ACL}^{\mathrm{a}} \text { Marker } \\
\text { Items for Factor }\end{array}$ \\
\hline $\begin{array}{l}\text { I. Openness to Experience } \\
\text { (Intellect) }\end{array}$ & $\begin{array}{l}\text { Fantasy, } \\
\text { Aesthetics, } \\
\text { Feelings, } \\
\text { Actions, } \\
\text { Ideas, } \\
\text { Values }\end{array}$ & $\begin{array}{l}\text { The degree to } \\
\text { which a person } \\
\text { needs intellectual } \\
\text { stimulation, } \\
\text { change, and } \\
\text { variety. }\end{array}$ & $\begin{array}{l}\text { Commonplace, } \\
\text { Narrow-interest, } \\
\text { Simple- vs. } \\
\text { Wide-interest, } \\
\text { Imaginative, } \\
\text { Intelligent }\end{array}$ \\
\hline II. Conscientiousness & $\begin{array}{l}\text { Competence, } \\
\text { Order, } \\
\text { Dutifulness, } \\
\text { Achievement } \\
\text { striving, } \\
\text { Self-discipline, } \\
\text { Deliberation }\end{array}$ & $\begin{array}{l}\text { The degree to } \\
\text { which a person is } \\
\text { willing to comply } \\
\text { with conventional } \\
\text { rules, norms, and } \\
\text { standards. }\end{array}$ & $\begin{array}{l}\text { Careless, } \\
\text { Disorderly, } \\
\text { Frivolous vs. } \\
\text { Organized, } \\
\text { Thorough, } \\
\text { Precise }\end{array}$ \\
\hline III. Extraversion & $\begin{array}{l}\text { Warmth, } \\
\text { Gregariousness, } \\
\text { Assertiveness, } \\
\text { Activity, } \\
\text { Excitement } \\
\text { seeking, } \\
\text { Positive emotions }\end{array}$ & $\begin{array}{l}\text { The degree to } \\
\text { which a person } \\
\text { needs attention } \\
\text { and social } \\
\text { interaction. }\end{array}$ & $\begin{array}{l}\text { Quiet, } \\
\text { Reserved, Shy } \\
\text { vs. Talkative, } \\
\text { Assertive, } \\
\text { Active }\end{array}$ \\
\hline IV. Agreeableness & $\begin{array}{l}\text { Trust, } \\
\text { Straight- } \\
\text { forwardness, } \\
\text { Altruism, } \\
\text { Compliance, } \\
\text { Modesty, } \\
\text { Tender-mindedness }\end{array}$ & $\begin{array}{l}\text { The degree to } \\
\text { which a person } \\
\text { needs pleasant } \\
\text { and harmonious } \\
\text { relations with } \\
\text { others. }\end{array}$ & $\begin{array}{l}\text { Fault-finding, } \\
\text { Cold, } \\
\text { Unfriendly vs. } \\
\text { Sympathetic, } \\
\text { Kind, Friendly }\end{array}$ \\
\hline $\begin{array}{l}\text { V. Neuroticism (Emotional } \\
\text { Stability) }\end{array}$ & $\begin{array}{l}\text { Anxiety, } \\
\text { Angry hostility, } \\
\text { Depression, } \\
\text { Self-consciousness, } \\
\text { Impulsiveness, } \\
\text { Vulnerability }\end{array}$ & $\begin{array}{l}\text { The degree to } \\
\text { which a person } \\
\text { experiences the } \\
\text { world as } \\
\text { threatening and } \\
\text { beyond his/her } \\
\text { control. }\end{array}$ & $\begin{array}{l}\text { Tense, Anxious, } \\
\text { Nervous vs. } \\
\text { Stable, Calm, } \\
\text { Contented }\end{array}$ \\
\hline
\end{tabular}

Source: Hogan and Hogan (2007)

Note: a. ACL = Adjective Check List (Gough and Heilbrun, 1983) 
Table 2

Incentives and Performance on Intelligence Tests

\begin{tabular}{|c|c|c|c|c|}
\hline Study & $\begin{array}{l}\text { Sample and } \\
\text { Study Design }\end{array}$ & $\begin{array}{l}\text { Experimental } \\
\text { Group }\end{array}$ & $\begin{array}{c}\text { Effect size of } \\
\text { incentive (in } \\
\text { standard } \\
\text { deviations) }\end{array}$ & Summary \\
\hline $\begin{array}{l}\text { Edlund } \\
\text { (1972) }\end{array}$ & $\begin{array}{l}\text { Between } \\
\text { subjects study. } \\
11 \text { matched } \\
\text { pairs of low } \\
\text { SES children; } \\
\text { children were } \\
\text { about one } \\
\text { standard } \\
\text { deviation } \\
\text { below average } \\
\text { in IQ at } \\
\text { baseline }\end{array}$ & $\begin{array}{l}\text { M\&M candies } \\
\text { given for each } \\
\text { right answer }\end{array}$ & $\begin{array}{l}\text { Experimental group } \\
\text { scored } 12 \text { points } \\
\text { higher than control } \\
\text { group during a } \\
\text { second testing on an } \\
\text { alternative form of } \\
\text { the Stanford Binet } \\
\text { (about .eight } \\
\text { standard deviations) }\end{array}$ & $\begin{array}{l}\text { "...a carefully chosen } \\
\text { consequence, candy, } \\
\text { given contingent on } \\
\text { each occurrence of } \\
\text { correct responses to an } \\
\text { IQ test, can result in a } \\
\text { significantly higher IQ } \\
\text { score."(p. 319) }\end{array}$ \\
\hline $\begin{array}{l}\text { Ayllon \& } \\
\text { Kelly } \\
(1972) \\
\text { Sample 1 }\end{array}$ & $\begin{array}{l}\text { Within subjects } \\
\text { study. } 12 \\
\text { mentally } \\
\text { retarded } \\
\text { children (avg } \\
\text { IQ 46.8) }\end{array}$ & $\begin{array}{l}\text { Tokens given in } \\
\text { experimental } \\
\text { condition for } \\
\text { right answers } \\
\text { exchangeable for } \\
\text { prizes }\end{array}$ & $\begin{array}{l}6.25 \text { points out of a } \\
\text { possible } 51 \text { points } \\
\text { on Metropolitan } \\
\text { Readiness Test. } t= \\
4.03\end{array}$ & $\begin{array}{l}\text { "...test scores often } \\
\text { reflect poor academic } \\
\text { skills, but they may } \\
\text { also reflect lack of } \\
\text { motivation to do well } \\
\text { in the criterion }\end{array}$ \\
\hline $\begin{array}{l}\text { Ayllon \& } \\
\text { Kelly } \\
(1972) \\
\text { Sample } 2\end{array}$ & $\begin{array}{l}\text { Within subjects } \\
\text { study } 34 \text { urban } \\
\text { fourth graders } \\
(\text { avg IQ }=92.8)\end{array}$ & $\begin{array}{l}\text { Tokens given in } \\
\text { experimental } \\
\text { condition for } \\
\text { right answers } \\
\text { exchangeable for } \\
\text { prizes }\end{array}$ & $t=5.9$ & $\begin{array}{l}\text { test...These results, } \\
\text { obtained from both a } \\
\text { population typically } \\
\text { limited in skills and } \\
\text { ability as well as from } \\
\text { a group of normal }\end{array}$ \\
\hline $\begin{array}{l}\text { Ayllon \& } \\
\text { Kelly } \\
(1972) \\
\text { Sample } 3\end{array}$ & $\begin{array}{l}\text { Within subjects } \\
\text { study of } 12 \\
\text { matched pairs } \\
\text { of mentally } \\
\text { retarded } \\
\text { children }\end{array}$ & $\begin{array}{l}\text { Six weeks of } \\
\text { token } \\
\text { reinforcement } \\
\text { for good } \\
\text { academic } \\
\text { performance }\end{array}$ & $\begin{array}{l}\text { Experimental group } \\
\text { scored } 3.67 \text { points } \\
\text { out of possible } 51 \\
\text { points on a post-test } \\
\text { given under } \\
\text { standard conditions } \\
\text { higher than at } \\
\text { baseline; control } \\
\text { group dropped } 2.75 \\
\text { points. On a second } \\
\text { post-test with } \\
\text { incentives, exp and } \\
\text { control groups }\end{array}$ & $\begin{array}{l}\text { children (Experiment } \\
\text { II), demonstrate that } \\
\text { the use of } \\
\text { reinforcement } \\
\text { procedures applied to } \\
\text { a behavior that is } \\
\text { tacitly regarded as "at } \\
\text { its peak" can } \\
\text { significantly alter the } \\
\text { level of performance } \\
\text { of that behavior." (p. } \\
483 \text { ) }\end{array}$ \\
\hline
\end{tabular}




\begin{tabular}{|c|c|c|c|c|}
\hline & & & $\begin{array}{l}\text { increased } 6.25 \text { and } \\
7.17 \text { points, } \\
\text { respectively }\end{array}$ & \\
\hline $\begin{array}{l}\text { Clingman } \\
\text { and Fowler } \\
(1976)\end{array}$ & $\begin{array}{l}\text { Within subjects } \\
\text { study of } 72 \\
\text { first- and } \\
\text { second-graders } \\
\text { assigned } \\
\text { randomly to } \\
\text { contingent } \\
\text { reward, } \\
\text { noncontingent } \\
\text { reward, or no } \\
\text { reward } \\
\text { conditions. }\end{array}$ & $\begin{array}{l}\text { M\&Ms given for } \\
\text { right answers in } \\
\text { contingent cdtn; } \\
\text { M\&Ms given } \\
\text { regardless of } \\
\text { correctness in } \\
\text { noncontingent } \\
\text { condition }\end{array}$ & $\begin{array}{l}\text { Only among low-IQ } \\
(<100) \text { subjects was } \\
\text { there an effect of } \\
\text { the incentive. } \\
\text { Contingent reward } \\
\text { group scored about } \\
.33 \text { standard } \\
\text { deviations higher on } \\
\text { the Peabody Picture } \\
\text { Vocabulary test } \\
\text { than did no reward } \\
\text { group. }\end{array}$ & $\begin{array}{l}\text { "...contingent candy } \\
\text { increased the I.Q. } \\
\text { scores of only the 'low } \\
\text { I.Q.' children. This } \\
\text { result suggests that the } \\
\text { high and medium I.Q. } \\
\text { groups were already } \\
\text { functioning at a higher } \\
\text { motivational level than } \\
\text { children in the low } \\
\text { I.Q. group." }\end{array}$ \\
\hline $\begin{array}{l}\text { Zigler and } \\
\text { Butterfield } \\
(1968)\end{array}$ & $\begin{array}{l}\text { Within and } \\
\text { between } \\
\text { subjects study } \\
\text { of } 40 \text { low SES } \\
\text { children who } \\
\text { did or did not } \\
\text { attend nursery } \\
\text { school were } \\
\text { tested at the } \\
\text { beginning and } \\
\text { end of the year } \\
\text { on Stanford- } \\
\text { Binet } \\
\text { Intelligence } \\
\text { Test under } \\
\text { either } \\
\text { optimized or } \\
\text { standard } \\
\text { conditions. }\end{array}$ & $\begin{array}{l}\text { Motivation was } \\
\text { optimized } \\
\text { without giving } \\
\text { test-relevant } \\
\text { information. } \\
\text { Gentle } \\
\text { encouragement, } \\
\text { easier items after } \\
\text { items were } \\
\text { missed, and so } \\
\text { on. }\end{array}$ & $\begin{array}{l}\text { At baseline (in the } \\
\text { fall), there was a } \\
\text { full standard } \\
\text { deviation difference } \\
\text { ( } 10.6 \text { points and SD } \\
\text { was about } 9.5 \text { in } \\
\text { this sample) } \\
\text { between scores of } \\
\text { children in the } \\
\text { optimized vs } \\
\text { standardconditions } \\
\text { The nursery group } \\
\text { improved their } \\
\text { scores, but only in } \\
\text { the standard } \\
\text { condition. }\end{array}$ & $\begin{array}{l}\text { "...performance on an } \\
\text { intelligence test is best } \\
\text { conceptualized as } \\
\text { reflecting three distinct } \\
\text { factors: (a) formal } \\
\text { cognitive processes; } \\
\text { (b) informational } \\
\text { achievements which } \\
\text { reflect the content } \\
\text { rather than the formal } \\
\text { properties of } \\
\text { cognition, and (c) } \\
\text { motivational factors } \\
\text { which involve a wide } \\
\text { range of personality } \\
\text { variables. (p. 2) } \\
\text { “...the significant } \\
\text { difference in } \\
\text { improvement in } \\
\text { standard IQ } \\
\text { performance found } \\
\text { between the nursery } \\
\text { and non-nursery } \\
\text { groups was } \\
\text { attributable solely to } \\
\text { motivational } \\
\text { factors...” (p. 10) }\end{array}$ \\
\hline $\begin{array}{l}\text { Breuning } \\
\text { and Zella } \\
(1978)\end{array}$ & $\begin{array}{l}\text { Within and } \\
\text { between } \\
\text { subjects study } \\
\text { of } 485 \text { special }\end{array}$ & $\begin{array}{l}\text { Incentives such } \\
\text { as record } \\
\text { albums, radios } \\
(<\$ 25) \text { given for }\end{array}$ & $\begin{array}{l}\text { Scores increased by } \\
\text { about } 17 \text { points. } \\
\text { Results were } \\
\text { consistent across the }\end{array}$ & $\begin{array}{l}\text { "In summary, the } \\
\text { promise of } \\
\text { individualized } \\
\text { incentives on an }\end{array}$ \\
\hline
\end{tabular}




\begin{tabular}{|c|c|c|c|c|}
\hline & $\begin{array}{l}\text { education high } \\
\text { school students } \\
\text { all took IQ } \\
\text { tests, then were } \\
\text { randomly } \\
\text { assigned to } \\
\text { control or } \\
\text { incentive } \\
\text { groups to } \\
\text { retake tests. } \\
\text { Subjects were } \\
\text { below-average } \\
\text { in IQ. }\end{array}$ & $\begin{array}{l}\text { improvement in } \\
\text { test performance }\end{array}$ & $\begin{array}{l}\text { Otis-Lennon, } \\
\text { WISC-R, and } \\
\text { Lorge-Thorndike } \\
\text { tests. }\end{array}$ & $\begin{array}{l}\text { increase in IQ test } \\
\text { performance (as } \\
\text { compared with pretest } \\
\text { performance) resulted } \\
\text { in an approximate 17- } \\
\text { point increase in IQ } \\
\text { test scores. These } \\
\text { increases were equally } \\
\text { spread across subtests } \\
\text { The incentive } \\
\text { condition effects were } \\
\text { much less pronounced } \\
\text { for students have } \\
\text { pretest IQs between } 98 \\
\text { and } 120 \text { and did not } \\
\text { occur for students } \\
\text { having pretest IQs } \\
\text { between } 121 \text { and } 140 . " \\
\text { (p. } 225 \text { ) }\end{array}$ \\
\hline $\begin{array}{l}\text { Holt and } \\
\text { Hobbs } \\
(1979)\end{array}$ & $\begin{array}{l}\text { Between and } \\
\text { within subjects } \\
\text { study of } 80 \\
\text { delinquent } \\
\text { boys randomly } \\
\text { assigned to } \\
\text { three } \\
\text { experimental } \\
\text { groups and one } \\
\text { control group. } \\
\text { Each exp group } \\
\text { received a } \\
\text { standard and } \\
\text { modified } \\
\text { administration } \\
\text { of the WISC- } \\
\text { verbal section. }\end{array}$ & $\begin{array}{l}\text { Exp 1-Token } \\
\text { reinforcement } \\
\text { for correct } \\
\text { responses; Exp } 2 \\
\text { - Tokens } \\
\text { forfeited for } \\
\text { incorrect } \\
\text { responses } \\
\text { (punishment), } \\
\text { Exp 3-feedback } \\
\text { on } \\
\text { correct/incorrect } \\
\text { responses }\end{array}$ & $\begin{array}{l}\text { 1.06 standard } \\
\text { deviation difference } \\
\text { between the token } \\
\text { reinforcement and } \\
\text { control groups } \\
\text { (inferred from } t= \\
3.31 \text { for } 39 \text { degrees } \\
\text { of freedom0 }\end{array}$ & $\begin{array}{l}\text { "Knowledge of results } \\
\text { does not appear to be a } \\
\text { sufficient incentive to } \\
\text { significantly improve } \\
\text { test performance } \\
\text { among below-average } \\
\text { I.Q. } \\
\text { subjects...Immediate } \\
\text { rewards or response } \\
\text { cost may be more } \\
\text { effective with below- } \\
\text { average I.Q. subjects } \\
\text { while other conditions } \\
\text { may be more effective } \\
\text { with average or above- } \\
\text { average subjects." (p. } \\
\text { 83) }\end{array}$ \\
\hline $\begin{array}{l}\text { Larson, } \\
\text { Saccuzzo, } \\
\text { and Brown } \\
(1994)\end{array}$ & $\begin{array}{l}\text { Between } \\
\text { subjects study } \\
\text { of } 109 \text { San } \\
\text { Diego State } \\
\text { University } \\
\text { psychology } \\
\text { students }\end{array}$ & $\begin{array}{l}\text { Up to } \$ 20 \text { for } \\
\text { improvement } \\
\text { over baseline } \\
\text { performance on } \\
\text { cognitive speed } \\
\text { tests }\end{array}$ & $\begin{array}{l}\text { "While both groups } \\
\text { improved with } \\
\text { practice, the } \\
\text { incentive group } \\
\text { improved slightly } \\
\text { more." } \rightarrow \text { need to } \\
\text { calculate effect size, } \\
\text { but it was not large }\end{array}$ & $\begin{array}{l}2 \text { reasons why } \\
\text { incentive did not } \\
\text { produce dramatic } \\
\text { increase: 1) few or no } \\
\text { unmotivated subjects } \\
\text { among college } \\
\text { volunteers, 2) } \\
\text { information processing } \\
\text { tasks are too simple } \\
\text { for 'trying harder' to }\end{array}$ \\
\hline
\end{tabular}




\begin{tabular}{|c|c|c|c|c|}
\hline & & & & matter \\
\hline $\begin{array}{l}\text { Duckworth } \\
(2007)\end{array}$ & $\begin{array}{l}\text { Within subjects } \\
\text { study of } 61 \\
\text { urban low- } \\
\text { achieving high } \\
\text { school students } \\
\text { tested with a } \\
\text { group- } \\
\text { administered } \\
\text { Otis-Lennon } \\
\text { IQ test during } \\
\text { their freshman } \\
\text { year, then } \\
\text { again } 2 \text { years } \\
\text { later with a } \\
\text { one-on-one } \\
\text { (WASI) test }\end{array}$ & $\begin{array}{l}\text { Standard } \\
\text { directions for } \\
\text { encouraging } \\
\text { effort were } \\
\text { followed for the } \\
\text { WASI brief test. } \\
\text { Performance was } \\
\text { expected to be } \\
\text { higher because } \\
\text { of the one-on- } \\
\text { one } \\
\text { environment. }\end{array}$ & $\begin{array}{l}\text { Performance on the } \\
\text { WASI as juniors } \\
\text { was about } 16 \text { points } \\
\text { higher than on the } \\
\text { group-administered } \\
\text { test as freshmen. } \\
\text { Notably, on the } \\
\text { WASI, this } \\
\text { population looks } \\
\text { almost "average" in } \\
\text { IQ, whereas by } \\
\text { Otis-Lennon } \\
\text { standards they are } \\
\text { low IQ. } \mathrm{t}(60)= \\
\text { 10.67, }<<.001\end{array}$ & $\begin{array}{l}\text { The increase in IQ } \\
\text { scores could be } \\
\text { attributed to any } \\
\text { combination of the } \\
\text { following 1) an } \\
\text { increase in "g" due to } \\
\text { schooling at an } \\
\text { intensive charter } \\
\text { school, 2) an increase } \\
\text { in knowledge or } \\
\text { crystallized } \\
\text { intelligence, 3) an } \\
\text { increase in motivation } \\
\text { due to the change in } \\
\text { IQ test format, and/or } \\
\text { 4) an increase in } \\
\text { motivation due to } \\
\text { experience at high } \\
\text { performing school }\end{array}$ \\
\hline
\end{tabular}




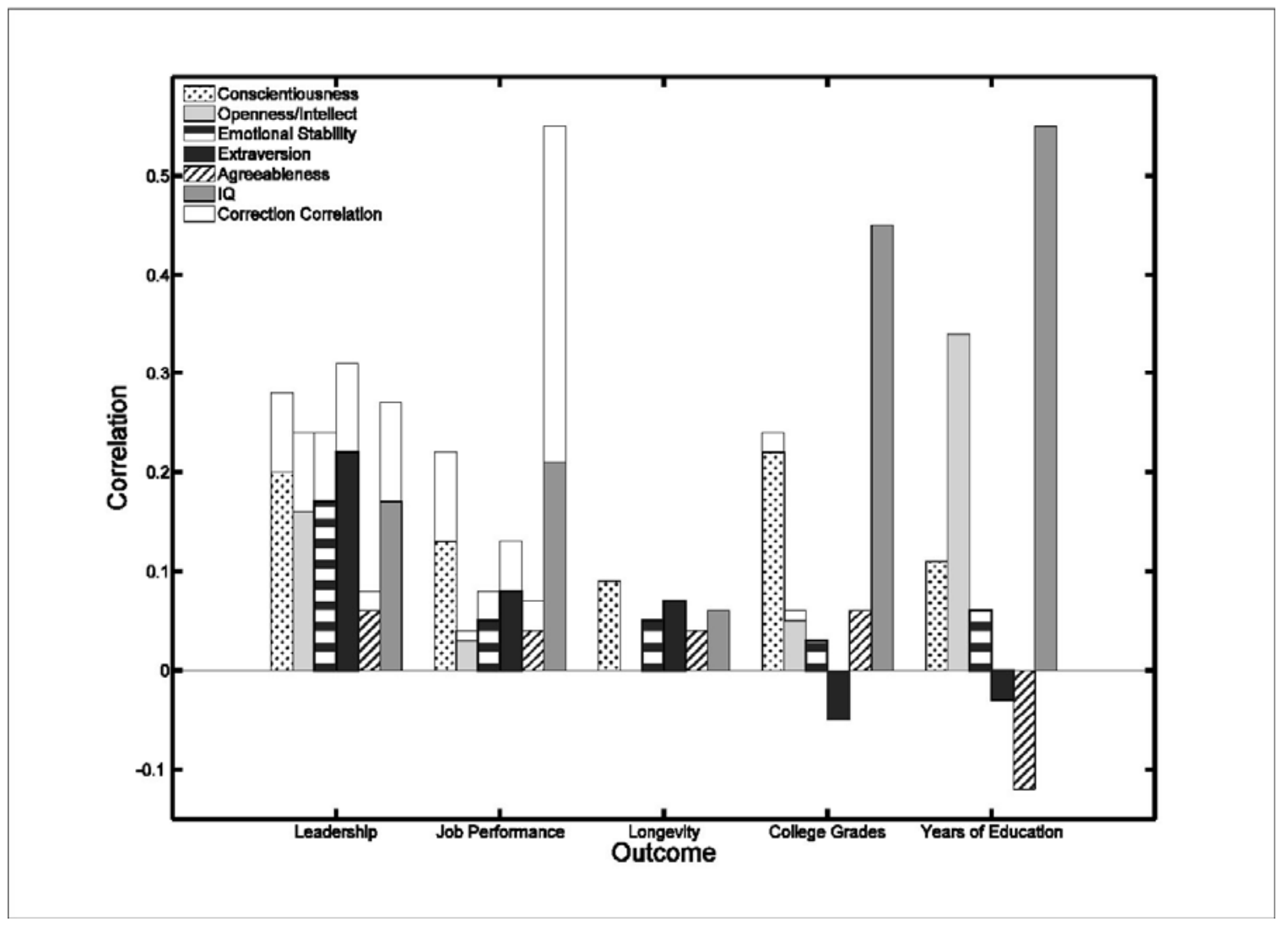

Figure 3

Predictive Validities IQ and Big Five Dimensions

Note: Details on the Measures of Outcomes for Figure 1 of the Web Appendix are available in Web Appendix D 
Social Vitality

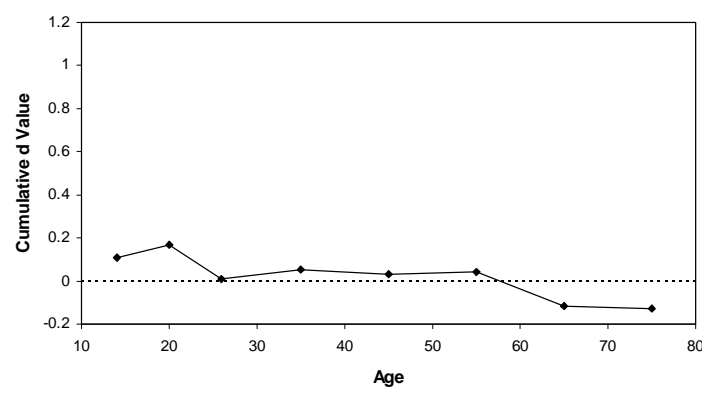

Agreeableness

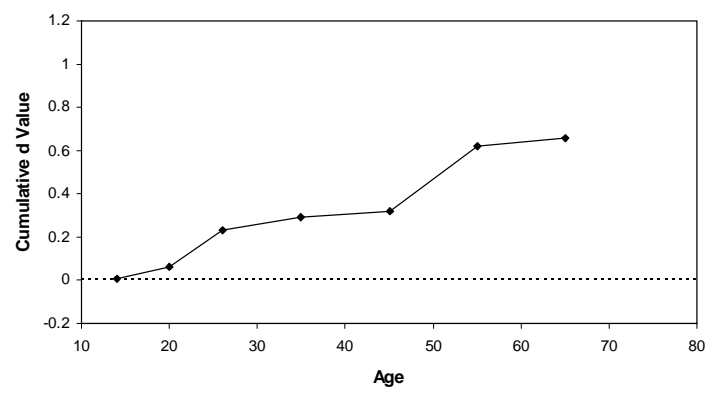

Emotional Stability

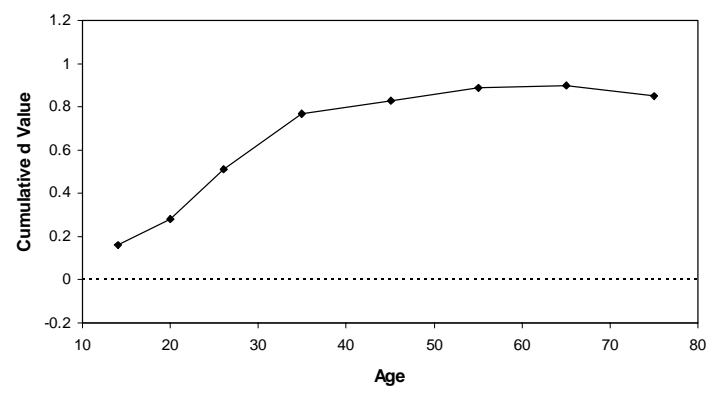

Social Dominance

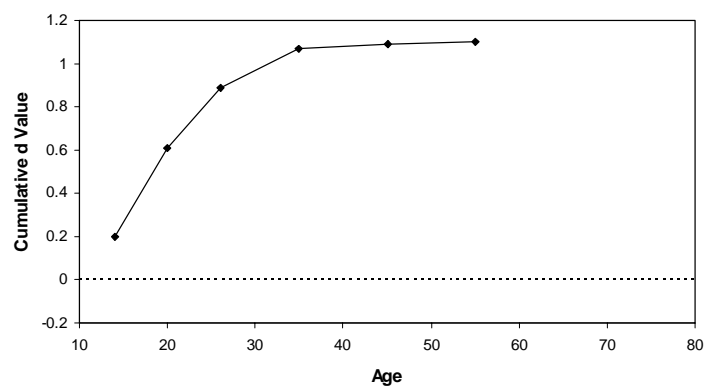

Conscientiousness

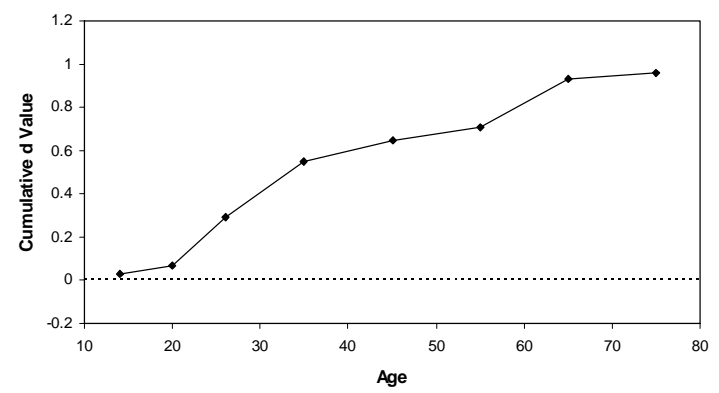

Openness to Experience

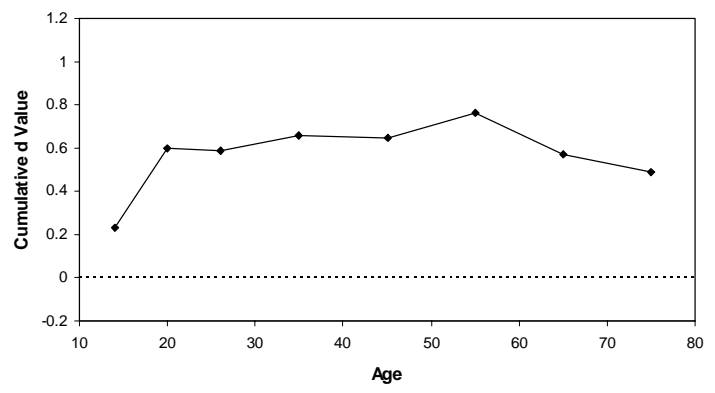

\section{Figure 4a}

Cumulative mean-level changes in personality across the life course

Note: Figure taken from Roberts, Walton and Viechtbauer (2006). Reprinted with permission of the authors. Social vitality and social dominance are aspects of Big Five extraversion. Cumulative d values represent total lifetime change in standard deviations. 

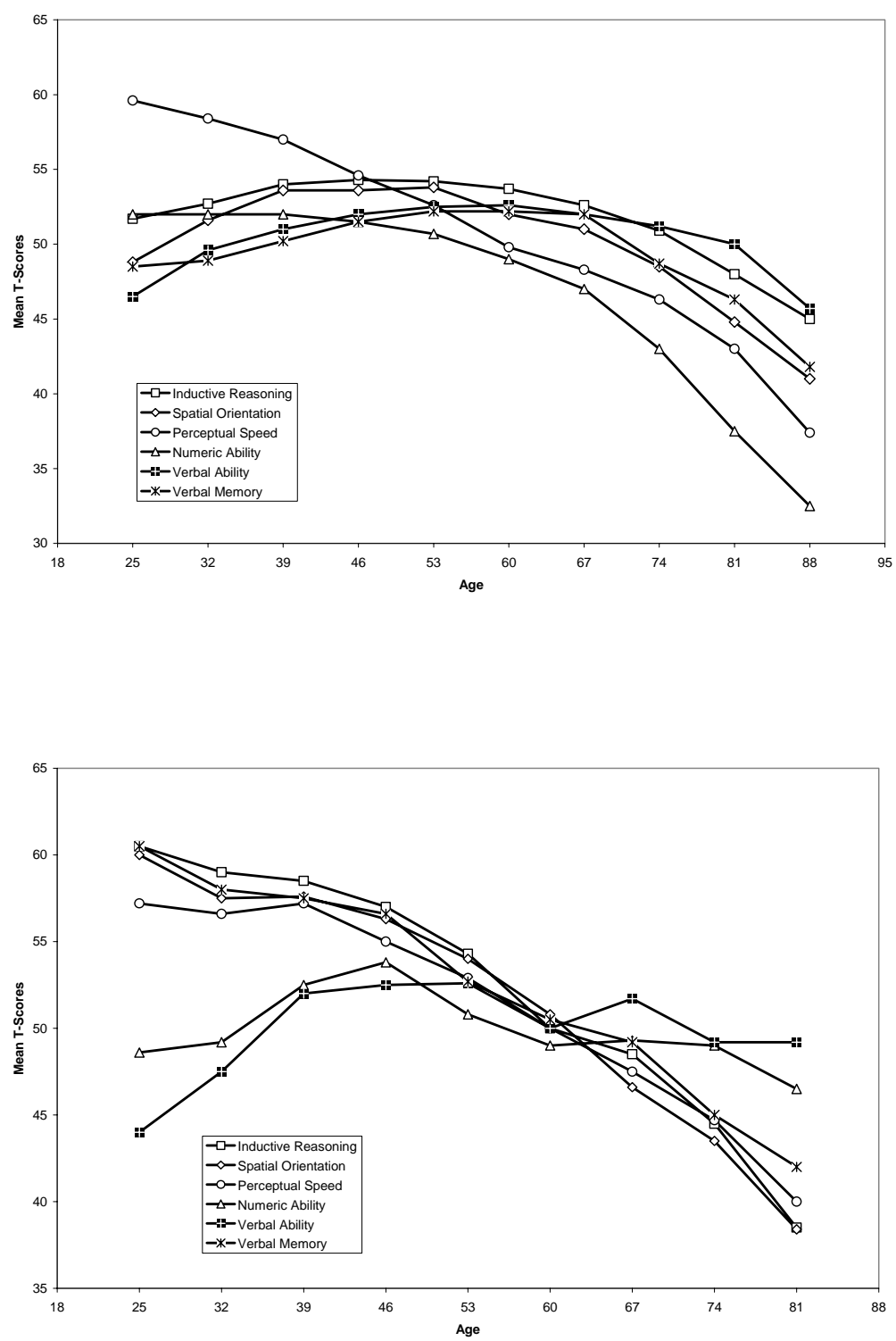

\section{Figure 4b}

Longitudinal analysis (top panel) and cross-sectional analysis (bottom panel) of mean-

level change in cognitive skills over the lifespan

Note: T-scores on the y-axis are standardized scores with a mean of 50 and a standard deviation of ten. Figures taken from Schaie (1994). Used with permission of the publisher. 


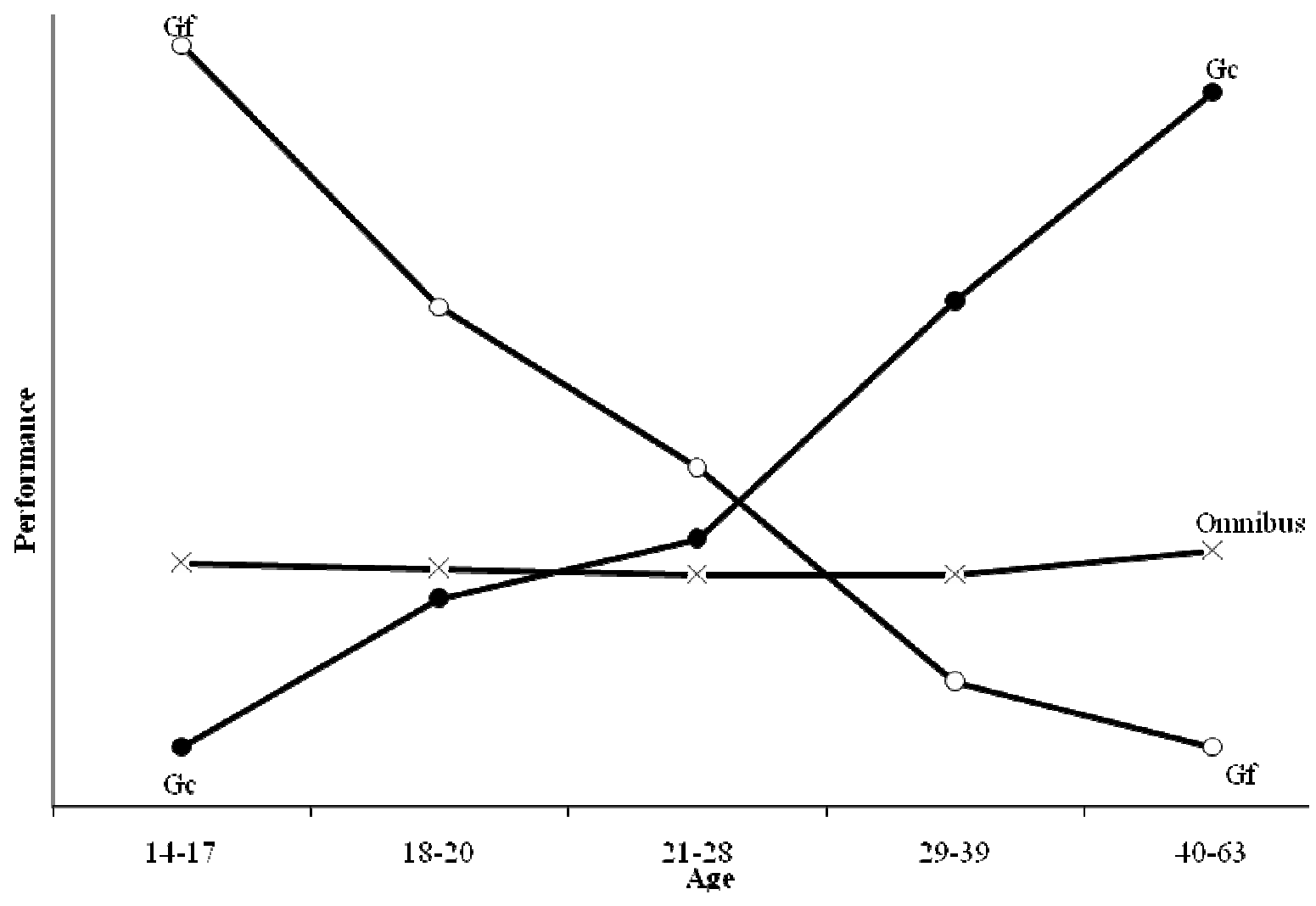

Figure 4c

Fluid intelligence decreases and crystallized intelligence increases across the lifespan Note: Figure from Horn (1970). Used with permission of Elsevier. 


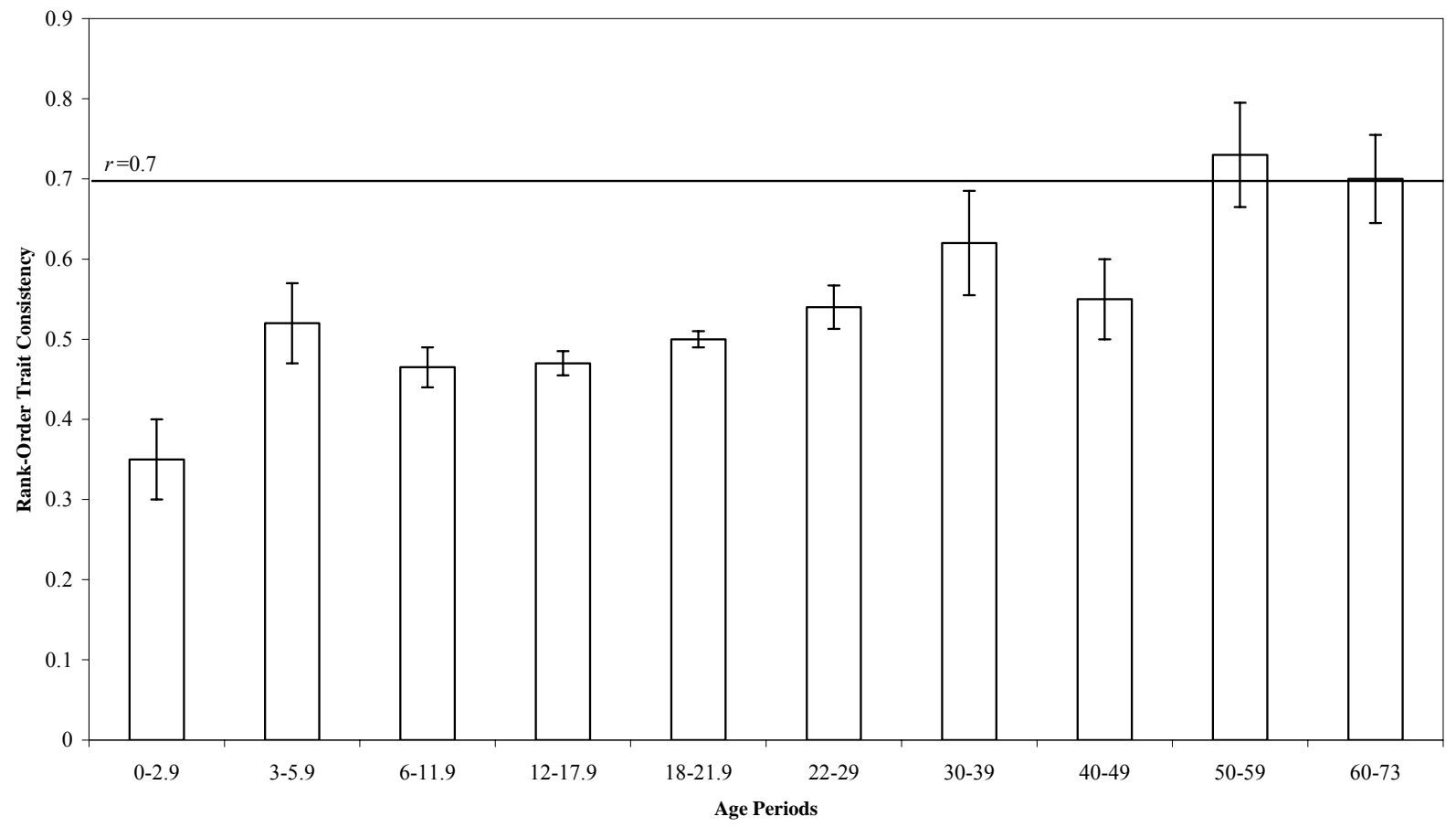

Figure 5a

Note: Figure taken from Roberts and DelVecchio (2000) meta-analysis and reflects testretest correlations over, on average, 6.7-year periods. Reprinted with permission of the authors. 


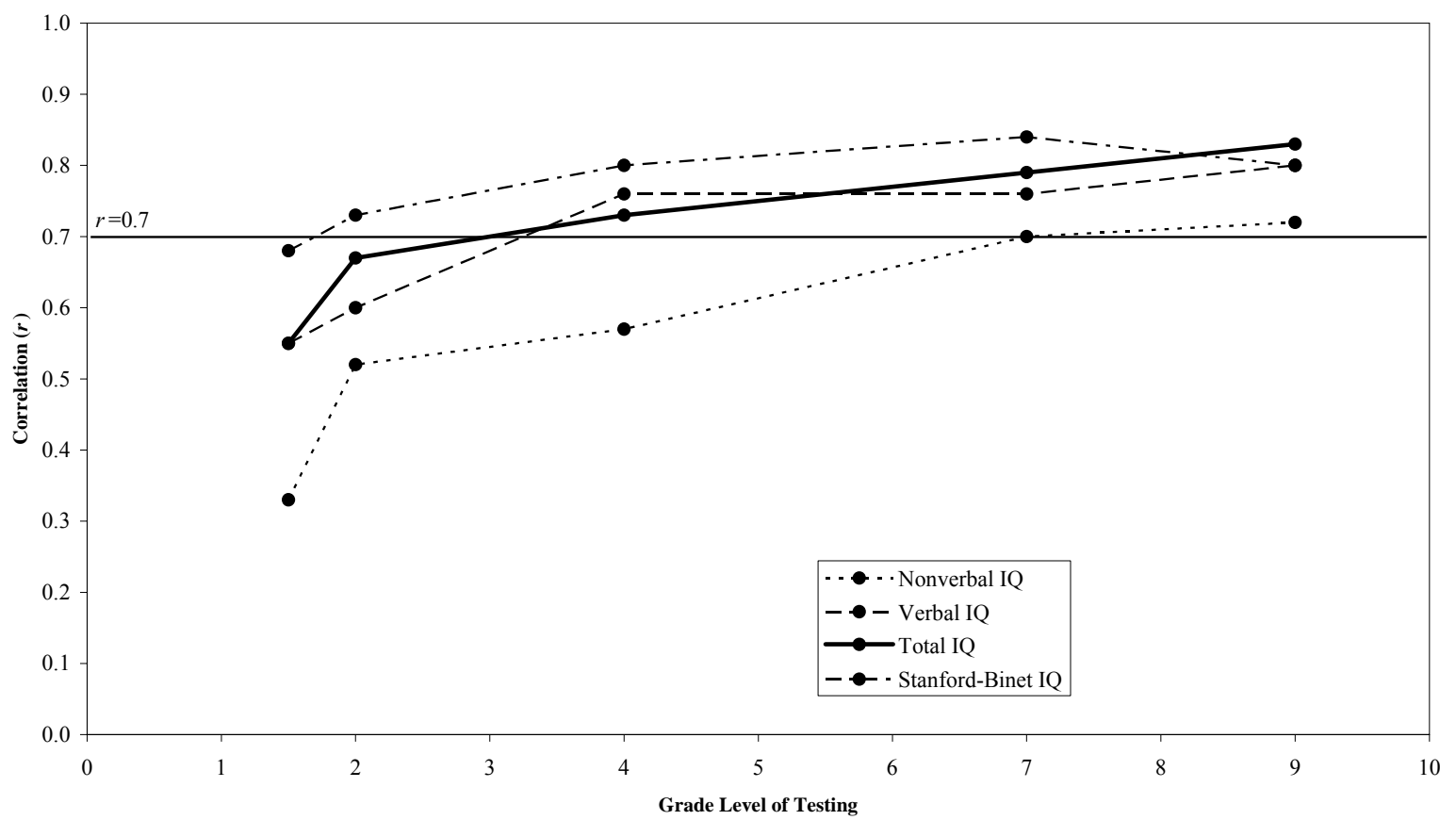

Figure 5b

Note: Figure reproduced from Hopkins and Bracht (1975), and reflects ten-year, test-retest correlations over ten-year intervals. Grade level, not age, is on the x-axis. Used with permission of the publisher. 


\section{Endnotes}

1 See, for example, Gottfredson (2002), Herrnstein and Murray (1994), and Heckman, Urzua, and Stixrud (2006).

2 The American Psychological Association Dictionary defines cognition as "all forms of knowing and awareness such as perceiving, concerning, remembering, reasoning, judging, imagining, and problem solving."

3 See Bowles, Gintis, and Osborne, 2001, for a review. Among other determinants of earnings, they summarize evidence on the labor market effects of beauty by Hamermesh and Biddle (1994) and Hamermesh, Meng, and Zhang (2002). Marxist economists (Bowles and Gintis, 1976) pioneered the analysis of the impact of personality on earnings. Mueser (1979) estimates empirical relationships between personality traits and earnings. Mueller and Plug (2006) relate the Big Five personality factors to earnings. Hartog $(1980,2001)$ draws on the psychology literature to analyze economic preferences. van Praag (1985) and van Praag and van Weeren (1988) also link economics with psychology.

4 See Schweinhart et. al (2005); Cunha et al. (2006), and Heckman et al. (2007).

5 Some psychologists believe that expectation, motivation, goals, values, and interests fall outside the construct of personality. Others take the position that insofar as these variables are persistent over time, they can be considered aspects of personality (see Costa and McCrae 1988). Broadly speaking, the field of personality and individual differences psychology is concerned with all dimensions on which people differ from one another. For a discussion of vocational interests, their measurement, and their theoretical relationship to personality traits, we direct the 
reader to Holland (1986), Larson, Rottinghaus, and Borgen (2002), and Low and Rounds (2006). McAdams (2006) and McAdams and Pals (2007) present a more comprehensive view of personality psychology including basic drives and motivations.

6 Large-scale longitudinal studies linking motivation to economic outcomes are rare. Duncan and Dunifon (1998) provide the best available evidence that individual differences in motivation measured in young adulthood predict labor market outcomes more than a decade later. However, they do not correct for the problem of reverse causality discussed below. As Cunha and Heckman $(2007,2008)$ show, young adults can predict over half of their future earnings. The Duncan and Dunifon motivation measure may be a consequence of agent expectations of future benefits rather than a cause of the future benefits.

7 Investment refers to the allocation of resources, broadly defined, for the purpose of increasing skills. Parents invest in their children directly and through choice of schools, but individuals can also invest in themselves.

8 Many theories of personality are cognitively-oriented. For example, Mischel (1968) and Bandura (1999) suggest that behavior is driven by cognitive operations, beliefs, and representations of reality (how people process information, what they believe to be true, and how they interpret their perceptions).

9 The $U_{i, j}$ can include measurement errors.

10 The strength of the correlation depends on the magnitudes of $\lambda_{j}, \lambda_{j}$, across the two tasks. 11 Several psychologists have attempted to broaden the term intelligence to include other capacities. Most notably, Sternberg $(2000,2001)$ suggests that the notion of intelligence should also include creativity and the ability to solve practical, real-world problems. Gardner (2004) 
includes in his theory of multiple intelligences, musical intelligence, kinaesthetic intelligence, and interpersonal and intrapersonal intelligence, among others.

12 Carroll (1993) analyzed 477 data sets and estimated a structure with $g$ as the highest-order factor, eight second-order ability clusters, and many over 70 more narrowly defined third-order abilities on a variety of different tests. Alternative hierarchical models, also with $g$ as the highest-order factor, have been proposed (for example, Cattell 1971; Lubinski 2004).

13 Cattell's student Horn (1970) elaborates: fluid intelligence is the ability to "perceive complex relations, educe complex correlates, form concepts, develop aids, reason, abstract, and maintain span of immediate apprehension in solving novel problems in which advanced elements of the collective intelligence of the culture were not required for solution" (p. 462). In contrast, crystallized intelligence is the same class of skills, "but in materials in which past appropriation of the collective intelligence of the culture would give one a distinct advantage in solving the problems involved" (p. 462).

14 Rindermann (2007) uses data on intelligence and achievement tests across nations to show that a single factor accounts for 94-95 percent of the variance across both kinds of tests. The high correlation between intelligence and achievement tests is in part due to the fact that both require cognitive ability and knowledge, even if to different degrees, that common developmental factors may affect both of these traits, and that fluid intelligence promotes the acquisition of crystallized intelligence.

15 Recent research by Conti and Pudney (2007) shows that more than one factor is required to summarize the predictive power of cognitive tests in economic data. This could be due to the 
existence of multiple intellective factors or because personality factors affect the measurement of cognitive factors as we discuss later on in this section.

16 Executive function has been characterized as the capacity to act on information as opposed to understanding the information. In the language of psychology, executive function refers to "the multi-operational system mediated by prefrontal areas of the brain and their reciprocal cortical and subcortical connecting pathways" (Ardila, Pineda, and Rosselli 2000; see Miller and Cohen 2001, for a review). Alvarez and Emory (2006) review evidence that involvement of the frontal lobes is necessary but not sufficient for performance on executive function; for any given executive function, other brain areas are also involved.

17 Kaplan and Saccuzzo (1997) provide a detailed overview of the different types of applications of psychological testing.

18 See Roberts et al. 2005b for a more complete history of intelligence testing.

19 In 1904, La Société Libre pour l'Etude Psychologique de l'Enfant appointed a commission to create a mechanism for identifying these pupils in need of alternative education led by Binet. See Siegler (1992) for an overview of Binet's life and work.

20 See Herrnstein and Murray (1994) for a discussion of the Raven test.

21 See Figure 1 in Web Appendix A for an example item.

22 See John and Srivastava (1999) for an historical overview of the development of the Big Five. See Costa and McCrae (1992a) and Digman (1990) for a review of the emergence of this concept.

23 http://ipip.ori.org, Goldberg et al. 2006.

24 See, for example, Carroll (1993). 
25 See Goldsmith et al. (1987) for a discussion of varying perspectives on temperament, including a summary of points where major theorists converge.

26 Indeed, some psychologists use the term "temperament" to indicate all aspects of personality that are biological in origin. They study temperament in both children and adults.

27 Measuring temperament presents unique methodological challenges. Self-report measures, by far the most widely used measure for adult personality, are not appropriate for young children for obvious reasons. One strategy is to ask parents and teachers to rate the child's overt behavior (for example, California Child Q-sort), but informants can only guess what a child might be thinking and feeling. Infants present a special challenge because their behavioral repertoire is so limited. One strategy is to place infants in a standard situation and code reactions under a standardized scenario (for example, the Strange Situation, which is used to distinguish infants who are securely attached to their caregiver versus insecurely attached). Young children can be interviewed using puppets or stories. For obvious reasons, all measures of temperament are more difficult and more expensive to collect than adult self-report measures. This may explain their absence in large-sample studies.

28 See, for example, the studies summarized in Bowles, Gintis, and Osborne (2001), the original analyses presented in that paper, and Mueller and Plug (2006).

29 More rarely, the multitrait-multimethod matrix approach developed by Campbell and Fiske (1959) is used for this purpose.

30 Hansen, Heckman, and Mullen show how to allow $Q_{i}$ to depend on $f_{i}$ and still identify the model. We discuss this work in the web appendix to this paper. 
31 Indeed, as documented in Cunha and Heckman (2007a), the factors associated with personality are also correlated with the cognitive factors.

32 Cronbach's is a widely used measure of intercorrelation among test scores, that is, a measure of importance of the variance of the $\varepsilon_{i, l}^{n}$ uniquenesses relative to the variance of the factors. See Lord and Novick (1968) for a precise definition.

33 See http://www.hoganassessments.com/products services/hpi.aspx and also Hogan, Hogan, and Roberts (1996).

34 See also the notes on ability bias posted at the website for this paper in Web Appendix C. 35 See, for example, Heckman and Vytlacil (2007b).

36 Hogan and Hogan (2007) use a version of this procedure. In this regard, they appear to be an exception among personality psychologists. However, in psychometrics, there is a long tradition of doing predictive analysis based on factor analysis (see, for example, the essays in Cudeck and MacCallum 2007), but there is no treatment of the problem of reverse causality as analyzed by Hansen, Heckman, and Mullen (2004).

37 For example, Cragg and Donald (1997) present classical statistical methods for determining the number of factors. In addition to their techniques, there are methods based on Bayesian posterior odds ratios.

38 See Ones and Viswesvaran (1998); Viswesvaran and Ones (1999).

39 The problem of the transportability of the measurement of a trait in one environment to another is a manifestation of the problem of "external validity" that has long been discussed in the literature on policy evaluation starting with the early work of Haavelmo (1944) and Marschak (1953). Heckman (2005), and Heckman and Vytlacil (2007a) are recent discussions of 
this recurring issue. Levitt and List $(2007 \mathrm{a}, \mathrm{b})$ consider the issue of external validity in the context of lab experiments in economics. The solution to the problem of external validity entails the construction of formal models for extrapolation and interpretation. Equation (5) is one such model. If a different model is required for each situation (so $h_{l}$ becomes $h_{l}^{n}$ ), the problem becomes hopelessly complicated and no situation-independent definition of a true latent trait is possible.

40 It is likely that performance on personality tests also depends on cognitive ability, but that is less well documented. For example, it is likely that more intelligent people can ascertain the rewards to performance on a personality inventory test. Motivation is sometimes, but not usually, counted as a personality trait.

41 See Hansen, Heckman, and Mullen (2004) for an analysis of the causal effects of schooling on achievement tests. Heckman, Stixrud, and Urzua (2006) consider the causal effects of schooling on measures of personality skills.

42 The studies in Table 2 do not include direct measures of personality traits.

43 An ERP is an electrophysiological response of characteristic form and timing to a particular category of stimuli.

44 Jensen (1980), chapter 12, focuses on racial differentials in response to rewards rather than absolute levels of incentive effects. The evidence he reports is consistent with our analysis of Table 2. He also discusses the literature up to 1980 on the role of personality in shaping IQ. Our analysis reviews many studies not available to him. 
45 In economics, Hansen, Heckman, and Mullen (2004), Heckman, Urzua, and Stixrud (2006), and Urzua (2007) perform such adjustments and account for the reciprocal interactions discussed by the psychologists.

46 See Harrison, Lau, and Williams (2002); Besharov and Coffey (2003); Benhabib, Bisin, and Schotter (2004) and Harrison and Lau (2005). Dynamic complementarity, market environments and information arrival can rationalize the evidence on hyperbolic discounting. 47 Heckman (1976) from lifecycle human capital decisions, Hausman (1979) from air conditioner demand, Ruderman, Levine, and McMahon (1987) from gas water heaters, freezers and Gately (1980) from refrigerator demand.

48 Borghans and Golsteyn (2006) investigate the link between body mass index (BMI) and proxies for the discount rate.

49 See, for example, Harrison and List (2004) and List (2004, 2006, 2007).

50 Van Praag (1985) estimates time-discount weights varying by year by linking psychological measures about the valuation of income to income patterns.

51 Using questionnaires, Borghans and Golsteyn (2007) show that the ability to imagine the future affects the discount rate.

52 Numeracy refers to the capability of translating preferences into an annual interest rate.

53 Heckman (1976) shows that more educated people have lower discount rates. More able people are more likely to attend more years of school.

54 Further support for this disassociation comes from a cross-cultural study by Du, Green, and Meyerson (2002), in which Chinese graduate students discounted delayed rewards much more steeply than Japanese students, but Japanese students discounted probabilistic rewards more 
steeply than did the Chinese. Barsky et al. (1997) report that their estimates of time preference and risk tolerance are independent.

55 The two cognitive ability tests used by Dohmen et al. (2007) tests were a coding speed and vocabulary test.

56 Dreber and Hoffman (2007) suggest that the gender difference in risk aversion can be partly explained by exposure to prenatal hormones, suggesting that risk preference is not fully environmentally determined.

57 See Zuckerman (1994).

58 Zuckerman (2007) suggests that sensation seeking is related more closely to Big Five conscientiousness (inversely), but there is obvious conceptual overlap with excitement seeking, a facet of Big Five extraversion on the NEO-PI-R questionnaire, as well as with Big Five openness to experience.

59 Heckman (1974) is an early effort that estimates the population distribution of indifference curves between goods and leisure.

60 Euwals and van Soest (1999) uses the distinction between desired vs. actual hours worked to measure the preference for leisure. Of course, this could be due to constraints in the labor market.

61 "Restriction on range" (see Lord and Novick 1968) is truncation on the variable being studied. In a model with normal random variables, such restriction reduces the correlation. Lack of reliability refers to the presence of error variance in the total variance of any given measure. The degree to which corrections due to these statistical artifacts are justified is a matter of debate. 
62 See the additional discussion in Web Appendix D.

63 Interestingly, openness to experience predicts how long an individual stays in school $(r=.34)$ better than the grades they earn while in school $(r=.05)$. Similarly, Wong and Csikszentmihalyi (1991) find that an orientation toward work and long-term goals predicts higher grades, whereas enjoyment while studying is a better predictor of the difficulty level of courses selected by students.

64 Evidence is mixed regarding the effects of IQ on long-term (versus initial) performance. Goff and Ackerman (1992) have suggested that insofar as IQ measures maximal performance, personality measures, which assess "typical performance," might be better predictors over the long-term. Humphreys and Taber (1973) and Lin and Humphreys (1977) present indirect empirical support for this hypothesis: their postdictive and predictive studies suggest that IQ is a superior predictor of first-year grades in college and graduate school than of grades in subsequent years. Chamorro-Premuzic and Furnham (2005) suggested that a decline in the predictive validity of IQ may have as its counterpart an increase in the predictive validity of personality. Against this, Willingham (1985) has argued that the decline in the predictive validity of IQ as students progress through the education system is due entirely to a degradation of the validity of grades and increasing restriction on range. Moreover, Schmidt and Hunter (2004) find that $g$ is as robust a predictor of performance among experienced workers as among new hires.

65 There is wider evidence that personality traits are associated with investment behaviour. Colquitt, LePine, and Noe (2000) performed a meta-analysis of 256 studies to determine the psychological characteristics that are related to training motivation. Internal locus of control, 
achievement motivation, conscientiousness, self-efficacy have a moderate ( $r$ between .3 and .5 ) positive relationship with training motivation, defined specifically as the direction, intensity, and persistence of learning-directed behavior in training contexts. In contrast, anxiety has a strong negative relationship $(r=-.6)$ with motivation to learn. Whereas IQ is a better predictor of academic outcomes, Big Five conscientiousness is a slightly better predictor longevity and leadership. To the extent that these post-schooling outcomes are as important, from a subjective and societal point of view, one can make the case that personality skills are even more important than cognitive skills (see McClelland 1973).

66 There is also conceptual overlap with the confidence facet of Big Five conscientiousness as conceptualized in the NEO-PI-R questionnaire.

67 It would be useful to investigate whether their "core evaluation" is the same as the "personality factor" identified by Heckman, Stixrud, and Urzua (2006), Urzua (2007), and Cunha and Heckman (2007a) that is predictive of many adult behaviors, including wages, employment, job turnover, and accumulated work experience.

68 Squared effect sizes cumulate to total proportion of variance explained only if the predictor variables are uncorrelated (Goldberger 1968).

69 Under a normality assumption, their measure and effect size can be mapped into each other. The more general measures do not require normality. 70 Some psychological studies correct for normal measurement error. The econometric studies account for non-normal measurement errors. See Cunha, Heckman, and Schennach (2007). 71 Environments and investments have an immediate, short-term impact on behavior. Most individuals will exert more effort if they are compensated to do so, will be more sociable if there 
are incentives to do so, and so on. Thus, the same person may display very different behaviors in different settings. The influence of situational factors on behavior is recognized but not controlled for or measured. In psychology, the concept of a standardized incentive environment remains to be developed or applied. Equation (5) and (6) is a framework for discussing and developing standardized measures.

72 Normative refers to what most people or the average person experiences. If most people deliberately do something that causes change, it would be normative. But that seems unlikely. Therefore, most deliberative change is non-normative, but this is not logically necessarily true. 73 Cross-sectional estimates of mean-level change are biased by cohort effects (for example, the Flynn effect) whereas longitudinal estimates are biased by test-retest learning (when the same IQ tests are administered repeatedly to the same subjects) and by selective attrition. Thus, both estimates must be considered in conjunction as evidence for mean-level change.

74 Plomin and the essays in the December issue of Monographs for the Society for Research in Child Development (2007) extend this analysis to childhood.

75 We note here that while genes remain constant through the lifecourse, the expression of genes is determined, in part, by experience.

76 Devlin, Daniels, and Roeder (1997) suggest that traditional estimates of the heritability of IQ may be inflated because they fail to take into account the effect of the environment of the maternal womb. See also Rutter (2006) and an emerging literature on epigenetics. 77 Lykken (2007) suggests that heritability estimates for personality are substantially higher when situational influence and measurement error are minimized by giving multiple measures at least a few months apart. 
78 Gene-environment interactions are another means by which genes and environment jointly influence traits. The effects of the environment depends on the genes and vice versa (see Caspi et al. 2003; Moffitt, Caspi, and Rutter 2005; and Caspi et al. 2002).

79 A second crucial assumption is that environmental influence can be amplified by a "social multiplier" effect: smarter individuals create for one another an enriched environment, which in turn increases intelligence, and so on. Some caution must be taken with this literature. Blair et al (2005) attribute the Flynn effect to increasing access to formal schooling early in the twentieth century and, from the mid-century onward, to increasing fluid cognitive demand of mathematics curricula. Flynn (2007) concurs about the former but believes that the latter had negligible impact.

80 The literature establishes that shared environments become less important as children age. This literature does not say that environments do not matter. This can arise because genetically similar children (or their parents) choose different environments to distinguish themselves or because of parental investment (Lizzeri and Siniscalchi 2006).

81 We note that there is controversy in the literature about the validity of conventional estimates of heritability. It centers on the linearity and additivity assumptions, the assumed absence of interactions between genes and environment, and the assumption that genes do not select environments.

82 See also Hansen, Heckman, and Mullen (2004) for estimates of the causal effect of schooling on AFQT.

83 However, the data are also consistent with alternative explanations such as extreme stress permanently damaging brain structures. 
84 See Cunha, Heckman, and Schennach (2007).

85 This is represented by cross effects of $f_{i, t}$ on $f_{i, t+1}$ in equation (7).

86 Some evidence that further intervention can produce enduring change in non-clinical populations comes from Gillham and Reivich (1999) who show that children taught to make more optimistic causal attributions about negative events maintain this optimistic outlook two years post-intervention.

87 See Ericsson and Ward (2007) for a recent review of the evidence.

88 See Camerer and Loewenstein (2004) for a good introduction to behavioral economics and the papers in Camerer, Loewenstein, and Rabin (2004). Fudenberg (2006) presents a critical review of the literature.

89 Thurstone (1927), Block and Marschak (1960), Marschak (1960), Becker (1962), Bock and Jones (1968), McFadden (1974, 1981), and Falmagne (1985) develop models that recognized that constraints (choice sets) may largely determine behavior. Becker's random consumer model and Sanderson's (1974) extension of it are the most radical versions of this approach. List (2004) is a recent application of this model.

90 The "taste" shock may be interpreted as either a utility (preference) or as a random element that determines which bundle of $B_{i}$ is selected by agent $i$.

91 Allowing personality traits to determine, or screen out certain elements of possible choice sets is reminiscent of Tversky's elimination by aspects (EBA) model (see Tversky 1972a,b). McFadden (1981) discusses this model and its relationship to other random utility choice models. In our setup, psychological constraints eliminate certain components of choice. 
92 Frederick, Loewenstein, and O'Donoghue 2002, review the classical literature in economics relating time preference to a failure of imagination.

93 The model of equation (7) is consistent with the axioms of stochastic revealed preference. See McFadden (1981) for one statement of the axioms of stochastic revealed preference. 94 But see McAdams (2006) and McAdams and Pals (2006). 95 See Sattinger (1993) for a discussion of hedonic models of earnings. This specification subsumes the conventional labor-leisure model as a special case where $e^{J+1}$ is time allocated to market and $Z_{J+1}=w e^{J+1}$, where $w$ is the wage rate which may be person specific. 96 Michael (1973) analyzes a scalar environmental variable (education) that plays the role of public goods in our analysis. The environmental variable is not chosen but affects the productivity of the other inputs.

97 One specification of the task functions writes, in the case of scalar $e, T^{j}=h_{j}\left(f^{j} e^{j}\right)$ so that the task depends on the product of $f^{j}$ and $e^{j}$. In the case of public goods for traits $\left(f^{j}=\bar{f}\right)$, the level of energy applied to a task augments or reduces the output of the traits. Thus, if $e^{j}=0$, the trait is effectively not allocated to the task. For example, agreeable people could decide not to be agreeable in certain situations. Borghans, Ter Weel, and Weinberg (2007) argue that suppressing certain psychological traits is harder for some people than others. In our framework, the utility cost of $e^{j}$ is higher for such persons.

98 Baumeister has recently proposed that the trait of self-control be conceived of as a limited resource, the finite capacity of which varies from individual to individual. Self-control entails overriding lower-level processes (for example, impulses and emotions) by higher-level processes (that is, processes that are mediated by frontal areas and therefore are classified as executive 
functions). All brain functions rely on glucose and are metabolically expensive, but higher-level processes are particularly impaired by decreases in available glucose. (See Baumeister et al., 1998; Gailliot et al., 2007). Their analysis corresponds to a public goods case with glucose as a component of $e$, with $f$ a public good and with $\bar{f}$ differing among people.

99 In both cases, as emphasized by Pollak and Wachter (1975), non-constant returns to scale produce additional substitution effects. Our public goods case captures one aspect of their analysis of jointness in production.

100 Thus an angry person may transfer his or her anger to the home sector and thus avoid the costs of overriding his or her anger on the job. Alternatively, in a public goods case, the person would allocate more effort to controlling anger on the job than in controlling it at home.

101 That is, increasing in its arguments and twice differentiable. Henderson and Quandt (1958) formulate such a general model.

102 We note, however, that the evidence on differences in discount rates across goods is sensitive to the role of markets in intertemporal arbitrage. In the absence of transaction costs, market and personal rates of time preference must be in agreement.

103 See Samuelson (1937) and Strotz (1955).

104 We consider uncertainty below.

105 See Johnsen and Donaldson (1985). The model of Becker and Murphy (1988) is an example of a non-separable model that is time consistent.

106 See the evidence on age dependent preferences in Browning and Meghir (1991) and the survey of the evidence presented in Browning, Hansen, and Heckman (1999).

107 Durlauf and Fafchamps (2005) and Durlauf and Young (2001) survey this literature. 
108 See the survey in Starmer (2000).

109 See Hansen (2007) and the references contained therein.

110 There is some confusion in the literature about the role of additive separability in models of dynamic consistency of decision making under uncertainty. Johnsen and Donaldson (1985) establish that dynamic consistency requires weak separability of intertemporal preferences but not the strong separability used in standard models of consumer decision making. Consider a two period model of agent decision making. $X$ is current consumption. $Y_{s}$ is future consumption in state $s$, which occurs with $P_{s}$. Under a certain interest rate $r$, the standard expected utility theory postulates that agents maximize for a three-possible-outcome-second-period-model, $U(X)+P_{1} U\left(Y_{1}\right)+P_{2} U\left(Y_{2}\right)+P_{3} U\left(Y_{3}\right)$ subject to $A=X+\sum_{s=1}^{3} \frac{P_{s}}{1+r} Y_{s}$. This produces time consistent preferences for the usual reasons. However, keeping probabilities implicit, the following non-expected model of utility maximization

$U\left(X, Y_{1}, Y_{2}, Y_{3}\right)=\left[X+\log \left(X+Y_{1}\right)+\left(X^{1 / 2} Y_{2}^{1 / 2}\right)^{1 / 3}\left(X Y_{3}\right)\right]^{1 / 2}$

also produces time consistent preferences. Note that in this specification even if $P_{1}=P_{2}=P_{3}$, discount rates differ for different second period goods.

${ }^{111}$ See Epstein and LeBreton (1993), Gilboa and Schmeidler (1993), Siniscalchi (2006), and Hansen and Sargent (2008) for analyses of decision making under ambiguity. Ellsberg (1961) is the classic reference. 
112 Borghans, ter Weel, and Weinberg (2007) provide evidence of assignment based on "people skills" in the labor market using British and German data. Krueger and Schkade (2007) provide similar evidence for gregarious workers in the United States.

113 There is a subliterature in psychology on " $g$ " that pits " $g$ " against personality characteristics in terms of their predictive power (see Gottfredson, 2002). This literature creates a false dichotomy. While " $g$ " is predictive in a much wider variety of settings, in particular settings, as noted in section V, certain personality traits are more predictive than " $g$ ".

114 We preserve the distinction made in equation (3) that latent traits $\left(f_{t}\right)$ and manifest traits $\left(C_{t}\right)$ may differ. We can equate $C_{t}$ with the $M_{j, t}^{k}$ in the discussion surrounding equation (3). 115 See a review of the emerging field of neuroeconomics by Camerer, Loewenstein, and Prelec (2005). On the biological basis of personality, see Canli (2006). 